Cochrane Database of Systematic Reviews

\title{
Multi-disciplinary rehabilitation for acquired brain injury in adults of working age (Review)
}

Turner-Stokes L, Pick A, Nair A, Disler PB, Wade DT

Turner-Stokes L, Pick A, Nair A, Disler PB, Wade DT.

Multi-disciplinary rehabilitation for acquired brain injury in adults of working age.

Cochrane Database of Systematic Reviews 2015, Issue 12. Art. No.: CD004170.

DOI: 10.1002/14651858.CD004170.pub3.

www.cochranelibrary.com 
HEADER 1

ABSTRACT

PLAIN LANGUAGE SUMMARY

BACKGROUND

OBJECTIVES

METHODS

Figure 1.

RESULTS

Figure 2.

Figure 3.

DISCUSSION

AUTHORS' CONCLUSIONS

ACKNOWLEDGEMENTS

REFERENCES

CHARACTERISTICS OF STUDIES

ADDITIONAL TABLES

APPENDICES

WHAT'S NEW

HISTORY

CONTRIBUTIONS OF AUTHORS

DECLARATIONS OF INTEREST

SOURCES OF SUPPORT

INDEX TERMS

\section{TABLE OF CONTENTS}


[Intervention Review]

\section{Multi-disciplinary rehabilitation for acquired brain injury in adults of working age}

Lynne Turner-Stokes ${ }^{1}$, Anton Pick ${ }^{2}$, Ajoy Nair ${ }^{3}$, Peter B Disler ${ }^{4}$, Derick T Wade 5

1Regional Hyper-acute Rehabilitation Unit, King's College London and Northwick Park Hospital, Harrow, UK. ${ }^{2}$ Cicely Saunders Institute, King's College London, London, UK. ${ }^{3}$ Alderbourne Rehabilitation Unit, Hillingdon Hospital, Uxbridge, UK. ${ }^{4}$ Bendigo Hospital and Monash University, Bendigo, Australia. ${ }^{5}$ Oxford Centre for Enablement, University of Oxford, Oxford, UK

Contact address: Lynne Turner-Stokes, Regional Hyper-acute Rehabilitation Unit, King's College London and Northwick Park Hospital, Watford Road, Harrow, Middlesex, HA1 3UJ, UK. lynne.turner-stokes@dial.pipex.com.

Editorial group: Cochrane Injuries Group

Publication status and date: New search for studies and content updated (conclusions changed), published in Issue 12, 2015.

Citation: Turner-Stokes L, Pick A, Nair A, Disler PB, Wade DT. Multi-disciplinary rehabilitation for acquired brain injury in adults of working age. Cochrane Database of Systematic Reviews 2015, Issue 12. Art. No.: CD004170. DOI: 10.1002/14651858.CD004170.pub3.

Copyright @ 2015 The Cochrane Collaboration. Published by John Wiley \& Sons, Ltd.

\section{A B S T R A C T}

\section{Background}

Evidence from systematic reviews demonstrates that multi-disciplinary rehabilitation is effective in the stroke population, in which older adults predominate. However, the evidence base for the effectiveness of rehabilitation following acquired brain injury (ABI) in younger adults has not been established, perhaps because this scenario presents different methodological challenges in research.

\section{Objectives}

To assess the effects of multi-disciplinary rehabilitation following $\mathrm{ABI}$ in adults 16 to 65 years of age.

\section{Search methods}

We ran the most recent search on 14 September 2015. We searched the Cochrane Injuries Group Specialised Register, The Cochrane Library, Ovid MEDLINE(R), Ovid MEDLINE(R) In-Process \& Other Non-Indexed Citations, Ovid MEDLINE(R) Daily and Ovid OLDMEDLINE(R), Embase Classic+Embase (OvidSP), Web of Science (ISI WOS) databases, clinical trials registers, and we screened reference lists.

\section{Selection criteria}

Randomised controlled trials (RCTs) comparing multi-disciplinary rehabilitation versus routinely available local services or lower levels of intervention; or trials comparing an intervention in different settings, of different intensities or of different timing of onset. Controlled clinical trials were included, provided they met pre-defined methodological criteria.

\section{Data collection and analysis}

Three review authors independently selected trials and rated their methodological quality. A fourth review author would have arbitrated if consensus could not be reached by discussion, but in fact, this did not occur. As in previous versions of this review, we used the method described by Van Tulder 1997 to rate the quality of trials and to perform a 'best evidence' synthesis by attributing levels of evidence on the basis of methodological quality. Risk of bias assessments were performed in parallel using standard Cochrane methodology. However, the Van Tulder system provided a more discriminative evaluation of rehabilitation trials, so we have continued to use it for our primary synthesis of evidence. We subdivided trials in terms of severity of brain injury, setting and type and timing of rehabilitation offered.

\section{Main results}

We identified a total of 19 studies involving 3480 people. Twelve studies were of good methodological quality and seven were of lower quality, according to the van Tulder scoring system. Within the subgroup of predominantly mild brain injury, 'strong evidence' suggested 
that most individuals made a good recovery when appropriate information was provided, without the need for additional specific interventions. For moderate to severe injury, 'strong evidence' showed benefit from formal intervention, and 'limited evidence' indicated that commencing rehabilitation early after injury results in better outcomes. For participants with moderate to severe ABI already in rehabilitation, 'strong evidence' revealed that more intensive programmes are associated with earlier functional gains, and 'moderate evidence' suggested that continued outpatient therapy could help to sustain gains made in early post-acute rehabilitation. The context of multi-disciplinary rehabilitation appears to influence outcomes. 'Strong evidence' supports the use of a milieu-oriented model for patients with severe brain injury, in which comprehensive cognitive rehabilitation takes place in a therapeutic environment and involves a peer group of patients. 'Limited evidence' shows that specialist in-patient rehabilitation and specialist multi-disciplinary community rehabilitation may provide additional functional gains, but studies serve to highlight the particular practical and ethical restraints imposed on randomisation of severely affected individuals for whom no realistic alternatives to specialist intervention are available.

\section{Authors' conclusions}

Problems following ABI vary. Consequently, different interventions and combinations of interventions are required to meet the needs of patients with different problems. Patients who present acutely to hospital with mild brain injury benefit from follow-up and appropriate information and advice. Those with moderate to severe brain injury benefit from routine follow-up so their needs for rehabilitation can be assessed. Intensive intervention appears to lead to earlier gains, and earlier intervention whilst still in emergency and acute care has been supported by limited evidence. The balance between intensity and cost-effectiveness has yet to be determined. Patients discharged from in-patient rehabilitation benefit from access to out-patient or community-based services appropriate to their needs. Group-based rehabilitation in a therapeutic milieu (where patients undergo neuropsychological rehabilitation in a therapeutic environment with a peer group of individuals facing similar challenges) represents an effective approach for patients requiring neuropsychological rehabilitation following severe brain injury. Not all questions in rehabilitation can be addressed by randomised controlled trials or other experimental approaches. For example, trial-based literature does not tell us which treatments work best for which patients over the long term, and which models of service represent value for money in the context of life-long care. In the future, such questions will need to be considered alongside practice-based evidence gathered from large systematic longitudinal cohort studies conducted in the context of routine clinical practice.

\section{PLAIN LANGUAGE SUMMARY}

\section{Rehabilitation for adults of working age who have a brain injury}

Background: Studies show that multi-disciplinary (MD) rehabilitation is beneficial for patients with brain damage from stroke. Some MD programmes are targeted to working-age adults who have brain injury following trauma or other causes. These patients tend to be younger than most stroke patients and may have different treatment goals, such as returning to work or parenting. Brain-injured people can have a variety of difficulties, including problems with physical functions, communication, thought processes, behaviour or emotions. The seriousness of problems can vary from mild to severe. MD rehabilitation addresses one or more of these areas instead of focusing on a single aspect such as physical (motor) function.

Review question: The authors of this Cochrane review looked for studies of MD rehabilitation in adults, 16 to 65 years of age, with acquired brain injury $(A B I)$ from any cause.

Study characteristics: Studies eligible for inclusion in this review were controlled trials, in which one group of people received treatment (such as MD rehabilitation) and was compared with a similar group that received a different treatment. We found 19 relevant studies, which involved a total of 3480 people.

Search date: We searched the medical literature worldwide on 14 September 2015.

Review methods: We used the Van Tulder system to rate the strength of the evidence as it distinguished better between trials of different quality than the standard GRADE system on criteria that are important in the context of rehabilitation.

Key results: For mild brain injury, information and advice were usually more appropriate than intensive rehabilitation. As a whole, studies suggest that patients with moderate to severe brain injury who received more intensive rehabilitation showed earlier improvement, and that earlier rehabilitation was better than delayed treatment. Strong evidence supports the provision of cognitive rehabilitation in a therapeutic 'milieu', that is, an environment in which patients receive predominantly group-based rehabilitation alongside a peer group of others who are facing similar challenges. Trial-based literature provided little evidence related to other aspects of MD rehabilitation, so the review authors recommend that additional research should be done. Rehabilitation for brain injury is such an individualised and longterm process that research studies do not necessarily facilitate general conclusions.

Quality of the evidence: Overall the included studies were of good quality; 12 of 19 studies were judged to be of high quality according to the van Tulder scoring system. The other studies were at risk of bias because of elements of their design, for example, in one study, treatment depended on the availability of a bed in the rehabilitation unit. Bed availability is a haphazard way of allocating treatment to patients, and this makes results of the study prone to bias. 


\section{B A C K G R O U N D}

Brain injury rehabilitation services are increasingly defined by the needs of patients, rather than by underlying pathology (i.e. the disease or the diagnosis). Specialist multi-disciplinary rehabilitation services in the UK have been developed to serve the needs of younger and working age adults ( 16 to 65 years of age). This separation from services for 'older adults' is not simply ageist but arises because younger individuals often have different goals for rehabilitation (such as returning to work or parenting) that may be less relevant for an older, predominantly retired population. Moreover, younger adults may be able to continue learning and adapting over a longer time. Because they and society may have to live with the consequences of disability for many years, an opportunity to gain further recovery of independence following longer or more intensive rehabilitation, or both, may be economically worthwhile (Turner-Stokes 2006; Turner-Stokes 2007). Evidence indicates that younger individuals respond better in different environments than older persons (Gladman 1993; Kalra 1994). The Royal College of Physicians' National Clinical Guidelines for Stroke include the following recommendation: "Younger adults who have had a stroke should be managed within specialist medical and rehabilitation services that (1) recognise and manage the particular physical, psychological and social needs of younger patients with stroke (e.g. vocational rehabilitation, child care activities) and (2) are provided in an environment suited to their specific social needs" (Royal College of Physicians 2008).

Principal causes of acquired brain injury $(A B I)$ in this younger adult group include the following.

- Traumatic brain injury (TBI) - injury resulting from trauma to the head and its direct consequences, including hypoxia, hypotension, intracranial haemorrhage and raised intracranial pressure.

- Diffuse acquired brain injury - diffuse damage arising from trauma due to $\mathrm{TBI}$ or a range of other acute incidents including hypoxia (e.g. resulting from drowning, electrocution, anaesthetic accident), hypoglycaemia and viral encephalitis.

- Cerebrovascular accident (stroke) - may be ischaemic or haemorrhagic but includes a higher proportion of subarachnoid haemorrhage (from aneurysms or arterio-venous malformations) than strokes in the older population.

- Other causes - such as neurosurgical operations (e.g. removal of a meningioma), radiotherapy, cerebral abscess, bacterial meningitis and gunshot wounds.

It is pertinent, therefore, to consider the evidence for effectiveness of rehabilitation separately for the younger group of working-age adults, and to use a broad definition of 'acquired brain injury (ABI)' that encompasses all of the above conditions and represents the group of patients that typically presents for rehabilitation following a single-incident neurological insult. This approach is consistent with the UK National Service Framework (NSF) for Long-term Conditions, which focuses on common features of neurological conditions categorised by their pattern of progression (acute single insult, unpredictable variation, inevitable progression) rather than by specific pathological diagnoses. The present review has contributed to the evidence base to underpin the UK National Clinical Guidelines for Rehabilitation following Acquired Brain Injury (RCP/BSRM 2003) and the UK NSF for Long-term Conditions
(Department of Health 2005), which also highlight the particular needs of the working-age adult.

Individuals with $\mathrm{ABI}$ experience a wide range of deficits, depending on the nature and location of injury. They may present to rehabilitation with various combinations of physical, communicative, cognitive, behavioural, psychosocial and environmental problems. In keeping with the vocabulary used in the expanded World Health Organization International Classification of Functioning (WHO ICF) (Wade 2000; Wade 2003; Wade 2004), they demonstrate heterogeneity at each level, in that they:

- suffer a variety of pathologies;

- experience a great variety of impairments, with each individual presenting with a unique combination in terms of severity and nature of impairment;

- also experience varied limitations in, or restrictions on, activities (disabilities) and participation (previously known as 'handicap'); and

- approach rehabilitation from a variety of contexts - personal, social and physical.

This means that each individual has a unique set of needs. Different individuals need different programmes of rehabilitation; moreover, the same individual will need different programmes of rehabilitation at different stages in recovery. For example:

- during initial stages of recovery from acute injury, some patients will need to undergo a period of intensive in-patient rehabilitation to return to functional independence, and to make the transition from hospital back into the community; outcomes from these acute or subacute programmes tend to focus on reduction in impairment and disability; and

- once back in the community, attention turns more towards social integration, with return to work and financial independence if possible; community-based rehabilitation programmes supporting these activities correctly focus on outcome measures that reflect improved participation and psychosocial adjustment.

Wide variation in services is evident both between and within countries.

Heterogeneity of patients, rehabilitation services and outcomes poses a challenge to traditional interventional or randomised controlled trial-based methods (DeJong 2005; Horn 2005; Whyte 2002), as well as to assimilation of findings through meta-analysis. These problems are not unique to rehabilitation but are faced similarly by many medical specialities (Shiel 2008) and have been recognised by the Medical Research Council (MRC) in its approach to evaluation of complex interventions (Craig 2008).

The current review serves to:

- identify existing trial-based evidence in multi-disciplinary rehabilitation for $A B I$ in adults of working age;

- discuss explicitly issues for future expansion of the evidence base by traditional research methods; and

- identify gaps in knowledge and suggest appropriate methods by which these could be explored in the future. 
The method described below takes into account advice offered by Greener and Langhorne (Greener 2002) regarding the application of systematic reviews in the field of rehabilitation.

\section{OB JECTIVES}

To assess effects of multi-disciplinary rehabilitation following $A B I$ in adults 16 to 65 years of age.

Specific questions to be addressed by this review include the following.

- Does organised multi-disciplinary rehabilitation achieve better outcomes than are reported with the absence of such services for this group of patients?

- Does greater intensity (time, expertise or both) or earlier onset of rehabilitation lead to greater gains?

- Which types of programmes are effective, and in which setting?

- Which specific outcomes are influenced (dependency, social integration, mood, return to work, etc.)?

- Are demonstrable cost benefits associated with multidisciplinary rehabilitation?

\section{METHODS}

\section{Criteria for considering studies for this review}

\section{Types of studies}

We included all randomised controlled trials (RCTs) and controlled clinical trials (CCTs) that compared multi-disciplinary rehabilitation versus routinely available local services or versus lower levels of intervention; and trials that compared an intervention provided in different settings or at different levels of intensity. Controlled trials were eligible for inclusion provided they included a large element of chance in the availability of a place within a given service versus the possibility of referral elsewhere.

\section{Types of participants}

We included trials if the study population was predominantly of working age (i.e. mean age between 16 and 65 years) and if participants had acquired brain injury ( $\mathrm{ABI}$ ) from any cause (including traumatic brain injury (TBI), diffuse brain injury, stroke, subarachnoid haemorrhage, intracranial haemorrhage or mixed $A B I)$. We also planned to classify as eligible for inclusion trials that encompassed all ages but presented a separate subanalysis of the population 16 to 65 years of age, so that outcomes for adults within this age group were separately identifiable. We have not yet identified any trials in this category.

Rehabilitation programmes designed principally to meet the needs of older people may include a minority of younger individuals because more appropriate services for them are lacking, but in practice these programmes often fail to address the more extended rehabilitation goals of younger individuals (Kersten 2002; Roding 2003). For this reason, we did not contact study authors to ask about extracted information on younger adults within predominantly elderly study groups unless clear evidence indicated that they were identified and treated as a separate group. Again we have not identified such trials.

Classification of patients who have experienced $A B I$ is complex because, as noted above, individuals may have one or more of a wide range of impairments, each of differing severity. However, the nature and severity of neurological deficits tend to determine the type of rehabilitation programme offered, as well as goals for treatment and outcome measures used. For example, as a very crude generalisation, patients with mild $A B I$ primarily tend to have cognitive losses and goals for rehabilitation that tend to focus on enhanced participation, whereas patients in the moderate to severe category are more likely to have goals centred on improvement at the level of impairment and activity (disability). We did not include or exclude studies on the basis of severity, but we subgrouped them on this basis for purposes of analysis and discussion.

\section{Types of interventions}

Rehabilitation is broadly defined as a problem-solving educational process aimed at reducing disability and handicap experienced by someone as a result of disease or injury (Wade 1992). For the purposes of this review, we have defined multi-disciplinary rehabilitation as any intervention delivered by two or more disciplines working in co-ordinated effort to meet these objectives.

No agreement has been reached on classification of rehabilitation interventions and programmes. Again, broadly speaking, programmes may be described in terms of setting and content.

Rehabilitation settings include:

- in-patient settings - rehabilitation is delivered in the context of 24-hour care, which may be provided in a hospital ward or on a specialist acute or subacute rehabilitation unit;

- out-patient or day treatment settings - again may be found in a hospital environment or in a local community setting (e.g. day centre); and

- domiciliary or home-based settings - focused on the patient's own home and local community.

Terms currently found in the literature regarding programme content include:

- physical rehabilitation;

- cognitive and behavioural therapy;

- vocational and recreational therapy; and

- psychosocial and counselling input.

However, it is probable that the actual content of any two programmes within the same category varied greatly, and that similar programmes may have been given different labels.

Consequently, we included any study that stated or implied that it involved a multi-disciplinary or interdisciplinary rehabilitation programme, or used any of the labels above, provided it compared the named intervention versus some form of control.

For the same reasons, it is equally difficult to describe the control. For this review, we considered the following.

- Lower level or different type of intervention, such as routinely available local services, or minimal intervention, such as information only or single-session treatment.

- Waitlist control.

- Interventions given in different settings (such as in-patient vs community rehabilitation). 
- Treatment programme of lower intensity.

We excluded studies that assessed effects of the following.

- Therapy from a single discipline (e.g. physiotherapy), including studies on intensity of treatment within that single discipline.

- Two different forms of therapy with neither clearly defined as intervention nor control.

- Single uni-disciplinary intervention or modality (e.g. physical exercise).

- Coma arousal programmes (as these were already dealt with in a Cochrane review (Lombardi 2002)), except when these were provided as part of a co-ordinated multi-disciplinary approach.

\section{Types of outcome measures}

We were interested in outcomes that reflect the burden of disabling illness on individuals and families, and in the services provided for them. We excluded studies that reported only outcomes at the level of impairment.

Measurement of outcomes after rehabilitation can be described on two principal axes.

- Timing of measurement - from onset of disease or onset of rehabilitation.

- Level of measurement within the WHO ICF.

Many of these studies were undertaken when the previous WHO classification of Impairment, Disability and Handicap was current; therefore, we have included these terms in brackets alongside the current terms.

\section{Time}

For the purposes of this review:

- 'short term' refers to time from assessment at admission to discharge from the rehabilitation programme (regardless of its length) and up to six months after; and

- 'long term' refers to any time from six months after completion of the intervention, usually one year or longer.

\section{Outcomes}

Once again, no agreement has been reached on classification of outcome measures for research into rehabilitation after $A B I$, but for this review, we have categorised outcomes broadly as follows.

- Outcome measures focused on goals at level of impairment and activities (disability), for example:

* residual symptoms (e.g. post-traumatic amnesia (PTA), postconcussion symptoms);

* functional independence, including mobility, cognitive functioning and ability to perform basic activities of daily living (ADLs) (e.g. Barthel Index, Functional Independence Measure (FIM) or Functional Assessment Measure (FIM+FAM), Glasgow Outcome Scale (GOS)); and

* carer burden and stress (e.g. Caregiver Strain Index, Caregiver Burden Scale).

- Outcome measures focused on goals at level of participation (previously known as 'handicap') and personal context (psychosocial adjustment, quality of life) (Langhorne 1995), for example:

* discharge destination (e.g. home, institution);

* return to work;

* social integration or activities (e.g. Rivermead Head Injury Follow-Up Questionnaire (RHFUQ));

* extended activities of daily living (EADLs) (e.g. Community Integration Questionnaire (CIQ));

* health-related quality of life for patient and carer (e.g. General Health Questionnaire (GHQ), Short-Form-36 (SF-36)); and

* patient and carer mood (e.g. Hospital Anxiety and Depression Scale (HADS)) and satisfaction with services.

When given, we also included outcomes that reflected the use of resources. These included length of stay or treatment, subsequent re-admission to hospital, need for care including level of care and extent of support required after discharge.

\section{Search methods for identification of studies}

To reduce publication and retrieval bias, we did not restrict our search by language, date or publication status.

\section{Electronic searches}

The Cochrane Injuries Group Trials Search Co-ordinator searched the following.

- Cochrane Injuries Group Specialised Register (14/09/2015).

- Cochrane Central Register of Controlled Trials (CENTRAL) (2015, Issue 8 of 12).

- Ovid MedLINE(R), Ovid MedLINE(R) In-Process \& Other Non-Indexed Citations, Ovid MEDLINE(R) Daily and Ovid OLDMEDLINE(R) (1946 to 14/09/2015).

- Embase Classic + Embase (OvidSP) (1947 to 14/09/2015).

- ISI Web of Science: Science Citation Index-Expanded (SCIExpanded) (1970 to 14/09/2015).

- ISI Web of Science: Conference Proceedings Citation IndexScience (CPCI-S) (1990 to 14/09/2015).

- Clinicaltrials.gov (www.clinicaltrials.gov) (14/09/2015).

- WHO International Clinical Trials Registry (http://apps.who.int/ trialsearch/Default.aspx) (14/09/2015).

We have reported search strategies in Appendix 1.

\section{Searching other resources}

Review authors searched the following clinical trials registries.

- Clinicaltrials.gov (www.clinicaltrials.gov).

- Rehabtrials.org (http://rehabtrials.org/).

- Current controlled trials (http://www.controlled-trials.com/).

We identified additional trials by handsearching reference lists in review articles and by consulting with colleagues and trialists.

\section{Data collection and analysis}

The search strategy was sensitive rather than precise, so we expected to find a large number of non-relevant articles. We assessed studies using a two-stage process: (1) trial selection, and (2) assessment of methodological quality. 


\section{Selection of studies}

To date, we have screened more than 7,000 article abstracts and titles for eligibility for inclusion in the review. First we excluded totally irrelevant articles, leaving a short list of 416 articles. Three review authors (LTS, AN, AP) independently undertook a preliminary screen of titles and abstracts for these 416 , considering the type of study, participants and interventions. This first selection stage resulted in categorisation to exclusion, selection or indecision. Disagreements between review authors were discussed in consensus meetings. If the first selection was indecisive or if disagreement persisted, we obtained the full article for further assessment. We were prepared to seek from trialists further information about the method of randomisation or the multi- disciplinary nature of rehabilitation interventions, when necessary. However, in practice, critical information was missing from earlier published studies (10 to 20 years old), and attempts to contact study authors were unsuccessful because they usually had retired or moved on. This process led to the exclusion of 382 articles, leaving 31 for probable inclusion.

For each trial selected for inclusion at stage 1 , at least two review authors independently assessed methodological quality using van Tulder's criteria (see below). For the original review (2005), DTW, LTS and AN assessed articles; for the previous update (2008), AN, IS, and LTS assessed articles; and for the current update (2015), AN, AP and LTS completed article assessments (see Figure 1). A fourth review author was available for arbitration in the event that consensus could not be reached by discussion, but this was not required. 
Figure 1. Study flow diagram. The numbers for identification, screening and eligibility are from updated searches in 2013, 2014 and 2015.

\# of studies included in

previous version of the review 16
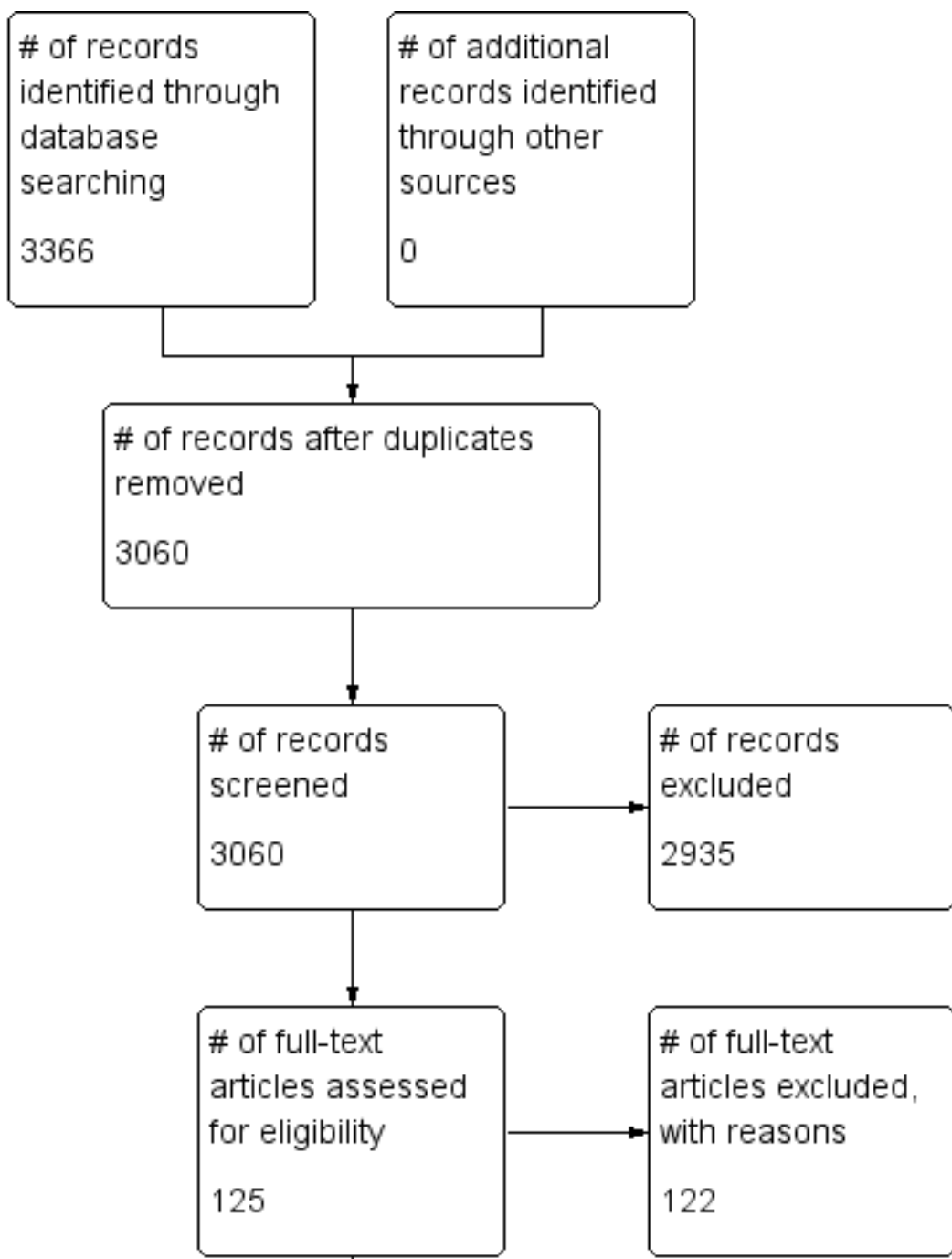

\# of studies

included in

qualitative

synthesis

19 
Figure 1. (Continued)

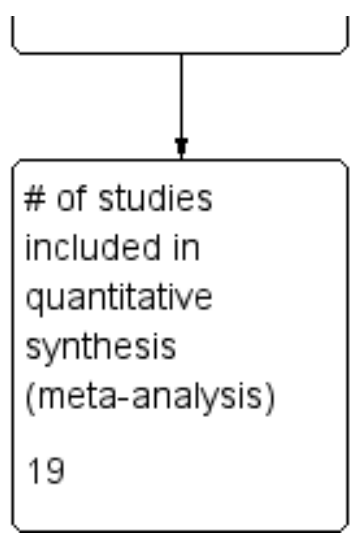

\section{Assessment of risk of bias in included studies}

The Cochrane Musculoskeletal Group (van Tulder 1997) proposed a checklist, which consisted of 19 quality-related criteria (11 criteria for internal validity, six descriptive criteria and two statistical criteria). Although subsequent lists have tended to focus more on the internal validity criteria (van Tulder 2003), this original checklist has been used for trials on low back pain and has been explored elsewhere in the context of complex interventions. It has been used in other reviews on rehabilitation (e.g. UK National Stroke Guideline, 2008; Royal College of Physicians 2008), including a Cochrane review on occupational therapy for stroke (Hoffmann 2010; Steultjens 2003b), and it has been adapted (Steultjens 2003a) to provide an abbreviated list for assessment of trials employing other trial designs (including patient series and cohort studies).

We considered that this expanded list provided a more sensitive basis for discriminating between trials of better and poorer quality in the present context. In this review, therefore, we rated methodological quality by using a standardised checklist based on one introduced by van Tulder 1997 (Table 1).

We would like to draw particular attention to the definitions listed below. As the standards for conducting and reporting clinical trials are becoming increasingly rigorous, we have taken the opportunity for this 2015 update to revisit the ratings for all included trials. When this has led to an adjustment in either direction, we have noted the reasons for this.

\section{Design}

- We identified allocation with procedures at high risk of bias such as alternation; or we used references to case record numbers, dates of birth or days of the week.

- We identified controlled study designs when no attempt at randomisation was made but with (1) prospective allocation to study groups, and (2) a large element of chance in the allocation. However, unacceptable designs included comparison of two entirely separate services and retrospective matching of controls from a separate unrelated database. We excluded studies that used these designs.

- Fatal flaws in study design or in execution meant that we determined the study to be inadequate, and we excluded it from the analysis. Examples of fatal flaws included withdrawal of more than $40 \%$ of participants, total or nearly total non- adherence to the protocol and very poor or non-adjusted comparability of baseline criteria.

\section{Blinding}

An essential feature of rehabilitation is the active engagement of patients and their families in the programme and treatment goals. If consent procedures include a proper description of trial alternatives (as they should), it is then rarely feasible to blind individuals properly to their allocated rehabilitation intervention. Even single blinding (through independent blinded assessment of outcomes) may be difficult in patients with cognitive impairment who not uncommonly volunteer unsolicited information during the course of an interview (Powell 2002).

Review authors accepted that blinding of participants and treating therapists was not feasible (irrespective of whether this is formally acknowledged by trial authors), and the best that could be achieved in this context was single blinding. We scored blinding of outcome assessors as positive when (1) assessors were blinded regarding treatment allocation, and (2) standardised assessment measures or procedures were used to structure the interviews. Otherwise we scored it as negative.

\section{Concealment of treatment allocation}

We used the following guide to define adequate procedures for treatment allocation concealment.

- An independent person who was not responsible for determining the eligibility of patients generated the assignment.

- Any form of centralised randomisation scheme (e.g. a computer system providing allocations in a locked, unreadable file that could be assessed only after characteristics of an enrolled participant were input).

- Numbered or coded containers; or sequentially numbered, sealed, opaque envelopes.

If concealment of treatment allocation was described only as 'random' or 'randomised', we classified risk as unclear.

\section{Scoring}

We considered RCTs to be of high methodological quality (using van Tulder's list) if the following were scored positively (Steultjens 2003a; Steultjens 2003b). 
- At least six of 11 internal validity items.

- At least three of six descriptive items.

- At least one of two statistical items.

Studies were rated as having low methodological quality if they achieved scores lower than these.

In line with current Cochrane methods, we have also included a risk of bias table, as recommended in the Cochrane Handbook for Systematic Reviews of Interventions (Higgins 2011). We performed a 'best evidence' synthesis by attributing levels of evidence on the basis of assessment of methodological quality as described above; we categorised evidence as 'strong', 'moderate' or 'limited' as described by van Tulder 2003 (Table 2). Thus we used two evaluative methods - one assessing only risk of bias, and the other measuring methodological quality. Overall we consider the van Tulder rating to provide a more informative assessment of research rigor in this context; therefore, we relied on this for our primary evaluation of trial quality and strength of evidence. When evaluations yielded conflicting results, we have discussed the reasons for this.

\section{Assessment of heterogeneity}

We expected to find too much clinical heterogeneity among the studies, particularly with regard to interventions and outcome measures (diversity of assessment tools, timing of measurements, presentation of results), to make quantitative analysis possible. Instead, we broadly grouped selected studies according to types of interventions and participants, and we subjected them to a qualitative descriptive analysis, as described below.

\section{Data synthesis}

Meta-analysis can be undertaken only if review authors agreed that study populations, interventions, outcomes and study designs are sufficiently consistent to allow pooling of data. Although dichotomous data (e.g. return to work) might reasonably be pooled, most outcome instruments commonly used to assess activity and participation are 'long ordinal' scales. Important concerns surround the validity of treating these as continuous data or reducing them to binary outcomes.

Since this review was first published, the Cochrane Library has adopted the GRADE system as its standard for evidence evaluation. Within this system, the quality of a body of evidence for each outcome is based on consideration of within-study risk of bias (methodological quality), directness of evidence, heterogeneity, precision of effect estimates and risk of publication bias. A limitation of this approach in the context of rehabilitation trials is its heavy focus on design features, many of which can never be met in the context of a complex intervention such as rehabilitation. We therefore found it to have poor discriminative value when applied to trials in this context.

Instead we performed 'best evidence' synthesis as described by van Tulder 2003 (Table 2), by attributing levels of evidence on the basis of assessment of methodological quality as described above; we categorised evidence as 'strong', 'moderate' or 'limited'.

We highlighted the strength of trial findings and gaps in current knowledge, and we identified future research directions.

\section{RESULTS}

\section{Description of studies}

From the 30 articles selected at stage 2, we identified 20 that met the eligibility criteria for consideration (Figure 1).

In the previous update of this review in 2008, 16 trials met the criteria for consideration, as described in a total of 24 articles.

- Two trials were excluded because of fatal flaws - Relander 1972 on the basis of $>40 \%$ attrition, and Bjorkdahl 2007 for the reasons given below.

- Six articles were supplementary papers providing additional details of programme content (Braverman 1999 and Warden 2000 for Salazar 2000), subgroup or specific analyses (King 1997 and Wenden 1998 for Wade 1997; Kwakkel 2002 for Kwakkel 1999) or follow-up data (Paniak 2000 for Paniak 1998).

- Two trials (Wade 1997; Wade 1998) reported data from the same programme but in different (sequential) cohorts of participants, so we treated these two papers as separate trials.

- The paper by Zhu 2007 presented findings from the completed study from which Zhu 2001 had presented preliminary findings (which were included in the original review).

- The trial by Björkdahl and colleagues was presented in two papers: Björkdahl 2006 reported main trial findings, and Bjorkdahl 2007 presented a subgroup analysis of carer burden. However, we excluded the latter analysis on the basis of fatal flaws (small numbers with high chance of type II error and poorly matched groups at baseline).

The latest updated search (2008 to 2015) yielded the six trials that met the eligibility criteria for consideration. We excluded two on the basis of fatal flaws.

- Browne 2013 - excluded on account of overall low quality (unclear matching of groups due to lack of functional outcome measures performed at baseline) and a considerable attrition rate of $30 \%$.

- Ownsworth 2008 - excluded on the basis of very small participant numbers and high chance of type II error; also, no evidence of outcome comparisons between intervention and control groups.

We discussed at length but eventually excluded a third trial (Vanderploeg 2008). Although this high-quality trial compared two approaches to rehabilitation, investigators did not identify a clearly hypothesised intervention and control, and so the study did not fit our pre-defined criteria. Instead we have referred to it in the Discussion section.

Therefore, we selected three new trials for inclusion in this review update (Cicerone 2008; Andelic 2012; Bai 2012), yielding a total of 19 trials, including:

- 10 single-blinded RCTs (Bai 2012; Björkdahl 2006; Cicerone 2008; Kwakkel 1999; Paniak 1998; Powell 2002; Slade 2002; Wade 1997; Wade 1998; Zhu 2007);

- four unblinded RCTs (Elgmark 2007; Salazar 2000; Shiel 2001; Smith 1981);

- five controlled clinical trials (CCTs) (Andelic 2012; Bowen 2001; Ozdemir 2001; Semlyen 1998; Werner 1996). (Andelic 2012 
included a supplementary article (Andelic 2014) that described a cost-effectiveness analysis.)

\section{Types of brain injuries}

Twelve of the 19 trials studied patients with traumatic brain injury (TBI), five studied stroke patients and one (Slade 2002) studied a mixed population with acquired brain injury (ABI).

\section{Participants}

The trials covered a range of severities of $A B I$. Three studies (Cicerone 2008; Wade 1997; Wade 1998) recruited people with brain injury of all severities, two (Elgmark 2007; Paniak 1998) recruited only people with mild $\mathrm{TBI}$ and the remainder recruited people with moderate to severe $A B I$. Between them, trials recruited 2729 patients and 132 carers.

\section{Interventions}

The interventions studied also varied. However, trials could be divided broadly into the following categories.

- Five trials (Elgmark 2007; Paniak 1998; Salazar 2000; Wade 1997; Wade 1998) enrolled all patients presenting acutely to hospital with TBI and included populations predominantly in the milder ambulatory category. The intervention was targeted primarily at increasing participation (social integration, return to work, etc.) and reducing post-concussional symptoms.

- Two trials (Andelic 2012; Bai 2012) enrolled patients with moderate to severe TBI during acute stages of recovery. In these trials, participants received some form of very early rehabilitation alongside their acute medical management. As a result of the severity of their injuries, rehabilitation emphasised reducing disability.

- Twelve trials (Björkdahl 2006; Bowen 2001; Cicerone 2008; Kwakkel 1999; Ozdemir 2001; Powell 2002; Semlyen 1998; Shiel 2001; Slade 2002; Smith 1981; Werner 1996; Zhu 2007) enrolled patients (following TBI or stroke) who were already presenting to rehabilitation services. This group, therefore, had greater levels of motor impairment and dependence on personal activities of daily living (ADLs), and interventions were targeted at improving function in ADLs (reduced disability), although measures of participation (reduced handicap) sometimes were also included.

Within this third group, trials covered a range of different interventions in different settings.

- Two trials assessed the impact of out-patient rehabilitation programmes, with one testing programmes of different intensity (Smith 1981), and the other testing therapy offered late after treatment (Werner 1996).

- Three trials assessed the benefits of a co-ordinated communitybased multi-disciplinary team approach for patients (Powell 2002) and carers (Bowen 2001). Björkdahl 2006 compared a short programme of home-based rehabilitation versus outpatient (day clinic) rehabilitation following a period of in-patient stroke rehabilitation.

- Two trials assessed the benefits of a specialist in-patient rehabilitation programme as opposed to local services (Semlyen 1998) or home-based advice (Ozdemir 2001).
- Four trials compared programmes of higher intensity versus treatment of lower (standard) intensity: two with a view towards assessing impact on length of stay (Shiel 2001; Slade 2002), and two (Kwakkel 1999; Zhu 2007) with focus on improving functional outcomes.

- Two trials (Cicerone 2008 and also a subgroup analysis within Salazar 2000) assessed the benefits of holistic neuropsychological rehabilitation programmes delivered in a 'therapeutic milieu' model for patients requiring cognitive rehabilitation following moderate to severe brain injury. Salazar 2000 compared this approach versus a limited home-based rehabilitation programme, and Cicerone 2008 compared it against a standard neurorehabilitation programme.

\section{Outcomes}

Within these groups, studies used different outcomes measured at different intervals over follow-up periods of various lengths. As anticipated, we found insufficient concordance between outcome measures, time points and types of interventions to allow pooling of data for meta-analysis.

\section{Adverse effects}

Rehabilitation can certainly have 'adverse effects', but in clinical practice this has often been considered unlikely; the absence of adverse effects, therefore, is hardly ever specifically recorded. Because adverse effects can and do occur, they should be recorded. We looked for information on adverse effects, but none of the included studies explicitly reported on them.

\section{Risk of bias in included studies}

According to the van Tulder scoring system of methodological quality, the maximum achievable score is 19. Results of scoring are shown in Table 3. Re-scoring of all studies has led to minor changes in the order of quality.

We identified 12 RCTs of high methodological quality according to the criteria given above. Wade 1997 noted that only 478 of 1156 originally randomly assigned participants ( $41 \%)$ could be traced to attend an interview. However, this is not unexpected in the oftenitinerant group of people who suffer head injuries. The trial was in part a feasibility study, and the inability to trace a larger proportion of these patients is a clinical reality and is itself an important finding of this particular trial. A detailed analysis of baseline characteristics was offered and demonstrated no significant differences between interviewed and non-interviewed groups. Therefore, we rated this study as having high quality. Two RCTs (Bai 2012; Björkdahl 2006) were of lower quality, as they were lacking in some aspects of methodological detail. Björkdahl 2006 was also small and was probably underpowered for comparisons of the two groups.

We identified three controlled studies which had low methodological quality (Bowen 2001; Ozdemir 2001; Werner 1996).

- Werner 1996 started off as a randomised trial, with a weighted 2:1 chance that participants would be allocated to active intervention (by picking a number of 666 or less from a sample of 1 to 1000); but after nine of the 16 original controls dropped out, trialists added five additional non-randomised control participants. In addition, the trial report did not include measures of variability or point estimates. 
- Bowen 2001 and Ozdemir 2001 reported unblinded trials with only short-term follow-up.

The two remaining low-scoring trials had a haphazard allocation procedure.

- Andelic 2012 involved patients with severe traumatic brain injury. Treatment allocation was dependent on availability of beds on the rehabilitation unit.

- Semlyen 1998 was a controlled study in which patients were admitted to a specialist multi-disciplinary (MD) rehabilitation programme or were passed back to their standard local services (LS), depending on geography and the availability of a vacancy in the specialist programme. Although an element of chance was present in this allocation, patients with the most severe brain injuries, whose needs could not be met by their local services, in fact had no alternative option and remained on the acute ward for longer periods until a specialist bed became available. Therefore, the multi-disciplinary rehabilitation group was significantly more disabled to start with, and participants were in hospital longer than the group referred to local services. This paper illustrates some of the important practical and methodological issues considered in the Discussion.

We also assessed included studies for methodological quality against the Cochrane risk of bias tool (Higgins 2011), and our summary of judgements can be seen in Figure 2 and Figure 3. As expected, there was a broad relationship between risk of bias and trial quality as rated by the van Tulder 2003 method, but not a close one. This is because van Tulder 2003 system includes a wider range of quality criteria, including reporting, duration of follow-up and cointerventions, which are important in the context of rehabilitation.

Figure 2. Risk of bias graph: review authors' judgements about each risk of bias item presented as percentages across all included studies. Nineteen studies are included in this review.

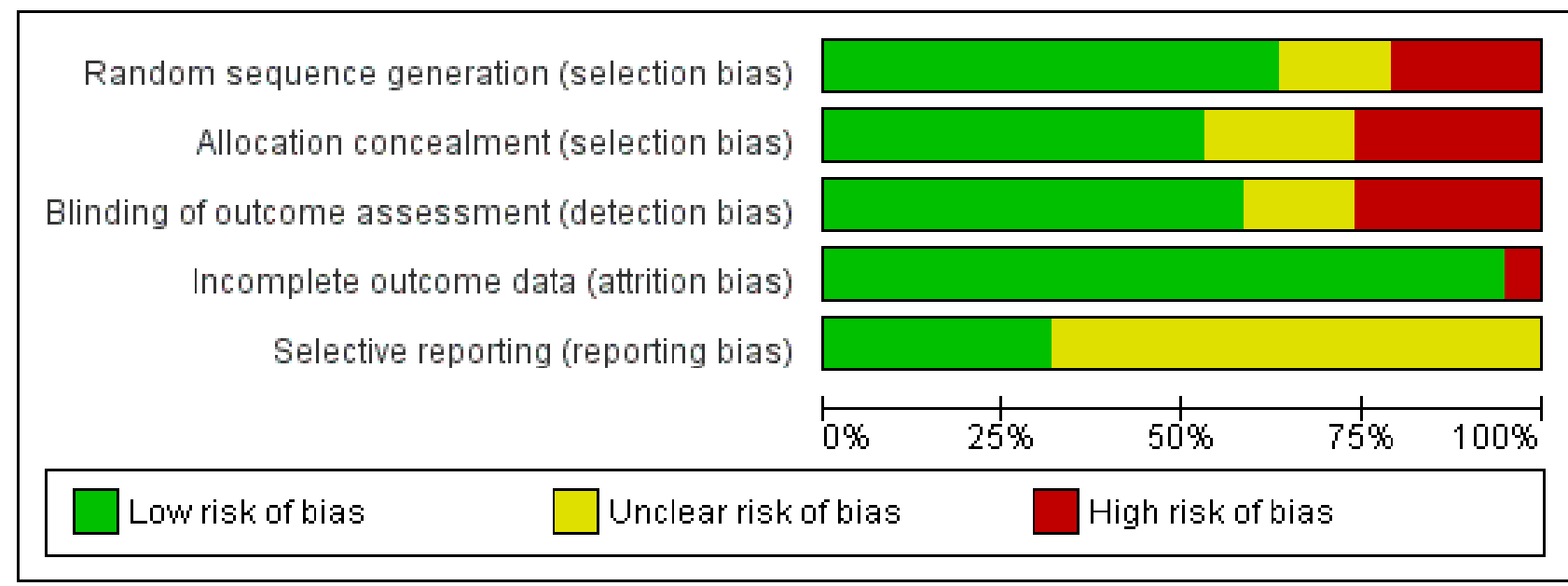


Figure 3. Risk of bias summary: review authors' judgements about each risk of bias item for each included study.

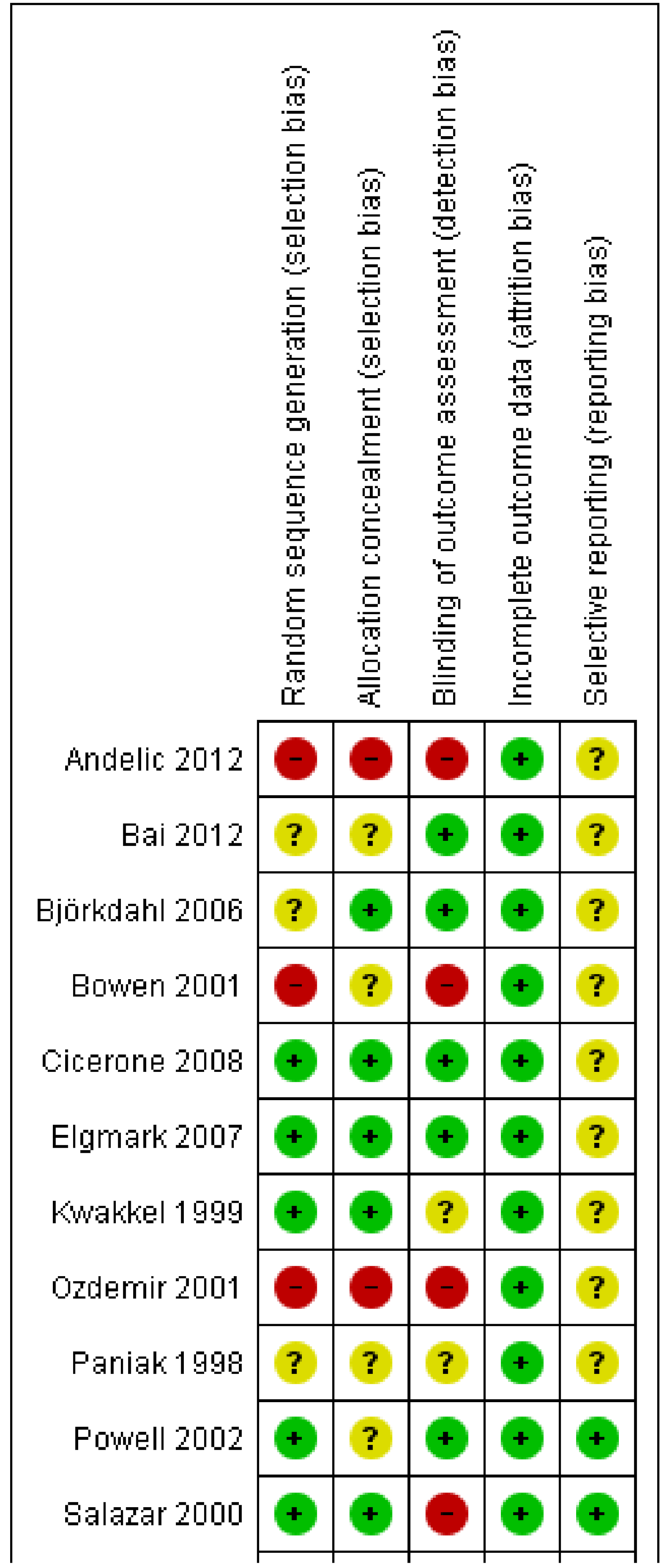


Figure 3. (Continued)

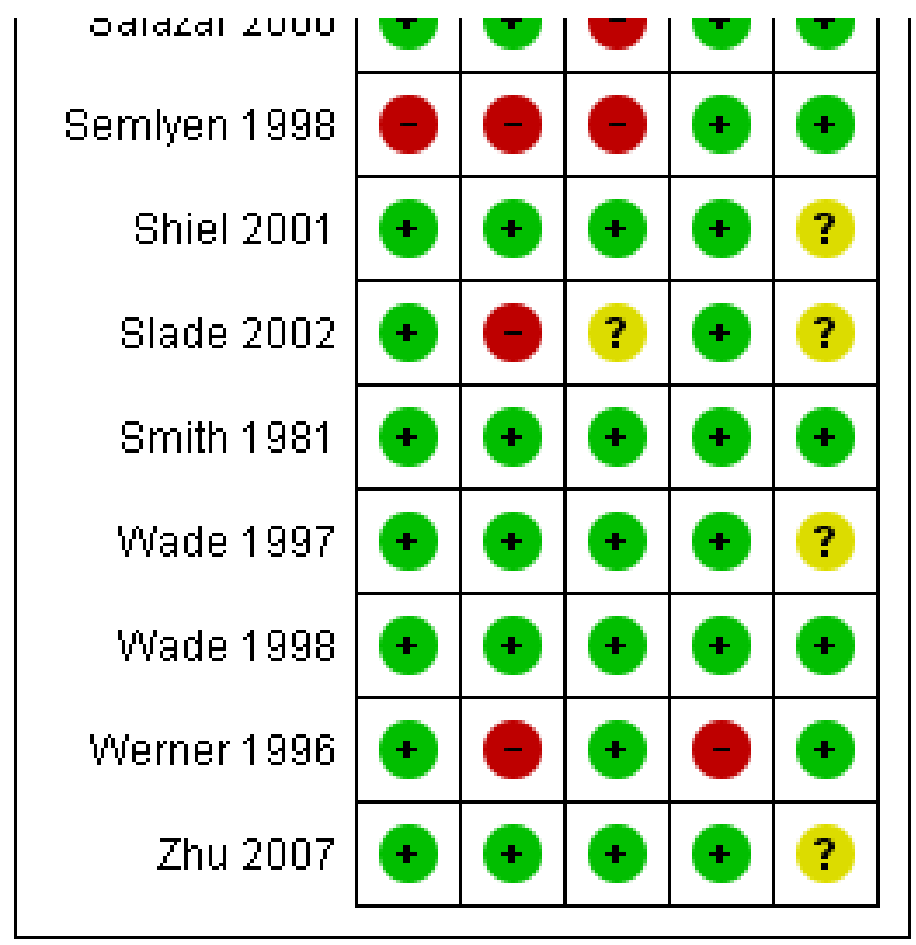

\section{Effects of interventions}

\section{Milder ambulatory patients}

Five trials predominantly addressed the milder ambulatory group (see Table 4).

Four trials (Elgmark 2007; Paniak 1998; Wade 1997; Wade 1998) compared a programme of treatment as needed (which consisted largely of community-based rehabilitation) versus a lesser intervention (Paniak: information only; Wade: standard follow-up arrangements, which usually meant no further input). We rated all as high-quality RCTs on the basis of all assessment criteria, and together they recruited a total of 1180 patients.

Salazar 2000 addressed a specific model of milieu-based neuropsychological rehabilitation in comparison with weekly telephone counselling and advice given at home, recruiting 120 patients with mild TBI. A subgroup analysis also demonstrated benefits in the more severe group (unconscious $>1$ hour) with respect to rate of return to military duty ( $80 \%$ vs $58 \%)$, as is discussed further below.

The general conclusion derived from all these studies was that intervention provided to a totally unselected group of patients with mild TBI was not effective. Both treatment and control intervention groups made substantial gains in terms of reduced post-concussion symptoms and enhanced participation, including return to work. No significant differences between groups were recorded.

In the trial by Wade 1997, a post hoc subgroup analysis demonstrated that those admitted to hospital or with posttraumatic amnesia (PTA) $>1$ hour $(n=121)$ demonstrated significant gains with treatment. They demonstrated these gains as fewer difficulties with everyday activities (increased participation) as measured by the Rivermead Head Injury Follow-Up Questionnaire (RHFUQ) (P value $<0.03$ )

A subsequent trial (Wade 1998) (218 completing participants) was undertaken. This trial prospectively selected the group admitted to hospital and again demonstrated improved outcomes for the treatment as needed group, with significantly fewer postconcussive symptoms (Rivermead Post-concussion Questionnaire $(\mathrm{RPQ})$ ) (Mann-Whitney $\mathrm{U}: \mathrm{z}=-2.27$; $\mathrm{P}$ value $<0.02$ ) and improved participation (RHFUQ) $(z=-2.54 ; P$ value $<0.01)$. The impact of proactive intervention appeared to be most marked for participants with PTA $<7$ days; these patients may be less likely than those more severely affected to present for services by themselves.

From the van Tulder 2003 'best evidence' synthesis of these studies, we concluded that 'strong evidence' suggests that:

- most patients with mild TBI make a good recovery;

- patients with PTA of less than one hour, usually not admitted to hospital, need no specific intervention;

- patients with PTA of one hour or longer do benefit from routine follow-up contact to receive information and advice; and

- a subgroup of patients with moderate to severe injury benefit from a higher level of intervention and may not present themselves unless routine follow-up is provided.

\section{Patients with greater limitations on activities, with generally more severe brain damage and generally requiring greater multi-disciplinary rehabilitation input}

The effectiveness of combined out-patient physiotherapy and occupational therapy was investigated by two trials in stroke patients (see Table 5). 
- Smith 1981 reported a good quality, unblinded RCT $(n=133)$ that demonstrated improved functional ability (Northwick Park ADL Index) for groups attending as out-patients as compared with a no-treatment control group ( $P$ value $<0.01$ ). A trend towards greater improvement with the more intense of two out-patient programmes was not tested for significance. However, gains for both treated groups were maintained at one-year follow-up, while the control group was seen to deteriorate ( $P$ value $<0.05$ ).

- Werner 1996 reported a single-blind CCT $(n=49)$ that was of much lower quality (see Table 3). This study assessed the benefits of late out-patient intervention (offered at least one year after a stroke). The treatment group demonstrated significant gains in function (an increase in FIM motor score of 6.6 vs 1.5; $P$ value $<0.03$ ) and socialisation (sickness impact profile -5.2 vs an increase of 2.6 in the control group; $P$ value $<0.04$ ) at three months, which were maintained at nine months. However, no significant change in mood (Beck Depression Inventory) was observed.

In summary, from the van Tulder 2003 synthesis, 'moderate evidence' shows that outpatient therapy improves outcomes of stroke rehabilitation; 'limited evidence' suggests that more intensive treatment regimens are associated with better outcomes; and 'indicative evidence' reveals that this type of intervention may be effective even late (at least one year) after stroke.

\section{Effectiveness of community-based co-ordinated multi- disciplinary rehabilitation}

This question was addressed by three trials (see Table 6).

- Powell 2002 reported a good quality, single-blind RCT $(n=110)$ of a multi-disciplinary community outreach service providing a home-based goal-oriented programme of two to six hours of intervention per week versus standard treatment. This group was more severely affected than the group studied by Wade 1998 (91\% with PTA for seven days vs only 7\%). Follow-up was variable but averaged approximately two years. Gains for the intervention group were reported as reduced disability (35.4\% showing improvement in Barthel Index vs $19.6 \%$ in the control group; $P$ value $<0.05$ ) and increased participation (significant changes on self organisation and psychological scales of the Brain Injury Community Rehabilitation Outcome Scales (BICRO)-39; P value $<0.05$ ), but no gains were observed for secondary outcomes, which included FIM+FAM and mood (Hospital Anxiety and Depression Scales (HADS)). Global disability scales such as FIM and FIM+FAM were noted to be insensitive, as most items did not change. A maximal gain index was calculated, which selected the subscales with maximal change. Rated in this way, changes in both disability (FIM +FAM) and participation (BICRO-39) reached a greater level of significance ( $P$ value $<0.025$ ).

- Bowen 2001 reported an unblinded CCT of lower quality in which carer outcomes were evaluated following input from a multi-disciplinary head injury specialist rehabilitation team in addition to standard services. An 'early' arm $(n=41)$ started the intervention before discharge, and a 'late' arm $(n=28)$ started after discharge. However, despite best intentions, only 23 of $41(56 \%)$ actually received early intervention and 19 or $28(67 \%)$ received late intervention, with some mixing noted between groups and with 14 participants receiving neither intervention. Nevertheless, intention-to-treat analysis revealed that the early intervention group still received significantly earlier treatment (median five days; $P$ value $<0.001$ ) than the late intervention group (median 40 days) post injury. At six months, after adjustment for confounding factors, a clinically plausible, superior outcome was reported for both intervention groups when compared with controls with regard to emotional status (Wimbledon Self Report Scale) and knowledge about brain injury. However, this finding did not reach Bonferroni-adjusted clinical significance $(P$ value $<0.01)$. Logistical difficulties with recruitment and service provision led to significant underpowering of this study and may have interfered with demonstration of a clinically significant effect.

- Björkdahl 2006 reported a small single-blinded RCT $(n=59)$ that compared a short programme of home-based rehabilitation with one of out-patient day rehabilitation following a period of in-patient stroke rehabilitation. Although neither group changed significantly in terms of impairment, both were reported to make significant gains in Assessment of Motor and Process Skills (AMPS) and in mobility over a one-year follow-up period. Although a trend toward earlier gains was observed in the home rehabilitation group, researchers noted no significant differences at any time point. Only the day clinic group changed significantly on functional measures (Functional Independence Measure), but the degree of change was small (5 FIM points over one year). Despite an a priori power calculation, the trial was probably underpowered to distinguish between groups and had a moderately high chance of a type II error. On the basis of this evidence, neither programme could be said to be better than the other, although the cost of the home-based programme was noted to be half that of the day clinic programme.

In summary, this group of studies provided 'limited evidence' that multi-disciplinary, community-based rehabilitation can improve functional outcomes for individuals at the level of 'activity' (disability) on the WHO ICF (especially when targeted towards specific goals).

\section{Specialist in-patient rehabilitation}

Two studies addressed the benefits of specialist in-patient rehabilitation in comparison with those of local services (Semlyen 1998) $(n=51)$ or a home-based advisory service (Ozdemir 2001) $(\mathrm{n}=60)$ (see Table 7). Both studies were small and exhibited low methodological quality.

- Methodological problems of Semlyen $1998(n=51)$ have already been highlighted. The 'multi-disciplinary (MD) rehabilitation' group was significantly more disabled at the outset. Thus, significantly greater gains evident at each measurement point up to 24 months may have reflected this lower starting point and the fact that many of the 'other rehabilitation' groups were already at ceiling levels on some scores. Carer distress was assessed using the General Health Questionnaire, which identified a higher proportion of 'cases' in the MD rehabilitation group at the outset, which fell between six and 12 months. By contrast, the proportion of cases in the 'other rehabilitation' groups started from a lower point but rose progressively throughout the follow-up period. By 12 months, carers in the 'other rehabilitation' group had significantly higher levels of distress than those in the MD rehabilitation group.

- Ozdemir 2001 reported an unblinded CCT in 60 stroke patients. Groups were well matched to start with. The treatment group 
made a five-fold greater gain in FIM score (mean $59.64 .8 \pm 14.1$ vs mean 12.3 4.8 \pm 13.4 ; $P$ value $<0.001$ ) and a two-fold change in Mini-Mental State Examination (MMSE) (mean $4.8 \pm 5.0$ vs mean 2.0 4.8 $\pm 2.1 ; P$ value $<0.025$ ) compared with the control group.

In summary, 'limited evidence' at the current time suggests that specialist in-patient rehabilitation services can improve functional outcomes in terms of both activity (reduced disability) and carer distress when compared with controls. However, this reflects in part the practical and ethical difficulties associated with allocating individuals with severe brain injury no opportunity for co-ordinated multi-disciplinary rehabilitation. This problem is elaborated in the Discussion section.

\section{Increased intensity of rehabilitation}

Four trials addressed the benefits of increased intensity of rehabilitation (see Table 8).

- Kwakkel 1999 reported a good quality, single-blinded RCT for 101 severely disabled stroke patients that compared a group with emphasis on arm training $(n=33)$, a group with emphasis on leg-training $(n=31)$ and a control group $(n=37)$, whose arms and legs were immobilised in an inflatable splint. Each treatment was applied for 30 minutes, five days a week, for the first 20 weeks after stroke; this was over and above a consistent basic level of intervention for all groups. Post hoc analysis by the Kruskal-Wallis test showed that leg training resulted in significantly greater independence (Barthel Index) and mobility (functional ambulation categories) than could be seen in the control group up to the first 20 weeks, and better dexterity (Action Research Arm Test) in the 'arm training' group from week 12 onwards. Effects of treatment appeared to be maintained at one year, but no significant differences were demonstrated between groups beyond six months.

- Shiel 2001 reported a two-centre RCT ( $n=51$ completing participants) for patients with moderate to severe traumatic brain injury. At each centre, participants were randomly assigned to receive routine treatment with or without input from an additional experienced staff member acting in a transdisciplinary capacity to supplement the rehabilitation programme. Those with added intensity of input made more rapid gains in independence (FIM+FAM) at both centres, with no evidence of any ceiling effect of therapeutic intensity beyond which no further response was observed. However, investigators reported marked differences between the two centres in terms of staffing levels and intensity of the routine programme. This led to substantially shorter lengths of stay at one centre, so that no significant reduction in length of stay was observed for the trial as a whole despite more rapid gains in independence.

- Slade 2002 conducted a good quality, single-blind RCT (n = 131) for a group with mixed $A B I$ that compared two rehabilitation programmes in the same setting - one more intensive than the other. Records of therapy input demonstrated that individuals were able to tolerate increased input with no adverse effects. Although investigators intended for the intensive group to receive $67 \%$ more therapy than the control group, the intensive group in fact received only $30 \%$ more. The intention to demonstrate reduced length of stay as a result of more intensive therapy was confounded by external delays in discharge. Analysis by a regression model was undertaken to account for confounding variables including impairment mix and factors that could not be controlled for in the study design (community delays and missed treatment). This revealed a significant reduction in length of stay (14 days; $P$ value $<0.001$ ) for the intensive group. Similar Barthel scores between groups at admission and at discharge confirmed that this reduced length of stay did not occur at the expense of poorer functional outcomes.

- Zhu 2007 reported a small but good quality single-blind RCT for individuals with moderate to severe traumatic brain injury ( $\mathrm{n}=$ 68 ) that compared different intensities of treatment (two vs four hours per day for up to six months). Analysis of time utilisation, presented in a preliminary report (Zhu 2001), showed that after the second week, most participants could tolerate therapy lasting longer than two hours per day. Functional and overall outcome status FIM and Glasgow Outcome Scale (GOS) scores were recorded monthly to every six months, then bi-monthly to each year. No significant differences were found between the two treatment groups beyond three months, but significantly more patients in the high-intensity group achieved a maximum FIM score at three months (47\% vs $19 \%)$ and GOS score at two months ( $28 \%$ vs $8 \%$ ), although these early functional gains did not appear to have a significant impact on length of stay. This study provides evidence that intensive rehabilitation may speed up recovery rather than changing final outcomes. Study authors concluded that early intensive rehabilitation can improve functional outcomes of individuals with $\mathrm{TBI}$ in the early months post injury and may (theoretically) increase their chances of early return to work, although actual return to work and job retention were not recorded as outcomes in this study. As most individuals did not remain in the programme beyond 90 days, it is not possible to know whether more prolonged intervention, or treatment targeted at goals beyond simple activities of daily living, could have capitalised on these earlier gains to produce higher-level gains in participation and in social integration.

In summary, from the van Tulder 2003 synthesis, 'strong evidence' shows that more intensive rehabilitation programmes are associated with earlier function gains once patients are fit to engage. No evidence showed a ceiling effect on therapeutic intensity in any of these studies. However, for intensive intervention to be cost-effective, it is necessary to demonstrate that it is associated with potential cost savings farther down the line (e.g. reduction in length of stay, long-term dependency) that might offset the additional costs of providing the initial programme. None of these studies undertook a direct analysis of cost-effectiveness, and at the current time, only 'moderate evidence' indicates that more intensive rehabilitation leads to reduced length of stay. On the other hand, length of stay is frequently affected by external confounders (such as lack of a suitable place to discharge the patient, or lack of community support for a patient otherwise ready for discharge) that may need to be controlled before this benefit can be demonstrated.

\section{Early versus delayed rehabilitation}

Two trials addressed the question of whether starting rehabilitation earlier after injury could result in better patient outcomes (see Table 9).

- Andelic 2012 was a controlled study involving patients with severe $\mathrm{TBI}$ ( $\mathrm{n}=61$ completing participants). Participants received early comprehensive rehabilitation ( 1 hour and 
45 minutes per day involving motor, sensory and facial components) starting immediately after admission to a dedicated rehabilitation section of the ICU $(n=33)$ or awaited eventual subacute rehabilitation on an in-patient brain injury unit $(n=31)$. In fact, some of the latter group received no rehabilitation at all. Treatment allocation was dependent on availability of beds in the rehabilitation section of the ITU. The early rehabilitation group showed significantly better functional outcomes with lower scores on GOSE and the Disability Rating Scale (DRS). In addition, participants in the early rehabilitation group showed increased independence (81\% living at home) compared with controls ( $23 \%$ living at home; $P$ value $=0.06$ ). As a result of its design, this study is subject to clear quality flaws as a result of lack of randomisation and blinding. In addition, functional measures were taken only at 12 months; therefore, no estimate of functional change or of functional similarity in intervention and control groups could be made at baseline. A subsequent cost-effectiveness analysis (Andelic 2014) used a decision tree model to compare hospitalisation costs, health effects and incremental cost-effectiveness ratios of a continuous chain versus a broken chain of rehabilitation. Across five years, the continuous chain of rehabilitation resulted in lower costs and better health effects. By replacing the broken chain with the continuous chain, Norwegian Krone 37.000 could be saved and 4.06 DRS points gained. (The study report gives an exchange rate of USD $1=$ NOK 6.09, so approximately $\$ 6,000$ in US dollars in 2012 could be saved.)

- Bai 2012 reported a single-blinded randomised controlled trial involving individuals with moderate to severe intracerebral haemorrhage ( $n=345$ completing participants). Participants were randomly assigned to an 'early rehabilitation' group ( $n=$ 181 ) or to a control group receiving standard ward care $(n=$ 183). Participants in the early rehabilitation group received a sixmonth programme of rehabilitation in three stages, beginning in the Emergency or Neurology Department during the first month after admission, and continuing into the community. Individuals in the control group received only routine medical care. The intervention group showed significantly higher Fugl-Meyer Assessment (FMA) and Modified Barthel Index (MBI) scores than were reported in controls at one, three and six months post stroke (all $P$ values $<0.05$ ). Study authors concluded that early rehabilitation can improve functional recovery among individuals with intracerebral haemorrhage. The quality of the paper is limited by the fact that very little information is provided on the processes of randomisation, treatment allocation and blinding. Moreover, no explanation is provided as to why the paper was published eight years after data were collected.

In spite of clear limitations in the quality of these two studies, taken together they provide 'limited evidence' to support commencing comprehensive rehabilitation acutely in patients with moderate to severe injury.

\section{Therapeutic milieu-based rehabilitation}

Two trials investigated use of a 'therapeutic milieu' model of rehabilitation (see Table 10). On the basis of models described by Ben-Yishay 1990 and Prigatano 1994, this approach comprises intensive holistic neuropsychological rehabilitation delivered as a largely group-based intervention in a residential setting.

- Cicerone 2008 reported a high-quality, single-blinded RCT for patients with TBI of mixed severity ( $n=62$ completing participants). Participants were randomly assigned to receive intensive cognitive rehabilitation (treatment $\operatorname{arm} \mathrm{n}=34$ ) or standard neurorehabilitation (control arm $\mathrm{n}=34$ ). Approximately 15 hours per week of both interventions was delivered at the same centre, but treatment orientation and programme structure varied. The cognitive group received 'intensive neurospsychological' rehabilitation based on the milieu model, with more group-based interventions provided in a therapeutic environment. The standard rehabilitation group consisted primarily of individual discipline-specific out-patient interventions. Study authors hypothesised that the intensive neuropsychological programme would result in greater improvement in community integration, productivity and life satisfaction than was provided by the standard programme. Participants in the treatment arm of this trial showed a statistically significant improvement on both the Community Integration Questionnaire (CIQ) and the Perceived Quality of Life Scale (PQOL) between pre-treatment and posttreatment assessment, and improvements were maintained at six-month follow-up compared with no significant change in the control arm. With respect to secondary outcomes, both treatment and control arms improved significantly on neuropsychological testing. Self efficacy was significantly improved in the treatment arm immediately post treatment, and improvement was maintained at follow-up, whereas the control arm demonstrated no significant change.

- Salazar 2000 compared an eight-week intensive in-patient cognitive rehabilitation programme modelled on the milieubased approach versus a home-based programme of weekly telephone contact providing counselling and advice from a psychiatric nurse for active military personnel with moderate to severe TBI. Although main results showed no significant differences between groups overall, post hoc analysis of participants in the more severe subgroup (i.e. those who were unconscious $>1$ hour at the time of injury; $n=75$ ) showed that individuals in the intervention group were more likely than controls to be 'fit for military duty' at one year ( $80 \%$ in intervention group vs $58 \%$ in control group; $P$ value $=0.05$ ). As the trial pre-dated the requirement for pre-registration, it is not known whether this sub-group analysis was pre-planned. However, brain injury severity is an anticipated confounding factor for rehabilitation outcome, and the findings resonate with other studies (e.g. Wade 1997 and Wade 1998) suggesting that it is the more severely injured patients who have most to gain from organised rehabilitation programmes.

In summary, from the van Tulder 2003 synthesis, these two highquality studies have provided reasonably 'strong evidence' that a milieu-based approach to in-patient rehabilitation is effective for individuals with moderate to severe $A B I$.

\section{DISCUSSION}

This review suggests that multi-disciplinary rehabilitation by expert neurological rehabilitation services improves outcomes after acute brain injury ( $\mathrm{ABI}$ ) in adults of working age, and that greater intensity is likely to lead to faster and possibly improved recovery. It also suggests that people with relatively minor traumatic brain injury (TBI) who are not admitted to hospital, or who do not have a period of post-traumatic amnesia lasting longer than 30 minutes, will recover without routine specialist follow-up and rehabilitation. 
New findings have emerged from this update.

- Evidence from two high-quality randomised controlled trials (RCTs) shows that in moderate to severe $A B I$, milieubased residential programmes (whereby patients undergo neuropsychological rehabilitation in a therapeutic environment with a peer group of individuals facing similar challenges) can be more effective than lower-level individual interventions.

- Limited evidence indicates that beginning rehabilitation earlier after injury, while patients are still in emergency or acute care settings, can lead to improved outcomes for people with moderate to severe $\mathrm{ABI}$.

This review highlights the need for further research to confirm the general conclusion, to investigate cost-effectiveness and to identify which components of the rehabilitation package are of particular importance.

\section{Context}

This review needs to be set in the context of other studies and reviews investigating specialist (neurological) rehabilitation. Several other Cochrane reviews have presented similar conclusions concerning other rehabilitation programmes for stroke (Stroke Unit Trialists Collaboration 2007) after hip or knee joint replacement (Khan 2008) for people with multiple sclerosis (Khan 2007) and for people with chronic obstructive pulmonary disease (Lacasse 2006).

Therefore, it is no surprise that this review suggests that rehabilitation is an effective intervention.

However, it must be stressed that these studies have primarily investigated the process of rehabilitation - not any specific intervention (therapy or treatment) or group of interventions. Investigators have shown that being involved in a service that encompasses a multi-disciplinary team of people with expertise in neurological rehabilitation and that focuses on reducing disability and increasing social participation through a problem-solving process generally improves patient outcomes.

Evidence from stroke rehabilitation, used to formulate the relevant recommendation (3.2.1B) in the third edition of the UK National Clinical Guideline for Stroke (Royal College of Physicians 2008), suggest that key features of a successful specialist rehabilitation service include the following.

- Multi-disciplinary team.

- All team members with relevant expertise.

- Educational programmes for staff, patients and relatives.

- Specific geographic base or location.

- Agreed upon protocols based on evidence to manage common problems, when possible.

\section{Limitations of this review}

This review took an inclusive approach to a broad area of clinical practice and a wide-ranging group of conditions under the collective banner of 'acquired brain injury'. This approach posed challenges for assessment and assimilation of available evidence.

First, the quality of included studies may have been too low to allow useful conclusions on their own. However, the presented synthesis using a 'best evidence' approach, which includes a measure of methodological quality, has facilitated a helpful comparison of various available studies. It also has allowed open acknowledgement of the limited evidence provided by these poorer studies, which nevertheless is the best currently available (or indeed likely to become available in some areas) for the reasons discussed below.

Second, a more piecemeal approach, undertaking many separate reviews of the various models of practice, might have been easier to interpret and analyse. However, patients rarely present with a single problem, and studies on single solutions are not necessarily useful or useable. They have their own weaknesses in recruiting very selected patients or in including many other variables that may affect outcomes. Thus, although some countries do plan or organise service provision around specific programmes of rehabilitation for specific diagnostic groups, a broader needsled approach to service provision for patient groups that are more mixed is probably more appropriate, and this is what we have evaluated. The stroke unit studies are the strongest example of research focused on a broad approach, not a piecemeal approach, and these researchers have been both clear in their outcomes and influential in the field.

Third, to hold the review to a manageable size, we carefully restricted considered studies to those falling within the scope of the protocol. Studies that investigated the process of rehabilitation within a single profession or in older people are not included. Within this update, we excluded Vanderploeg 2008 after much deliberation. This study from the US Defense and Veterans Brain Injury Center Study Group (the same group as Salazar 2000) is a well-conducted, high-quality study comparing two approaches to rehabilitation - a 'cognitive-didactic' approach and a 'functionalexperiential' approach - within a shared environment. Although investigators showed no statistically significant differences between the two approaches, they highlighted the importance of further investigation into different approaches to multi-disciplinary rehabilitation, which is beyond the scope of this review.

Last, we have focused on acute-onset conditions, but the process of rehabilitation and the types of problems faced by people with other types of diseases are similar. We note with interest findings of the waitlist controlled trial by Khan 2014 for brain cancer survivors, which demonstrated that multi-disciplinary rehabilitation can improve function, with gains maintained up to six months. Participants were allocated to treatment or control groups on the basis of need, for reasons that are entirely understandable in this population. However, this study did not meet the inclusion criteria for this review, as the requirement for 'a large element of chance' in the treatment allocation was not met.

We chose to limit the scope of this review, in part to fill a gap in the broader set of rehabilitation reviews, and in part because service commissioners (purchasers) perceive adults with acquired brain injury as a specific population needing a specific set of evidence. Other Cochrane reviews have focused on multidisciplinary rehabilitation for conditions such as multiple sclerosis (Khan 2007), motor neuron disease (Ng 2009) and Guillain-Barré syndrome (Khan 2010).

In summary, we believe that these limitations should be set in the context of the whole body of research into specialist rehabilitation, and that they do not detract from our conclusions. 


\section{Implications}

Direct findings of this review have some implications for service commissioning and provision, largely supporting development and use of specialist neurological rehabilitation services for people of working age with residual problems soon after acute-onset brain injury, however acquired.

The other main lessons to be learned relate to the nature of rehabilitation and ways that research into rehabilitation is undertaken.

Randomised controlled trials are the primary means by which treatment efficacy is demonstrated, mainly because of their ability to control for unknown confounding factors, many of which are found in rehabilitation. They are well suited to single, easily identified interventions, such as specific drugs or procedures.

However, rehabilitation is a complex intervention that has many inter-related and interdependent components. Changes that occur during rehabilitation must be evaluated against a backdrop of spontaneous recovery, but the relationships targeted may well be non-linear and unpredictable on an individual basis. This has been recognised with increasing frequency in many other areas of healthcare research.

In the context of research into both the rehabilitation process and more specific rehabilitation interventions (treatments), this review has highlighted a number of challenges.

- Patient numbers are relatively small.

- Heterogeneity is marked among relevant clinical characteristics, interventions, settings and outcomes.

- Resources required to randomly assign whole systems of care to different treatment groups are far greater than those required to deliver specific medications or procedures.

- The length of time over which rehabilitation may have its effects (always many months and usually several years) is usually longer than any funded research project.

In addition, the expanding body of evidence for effectiveness of multi-disciplinary rehabilitation in other conditions (particularly stroke) makes it increasingly difficult (both ethically and practically), to randomly assign study participants to non-specialist rehabilitation, as clinical equipoise cannot be argued.

That said, the reality is that specialist neurological rehabilitation services are not available to many patients, even in rich countries (such as UK and USA), so in theory it should still be possible to undertake randomised studies comparing rehabilitation by a specialist multi-disciplinary neurological rehabilitation team versus non-specialist, un-co-ordinated piecemeal rehabilitation, which is currently received by many people. In addition, designs such as cluster-randomised trials (in which an entire service may be randomly assigned, as opposed to individual participants) may help to address some of the challenges, even though they bring their own challenges in terms of complexity of design and analysis, and require larger numbers to produce the requisite statistical power.

We therefore recommend that such studies should be undertaken when possible to acquire a body of evidence equivalent to that acquired for stroke units - provided the various practical and logistical barriers can be overcome.

The studies identified in this review provide some useful insights into practical problems associated with research in this area that will need to be addressed in future studies.

\section{Recruitment and retention of participants}

When fully informed consent is obtained before engagement, as it should be, recruitment and retention can be problematic, especially for the control arm. For example, Werner 1996 started out as a weighted randomised study. Once recruited, however, many control group members demonstrated reluctance to attend for evaluations and expressed disappointment at not having been selected for treatment. After more than half of the control group defaulted from follow-up, trialists were forced to recruit an additional five controls in a non-randomised fashion.

\section{Differences between centres}

In view of the small number of patients available at any one centre, multi-centre studies are required. However, the additional heterogeneity introduced may outweigh the benefits of increased numbers for analysis. This problem was well illustrated in the study by Shiel 2001, in which two centres, chosen initially for their similarity of service, turned out to have critical differences in staffing levels and, therefore, in the intensity of rehabilitation offered as routine. This led to disparate lengths of stay that were sufficient to confound this critical outcome in statistical analysis.

\section{Time scale and interpretation}

Benefits of neurological rehabilitation typically accrue over several years, rather than over weeks or months. RCTs are typically conducted over a much shorter time. Definitive RCTs in this area should be funded to include follow-up over three to five years. This is rarely possible under existing funding programmes for RCTs.

\section{Outcome measurement}

Common (shared) measures are a necessary prerequisite for assimilation of data. Several global outcome assessments, such as the Barthel Activities of Daily Living (ADL) Index and the Functional Independence Measure (FIM), have been developed with the aim of creating comparable datasets, and they are widely used. Unfortunately, these measures pose further problems.

- Homogeneity: The measures themselves may be less homogeneous than was previously supposed. Analysis indicates that even the most consistently applied instruments behave differently in different cultures and settings (Tennant 2002), and several different versions of the Barthel Index are currently used (Turner-Stokes 1997).

- Sensitivity to targeted changes: Rehabilitation is increasingly targeted towards specific goals set for the individual and for the family. These global instruments address a range of dimensions, many of which are not likely to change in response to such targeted efforts. Overall scores therefore are unlikely to reflect the true benefits of the intervention. Powell 2002 attempted to overcome this problem by recording only dimensions that demonstrated maximal gain (maximum gain index). This enhanced statistical differences between treatment and control arms but might be considered to represent excessive manipulation of the data, especially as these selected 
dimensions were not identified as target areas before treatment was begun.

- Interpretation: Semlyen 1998 illustrates a dilemma for data interpretation. Participants who received multi-disciplinary rehabilitation were more disabled at the outset but by 12 months achieved the same level of function (Barthel Index) as those in other rehabilitation groups. This fact may be interpreted as showing an inverse bias for the treatment arm, which therefore demonstrated significantly greater gains during rehabilitation despite the lower starting point. Alternatively, it may be argued that this lower starting point offers a statistical advantage in providing greater opportunity for change on a scale with recognised ceiling effects.

- Ceiling effects: Possible ceiling effects of the FIM, which is commonly used as an outcome measure for brain injury rehabilitation, were seen in Zhu 2007. The same percentages of control and treatment group participants eventually reached maximum FIM score by one year post injury. However, the treatment group achieved high scores more quickly with significant differences detectable at three months. It is not possible to determine whether earlier return to full independence allowed patients to extend their horizons beyond basic activities of daily living, as the study did not record measures of extended activities of daily living, nor of participation.

Studies included within this review have used a wide variety of measures to explore psychosocial function (e.g. the Community Integration Questionnaire (CIQ), the Perceived Quality of Life Scale (PQOL), the Canadian Occupational Performance Measure (COPM), the Brain Injury Community Rehabilitation Outcome scales (BICRO-39)). Absence of consensus over which measures to use, however, prohibits analysis of pooled data.

These limitations in outcome measurement also underline the need to collect more person-centred measures, such as goal attainment scaling, to record whether the rehabilitation programme achieved intended goals for that individual, and to highlight the need for further development of standardised measures that record gains at various levels of impairment, activity and participation. In addition, given the diversity of actual needs for rehabilitation, outcomes should be interpreted in the light of both needs for rehabilitation and the extent to which these needs have been met. In the decade or so over which this review has been active, more sophisticated mechanisms have been introduced to capture needs, inputs and outcomes (Turner-Stokes 2012), as well as unmet needs (Turner-Stokes 2013). These and other developments should enhance the opportunity for evaluation of case mix-adjusted outcomes of rehabilitation in the future, to guide interpretation of study findings.

As in other complex areas of medical practice, it may be necessary to develop the evidence base for effective management through triangulation of a range of different research methods. In this review, we have included controlled studies, provided they met the pre-determined criteria. It is accepted that these research designs are open to a certain level of bias. However, given the problems noted above, review authors accepted that in the real-life context of clinical practice, this level of 'randomness' may be the best that can be achieved in the context of severe brain injury. In the future, these experimental designs will need to be considered alongside practice-based evidence (Horn 2007) gathered from large systematic, longitudinal cohort studies conducted in the context of routine clinical practice to address questions that cannot be answered by RCTs, such as which treatments work best for which patients over the long term, and which models of service represent value for money in the context of life-long care (Turner-Stokes 2008).

\section{AUTHORS' CONCLUSIONS}

\section{Implications for practice}

Various findings from this review serve to emphasise the varied nature of acquired brain injury and the need for different services to suit the needs of different populations. Implications for practice from this review are as follows.

- Although every patient presenting to hospital with $A B I$ should be given information about the nature of the brain injury and whom they should contact in case of problems, it appears that routine follow-up may be reserved for patients identified as having at least significant brain injury on the basis of their presentation or residual deficits. These individuals are most easily defined as those admitted to hospital or, if not, with any documented period of coma or post-traumatic amnesia extending for longer than 30 minutes.

- For patients engaged in rehabilitation, intervention should be offered as intensively as possible and should begin as early as possible, although the balance between intensity and costeffectiveness has yet to be determined.

- In-patient and residential neuropsychological rehabilitation services should consider moving towards the milieu-based model of rehabilitation as described by Ben-Yishay and Prigatano.

- Patients discharged from in-patient rehabilitation settings, who have ongoing rehabilitation needs and goals, should have access to follow-up out-patient or community-based services appropriate to their needs.

\section{Implications for research}

Important questions remain to be answered regarding the effectiveness of rehabilitation interventions in acquired brain injury. When these cannot be answered by well-designed RCTs, they may still be appropriately addressed by alternative methods or by closer examination of research questions. In particular, researchers need to explore:

- effectiveness of specific interventions within the overall rehabilitation programme, and characteristics that render patients most likely to gain benefit;

- methods that can be used to assess an individual's ability to engage in and benefit from intensive rehabilitation, and the most appropriate level of intensity;

- cost-effectiveness of rehabilitation interventions and their impact on quality of life for both patients and carers;

- appropriate outcome measures and better understanding of behaviour in different cultural settings, as well as statistical handling;

- improved measurement techniques for assessment of targeted interventions, such as goal attainment, or agreed methods for refining global instruments to focus on areas of particular interest or relevance to the intervention: 
- long-term (> 12 months) effects of rehabilitation, in terms of both patient outcomes and social costs associated with ABI (care costs and loss of income for patient and family); and

- appropriate methods for incorporating other research designs into formal reviews and meta-analyses.

\section{ACKNOWLEDGEMENTS}

This study was funded by grants from the Department of Health Research and Development Programme and from the Luff Foundation. The review authors would like to acknowledge Fiona Renton, Karen Blackhall and Deirdre Beecher of the Cochrane Injuries Group for help with literature searching; Emma Sydenham for assistance with the risk of bias tables and general editing; Kanchana Jeganathan and staff from the John Squire Library, Northwick Park Hospital, for assistance in gathering the references; and Dr Beatrice Zhang for kind assistance with interpretation of various papers published in the Chinese literature.

Imad Sedki contributed to the 2009 and 2010 versions of the review.

This project was supported by the UK National Institute for Health Research, through Cochrane Infrastructure funding to the Cochrane Injuries Group. The views and opinions expressed are those of the review authors and do not necessarily reflect those of the Systematic Reviews Programme, NIHR, NHS or the Department of Health. 


\section{RE F E R E N C E S}

\section{References to studies included in this review}

Andelic 2012 \{published data only\}

*Andelic N, Bautz-Holter E, Ronning P, Olafsen K, Sigurdardottir S, Schanke AK, et al. Does an early onset and continuous chain of rehabilitation improve the long-term functional outcome of patients with severe traumatic brain injury?. Journal of Neurotrauma 2012;29:66-74.

Andelic N, Ye J, Tornas S, Roe C, Lu J, Bautz-Holter E, et al. Costeffectiveness analysis of an early-initiated, continuous chain of rehabilitation after severe traumatic brain injury. Journal of Neurotrauma July 15, 2014;31(14):1313-20.

\section{Bai 2012 \{published data only\}}

Bai Y, Hu Y, Wu Y, Zhu Y, He Q, Jiang C, et al. A prospective, randomized, single-blinded trial on the effect of early rehabilitation on daily activities and motor function of patients with hemorrhagic stroke. Journal of Clinical Neuroscience 2012;19:1376-9.

\section{Björkdahl 2006 \{published data only\}}

Bjorkdahl A, Lundgren NA, Grimby G, Sunnerhagen S. Does a short period of rehabilitation in the home setting facilitate functioning after stroke? A randomized controlled trial. Clinical Rehabilitation 2006;20:1038-49.

\section{Bowen 2001 \{published data only\}}

Bowen A, Tennant A, Neumann V, Chamberlain MA. Neuropsychological rehabilitation for traumatic brain injury: Do carers benefit?. Brain Injury 2001;15(1):29-38.

\section{Cicerone 2008 \{published data only\}}

Cicerone KD, Mott T, Azulay J, Sharlow-Galella MA, Ellmo WJ, Paradise $S$, et al. A randomized controlled trial of holistic neuropsychologic rehabilitation after traumatic brain injury. Archives of Physical Medicine and Rehabilitation 2008;89:2239-49.

\section{Elgmark 2007 \{published data only\}}

Elgmark Andersson E, Emanuelson I, Björklund R, Stålhammar DA. Mild traumatic brain injuries: the impact of early intervention on late sequelae. A randomized controlled trial. Acta Neurochirurgica 2007;149:151-60.

Kwakkel 1999 \{published data only\} Kwakkel G, Kollen BJ, Wagenaar RC. Long term effects of intensity of upper and lower limb training after stroke: a randomised trial. Journal of Neurology, Neurosurgery and Psychiatry 2002;72(4):473-9.

* Kwakkel G, Wagenaar RC, Twisk JWR, Lankhorst GJ, Koetsier JC. Intensity of leg and arm training after primary middle-cerebral artery stroke: a randomised trial. Lancet 1999;354:189-94.

\section{Ozdemir 2001 \{published data only\}}

Ozdemir F, Birtane M, Tabatabaei R, Kokino S, Ekuklu G. Comparing stroke rehabilitation outcomes between acute in- patient and non-intense home settings. Archives of Physical Medicine and Rehabilitation 2001;82:1375-9.

Paniak 1998 \{published data only\}

* Paniak C, Toller Lobe G, Durand A, Nagy J. A randomized trial of two treatments for mild traumatic brain injury. Brain Injury 1998;12(12):1011-23.

Paniak C, Toller-Lobe G, Reynolds S, Melnyk A, Nagy J. A randomized trial of two treatments for mild traumatic brain injury: 1 year follow-up. Brain Injury 2000;14(3):219-26.

Powell 2002 \{published data only\}

Powell J, Heslin J, Greenwood R. Community based rehabilitation after severe traumatic brain injury: a randomised controlled trial. Journal of Neurology, Neurosurgery and Psychiatry 2002;72(2):193-202.

Salazar 2000 \{published data only\}

Braverman SE, Warden DL, Wilson BC, Ellis TE, Bamdad MJ, Salazar AM. A multidisciplinary TBI inpatient rehabilitation programme for active duty service members as part of a randomized clinical trial. Brain Injury 1999;13(6):405-15.

* Salazar AM, Warden DL, Schwab K, Spector J, Braverman S, Walter J, et al. Cognitive rehabilitation for traumatic brain injury: a randomized trial. Defense and Veterans Head Injury Program (DVHIP) Study Group. JAMA 2000;283(23):3075-81.

Warden DL, Salazar AM, Martin EM, Schwab KA, Coyle M, Walter J. A home program of rehabilitation for moderately severe traumatic brain injury patients. The DVHIP Study Group. Journal of Head Trauma Rehabilitation 2000;15(5):1092-102.

Semlyen 1998 \{published data only\}

Semlyen JK, Summers SJ, Barnes MP. Traumatic brain injury: efficacy of multidisciplinary rehabilitation. Archives of Physical Medicine and Rehabilitation 1998;79(6):678-83.

Shiel 2001 \{published data only\}

Shiel A, Burn JP, Henry D, Clark J, Wilson BA, Burnett ME, et al. The effects of increased rehabilitation therapy after brain injury: results of a prospective controlled trial. Clinical Rehabilitation 2001;15(5):501-14.

Slade 2002 \{published data only\}

Slade A, Tennant A, Chamberlain A. A randomised controlled trial to determine the effect of intensity of therapy upon length of stay in a neurological rehabilitation setting. Journal of Rehabilitation Medicine 2002;34:260-6.

Smith 1981 \{published data only\}

Smith D, Goldenberg E, Ashburn A, Kinsella G, Sheikh K, Brennan PJ, et al. Remedial therapy after stroke: a randomised controlled trial. British Medical Journal 1981;282:517-20.

\section{Wade 1997 \{published data only\}}

King NS, Crawford S, Wenden FJ, Moss NE, Wade DT. Interventions and service need following mild and moderate 
head injury: the Oxford Head Injury Service. Clinical Rehabilitation 1997;11(1):13-27.

* Wade DT, Crawford S, Wenden FJ, King NS, Moss NE. Does routine follow up after head injury help? A randomised controlled trial. Journal of Neurology, Neurosurgery and Psychiatry 1997;62(5):478-84.

Wenden FJ, Crawford S, Wade DT, King NS, Moss NEG. Assault, post-traumatic amnesia and other variables related to outcome following head injury. Clinical Rehabilitation 1998;12(1):56-63.

Wade 1998 \{published data only\}

Wade DT, King NS, Wenden FJ, Crawford S, Caldwell FE. Routine follow up after head injury: a second randomised controlled trial. Journal of Neurology, Neurosurgery and Psychiatry 1998;65(2):177-83.

\section{Werner 1996 \{published data only\}}

Werner RA, Kessler S. Effectiveness of an intensive outpatient rehabilitation program for postacute stroke patients. American Journal of Physical Medicine and Rehabilitation 1996;75(2):114-20.

\section{Zhu 2007 \{published data only\}}

* Zhu XL, Poon WS, Chan CH, Chan SH. Does intensive rehabilitation improve the functional outcome of patients with traumatic brain injury (TBI)? A randomized controlled trial. Brain Injury 2007;21(7):681-90.

Zhu XL, Poon WS, Chan CH, Chan SH. Does intensive rehabilitation improve the functional outcome of patients with traumatic brain injury? Interim result of a randomized controlled trial. British Journal of Neurosurgery 2001;15(6):464-73.

\section{References to studies excluded from this review}

\section{Bjorkdahl 2007 \{published data only\}}

Bjorkdahl A, Nilsson AL, Sunnerhagen KS. Can rehabilitation in the home setting reduce the burden of care for the nextof-kin of stroke victims?. Journal of Rehabilitation Medicine 2007;39:27-32

\section{Browne 2013 \{published data only\}}

Browne AL, Appleton S, Fong K, Wood F, Coll F, de Munck S, et al. A pilot randomized controlled trial of an early multidisciplinary model to prevent disability following traumatic injury. Disability \& Rehabilitation 2013;35:1149-63.

\section{Ownsworth 2008 \{published data only\}}

Ownsworth T, Fleming J, Shum D, Kuipers P, Strong J. Comparison of individual, group and combined intervention formats in a randomized controlled trial for facilitating goal attainment and improving psychosocial function following acquired brain injury. Journal of Rehabilitation Medicine 2008;40:81-8.

\section{Relander 1972 \{published data only\}}

Relander M, Troupp H, Bjorksten G. Controlled trial of treatment for cerebral concussion. British Medical Journal 1972;4:777-9.
Sonoda 2004 \{published data only\}

Sonoda S, Saitoh E, Nagai S, Kawakita M, Kanada Y. Fulltime integrated treatment program, a new system for stroke rehabilitation in Japan. Comparison with conventional rehabilitation. American Journal of Physical Medicine and Rehabilitation 2004;83(2):88-93.

\section{Vanderploeg 2008 \{published data only\}}

Vanderploeg RD, Schwab K, Walker WC, Fraser JA, Sigford BJ, Date ES, et al. Rehabilitation of traumatic brain injury in active duty military personnel and veterans: Defense and Veterans Brain Injury Center randomized controlled trial of two rehabilitation approaches. Archives of Physical Medicine and Rehabilitation 2008;89:2227-38.

\section{References to ongoing studies}

\section{NCT00869154 \{published data only\}}

NCT00869154. Multidisciplinary Treatment in Patients With Mild Traumatic Brain Injury. Clinicaltrials.gov (Accessed December 2015).

\section{Additional references}

\section{Ben-Yishay 1990}

Ben-Yishay Y, Gold J. Therapeutic milieu approach to neuropsychological rehabilitation. In Woods RL, Editor. Neurobehavioural Sequelae of Traumatic Brain Injury. New York: Taylor \& Francis, 1990

\section{Craig 2008}

Craig P, Dieppe P, Macintyre S, Michie S, Nazareth I, Petticrew M. Developing and evaluating complex interventions: the new medical research guidance. British Medical Journal 2008;337:979-83

\section{DeJong 2005}

DeJong G, Horn SD, Conroy B, Nichols D, Healton EB. Opening the black box of post-stroke rehabilitation: stroke rehabilitation patients, processes, and outcomes. Archives of Physical Medicine and Rehabilitation 2005;86(12 Suppl 2):S1-S7.

\section{Department of Health 2005}

The National Service Framework for Long-term Conditions. Department of Health. London: Department of Health, 2005.

\section{Gladman 1993}

Gladman JR, Lincoln NB, Barer DH. A randomised controlled trial of domiciliary and hospital-based rehabilitation for stroke patients after discharge from hospital. Journal of Neurology, Neurosurgery and Psychiatry 1993;56(9):960-6.

\section{Greener 2002}

Greener J, Langhorne P. Systematic reviews in rehabilitation for stroke: issues and approaches to addressing them. Clinical Rehabilitation 2002;16(1):69-74.

\section{Higgins 2011}

Higgins JPT, Green S (editors). Cochrane Handbook for Systematic Reviews of Interventions Version 5.1.0 [updated 
March 2011]. The Cochrane Collaboration, 2011. www.cochranehandbook.org.

\section{Hoffmann 2010}

Hoffmann T, Bennett S, Koh CL, McKenna KT. Occupational therapy for cognitive impairment in stroke patients.

Cochrane Database of Systematic Reviews 2010, Issue 9. [DOI:

10.1002/14651858.CD006430.pub2]

\section{Horn 2005}

Horn SD, DeJong G, Ryser DK, Veazie PJ, Teraoka J. Another look at observational studies in rehabilitation research: going beyond the holy grail of the randomized controlled trial. Archives of Physical Medicine and Rehabilitation 2005;86(12 Suppl 2):S8-S15.

\section{Horn 2007}

Horn SD, Gassaway J. Practice-based evidence study design for comparative effectiveness research. Medical Care 2007;45 Suppl 2(10):50-7.

\section{Kalra 1994}

Kalra L. Does age affect benefits of stroke unit rehabilitation?. Stroke 1994;25(2):346-51.

\section{Kersten 2002}

Kersten P, Lou J, Ashburn A, George S, McLellan D. The unmet needs of young people who have had a stroke: results of a national UK survey. Disability and Rehabilitation 2002;24:860-6.

\section{Khan 2007}

Khan F, Ng L, Gonzalez S, Hale T, Turner-Stokes L. Multidisciplinary rehabilitation programmes following joint replacement at the hip and knee in chronic arthropathy. Cochrane Database of Systematic Reviews 2008, Issue 2. [DOI: 10.1002/14651858.CD004957.pub3]

\section{Khan 2008}

Khan F, Turner-Stokes L, Ng L, Kilpatrick T. Multidisciplinary rehabilitation for adults with multiple sclerosis. Cochrane Database of Systematic Reviews 2007, Issue 2. [DOI: 10.1002/14651858.CD006036.pub2]

\section{Khan 2010}

Khan F, Ng L, Amatya B, Brand C, Turner-Stokes L. Multidisciplinary care for Guillain-Barré syndrome. Cochrane Database of Systematic Reviews 2010;10:1-26. [DOI: 10.1002/14651858.CD008505.pub2]

\section{Khan 2014}

Khan F, Amatya B, Drummond K, Galea M. Effectiveness of integrated multidisciplinary rehabilitation in primary brain cancer survivors in an Australian community cohort: a controlled clinical trial. Journal of Rehabilitation Medicine 2014;46(8):754-60.

\section{Lacasse 2006}

Lacasse Y, Goldstein R, Lasserson TJ, Martin S. Pulmonary rehabilitation for chronic obstructive pulmonary disease. Cochrane Database of Systematic Reviews 2006, Issue 4. [DOI: 10.1002/14651858.CD003793.pub2]

\section{Lombardi 2002}

Lombardi F, Taricco M, De Tanti A, Telaro E, Liberati A. Sensory stimulation for brain injured individuals in coma or vegetative state. Cochrane Database of Systematic Reviews 2002, Issue 2. [DOI: 10.1002/14651858.CD001427]

\section{Ng 2009}

$\mathrm{Ng}$ L, Khan F. Multidisciplinary care for adults with amyotrophic lateral sclerosis or motor neuron disease. Cochrane Database of Systematic Reviews 2009, Issue 4. [DOI: 10.1002/14651858.CD007425.pub2]

\section{Prigatano 1994}

Prigatano GP, Klonoff PS, O'Brien KP, Altman IM, Amin K, Chiapello D, et al. Productivity after neuropsychologically oriented milieu rehabilitation. Journal of Head Trauma Rehabilitation 1994;9:91-102.

\section{Roding 2003}

Roding J, Lindstrom B, Malm J, Ohman A. Frustrated and invisible - younger stroke patients' experiences of the rehabilitation process. Disability and Rehabilitation 2003;25:867-74.

\section{Royal College of Physicians 2008}

Royal College of Physicians. National Clinical Guidelines for Stroke. Third Edition. National Clinical Guidelines for Stroke. 3rd Edition. London, UK: RCP, 2008.

\section{Shiel 2008}

Shiel A, Hawe P, Gold L. Complex interventions or complex systems? Implications for health economic evaluation. British Medical Journal 2008;336:1281-3.

\section{Steultjens 2003a}

Steultjens EMJ, Dekker J, Bouter LM, van Schaardenburg D, van Kuyk MAH, van den Ende CHM. Occupational therapy for rheumatoid arthritis. Cochrane Database of Systematic Reviews 2004, Issue 1. [DOI: 10.1002/14651858.CD003114.pub2]

\section{Steultjens 2003b}

Steultjens EMJ, Dekker J, Bouter LM, van de Nes JCM, Cup EHC van den Ende CHM. Occupational therapy for stroke patients: a systematic review. Stroke 2003;34(3):676-87.

\section{Tennant 2002}

Tennant A. The Rasch Model and standardising outcome in rehabilitation: the PRO-ESOR project. 13th European Congress in Physical and Rehabilitation Medicine, Brighton. 2002.

\section{Turner-Stokes 1997}

Turner-Stokes L, Turner-Stokes T. The use of standardised outcome measures in rehabilitation centres in the UK. Clinical Rehabilitation 1997;11:306-13.

\section{Turner-Stokes 2006}

Turner-Stokes L, Paul S, Williams H. Efficiency of specialist rehabilitation in reducing dependency and costs of continuing care for adults with complex acquired brain injuries. Journal of Neurology, Neurosurgery and Psychiatry 2006;77(5):634-9. 


\section{Turner-Stokes 2007}

Turner-Stokes L. Cost-efficiency of longer-stay rehabilitation programmes: can they provide value for money?. Brain injury 2007;21(10):1015-21.

\section{Turner-Stokes 2008}

Turner-Stokes L. Evidence for the effectiveness of multidisciplinary rehabilitation following acquired brain injury: a synthesis of two systematic approaches. Journal of Rehabilitation Medicine 2008;40(9):691-701.

\section{Turner-Stokes 2012}

Turner-Stokes L, Williams H, Sephton K, Rose H, Harris S, Thu A. Engaging the hearts and minds of clinicians in outcome measurement - the UK Rehabilitation Outcomes Collaborative approach. Disability and Rehabilitation 2012;34(22):1871-9.

\section{Turner-Stokes 2013}

Turner-Stokes L, McCrone P, Jackson DM, Siegert RJ. The Needs and Provision Complexity Scale: a multicentre prospective cohort analysis of met and unmet needs and their cost implications for patients with complex neurological disability. BMJOpen 2013; Vol. 3, issue 2:e002353. [DOI: 10.1136/ bmjopen-2012-002353]

\section{van Tulder 1997}

van Tulder MW, Assendelft WJJ, Koes BW, Bouter LM. Method guidelines for systematic reviews in the Cochrane Collaboration Back Review Group for spinal disorders. Spine 1997;22:2323-30.

\section{van Tulder 2003}

van Tulder M, Furlan A, Bombardier C, Bouter L, The Editorial Board of the Cochrane Collaboration Back Review Group. Updated method guidelines for systematic reviews in the Cochrane Collaboration Back Review Group. Spine 2003;28(12):1290-9.

\section{Wade 1992}

Wade DT. Measurement in Neurological Rehabilitation. Oxford: Oxford University Press, 1992.

\section{Wade 2000}

Wade DT, de Jong BA. Recent advances in rehabilitation. BMJ 2000;320:1385-8.

\section{Wade 2003}

Wade DT, Halligan P. New wine in old bottles: the WHO ICF as an explanatory model of human behaviour. Clinical Rehabilitation 2003;17(4):349-54.

\section{Wade 2004}

Wade DT, Halligan P. Do biomedical models of illness make for good healthcare systems?. BMJ 2004;329:1398-401.

\section{Whyte 2002}

Whyte J. Traumatic brain injury rehabilitation: are there alternatives to randomized clinical trials?. Archives of Physical Medicine and Rehabilitation 2002;83(9):1320-2.

* Indicates the major publication for the study

\section{CHARACTERISTICS OF STUDIES}

Characteristics of included studies [ordered by study ID]

Andelic 2012

\begin{tabular}{ll}
\hline Methods & Controlled study \\
\hline Participants & $\begin{array}{l}\text { Severe TBI } \\
\text { Recruited (completed follow-up) } n=64 \text { (61): early rehabilitation group } n=33 \text { (31); subacute rehabilita- } \\
\text { tion group } n=31(30)\end{array}$ \\
\hline Interventions & $\begin{array}{l}\text { Early rehabilitation in Early Rehabilitation Section of ITU or standard subacute rehabilitation after } \\
\text { waiting period at a local hospital or in a nursing home }\end{array}$ \\
\hline Outcomes & Glasgow Outcome Scale Extended (GOSE) \\
& Disability Rating Scale (DRS) \\
Employment status at 12 mo \\
Home care setup
\end{tabular}

\section{Risk of bias}


Andelic 2012 (Continued)

Random sequence genera- High risk tion (selection bias)
Not an RCT. The trial used availability of a bed in the early rehabilitation unit to assign people to the active or control arms. If a bed was not available, the patient was entered into the control group.

\begin{tabular}{lll}
\hline $\begin{array}{l}\text { Allocation concealment } \\
\text { (selection bias) }\end{array}$ & High risk & There was no allocation concealment
\end{tabular}

\begin{tabular}{lll}
\hline $\begin{array}{l}\text { Blinding of outcome as- } \\
\text { sessment (detection bias) } \\
\text { All outcomes }\end{array}$ & High risk & Assessors not blinded \\
\hline $\begin{array}{l}\text { Incomplete outcome data } \\
\text { (attrition bias) } \\
\text { All outcomes }\end{array}$ & Low risk & Acceptable attrition. Follow-up of $61 / 65$ people (95\%) \\
\hline $\begin{array}{l}\text { Selective reporting (re- } \\
\text { porting bias) }\end{array}$ & Unclear risk & $\begin{array}{l}\text { Based on the published report, the results for all primary and secondary out- } \\
\text { come measures are available. The review authors did not search for the study } \\
\text { protocol. The study report does not give details of a study registration number, } \\
\text { and we are unable to check the reporting of outcomes against the study regis- } \\
\text { tration details. }\end{array}$ \\
\hline
\end{tabular}

Bai 2012

\begin{tabular}{ll}
\hline Methods & Single-blind RCT \\
\hline Participants & Moderate to severe intracerebral haemorrhage \\
& Randomly assigned $\mathrm{n}=364$ : early rehabilitation group $\mathrm{n}=181$; control group $\mathrm{n}=183$ \\
& (all completed) \\
\hline Interventions & $\begin{array}{l}\text { Intervention arm received a standardised 6-mo 3-stage rehabilitation programme starting on admis- } \\
\text { sion }\end{array}$ \\
\hline Control arm received standard medical care only \\
\hline Fugl-Myer Assessment (FMA) \\
Modified Barthel Index (MBI) \\
\hline Follow-up: 1,3 and 6 mo
\end{tabular}

\section{Risk of bias}

\begin{tabular}{lll}
\hline Bias & Authors' judgement & Support for judgement \\
\hline $\begin{array}{l}\text { Random sequence genera- } \\
\text { tion (selection bias) }\end{array}$ & Unclear risk & $\begin{array}{l}\text { Method of randomisation not specified. Quote: "the patients were randomized } \\
\text { into two treatment groups" p. } 1377\end{array}$ \\
\hline $\begin{array}{l}\text { Allocation concealment } \\
\text { (selection bias) }\end{array}$ & Unclear risk & Method of allocation concealment not specified \\
\hline $\begin{array}{l}\text { Blinding of outcome as- } \\
\text { sessment (detection bias) } \\
\text { All outcomes }\end{array}$ & Low risk & $\begin{array}{l}\text { Outcome assessors blinded. Quote: "All measurements were recorded by an } \\
\text { assessor who was blinded to the study design and details." p. 1376 }\end{array}$ \\
\hline
\end{tabular}


Bai 2012 (Continued)

Incomplete outcome data Low risk Acceptable attrition. Follow-up of 364/364 people (100\%)
(attrition bias)
All outcomes

All outcomes

Selective reporting (re- Unclear risk porting bias)

Based on the published report, the results for all primary and secondary outcome measures are available. The review authors did not search for the study protocol. The study report does not give details of a study registration number, and we are unable to check the reporting of outcomes against the study registration details.

Björkdahl 2006

\begin{tabular}{ll}
\hline Methods & Single-blind RCT \\
\hline Participants & Stroke \\
& Randomly assigned (completed) $\mathrm{n}=61$ (59): home group $\mathrm{n}=30(29)$; day clinic group $\mathrm{n}=29(29)$ \\
\hline Interventions & 9 h of training per week for 3 wk \\
& Home group: OT and PT trained patient at home with family \\
& Day clinic group: multi-professional team trained patient in the day clinic \\
\hline
\end{tabular}

\section{Outcomes}

Assessment of Motor and Process Skills (AMPS)

Functional Independence Measure (FIM)

Instrumental Activity Measure

30-Metre Walking Test

National Institutes of Health Stroke Scale (NIHSS)

Barrow Neurological Institute screening for higher cerebral functions

Notes $\quad$ Follow-up: 3 wk, 3 mo, 1 y

\section{Risk of bias}

\begin{tabular}{lll}
\hline Bias & Authors' judgement & Support for judgement \\
\hline $\begin{array}{l}\text { Random sequence genera- } \\
\text { tion (selection bias) }\end{array}$ & Unclear risk & $\begin{array}{l}\text { Method of randomisation not specified. Quote: "...were randomized" p. 1039. } \\
\text { Quote: "Information on randomization was kept in storage by the person allo- } \\
\text { cating to the groups until the study was finished." p. 1042 }\end{array}$ \\
\hline $\begin{array}{l}\text { Allocation concealment } \\
\text { (selection bias) }\end{array}$ & Low risk & Quote: "Using sealed envelopes." p. 1039. Authors' judgement: Probably done. \\
\hline $\begin{array}{l}\text { Blinding of outcome as- } \\
\text { sessment (detection bias) } \\
\text { All outcomes }\end{array}$ & Low risk & $\begin{array}{l}\text { Outcome assessors blinded. Quote: "Blinded assessors made all evaluations at } \\
\text { discharge and after the intervention at three weeks as well as at additional fol- } \\
\text { low-ups at three months and one year after discharge. Blinding was performed } \\
\text { by informing the subject not to comment on training (how and where)." p. } \\
1042\end{array}$ \\
\hline
\end{tabular}

Incomplete outcome data Low risk (attrition bias)

Acceptable attrition. Follow-up of 59/61 people (96.7\%) 
Björkdahl 2006 (Continued)

All outcomes

\section{Selective reporting (re- Unclear risk} porting bias)
Based on the published report, the results for all primary and secondary outcome measures are available. The review authors did not search for the study protocol. The study pre-dates the requirement of trial registration for publication.

Bowen 2001

\begin{tabular}{ll}
\hline Methods & Unblinded controlled trial \\
\hline Participants & Moderate to severe TBI \\
& $\begin{array}{l}\text { Carers } \mathrm{n}=96 \text { recruited: treatment group } \mathrm{n}=69 \text {, control group } \mathrm{n}=27 \\
\text { (all completed) }\end{array}$ \\
\hline Interventions & $\begin{array}{l}\text { Head Injury Neurorehabilitation Team (HINT) } \\
\text { Early = started pre-discharge } \\
\text { Late = started after discharge } \\
\text { Control = existing services }\end{array}$ \\
\hline Outcomes & $\begin{array}{l}\text { Carers' perception of how well informed they are } \\
\text { Carers' mood/emotion }\end{array}$ \\
\hline Notes & Follow-up: 6 mo
\end{tabular}

\section{Risk of bias}

Bias Authors' judgement Support for judgement

Random sequence genera- High risk Trial used date of admission to allocate to intervention

tion (selection bias)

Van Tulder guidance explicitly cites this as inadequate randomisation. Previous publication scored randomisation as adequate; therefore we have downgraded the van Tulder score.

Quote from the abstract: "Individual randomization was not possible and randomization by hospital site was rejected because of demographic and clinical differences between sites."

\begin{tabular}{|c|c|c|}
\hline $\begin{array}{l}\text { Allocation concealment } \\
\text { (selection bias) }\end{array}$ & Unclear risk & $\begin{array}{l}\text { Review authors' judgement: Unclear if done. Quote from abstract: "Group as- } \\
\text { signment was determined by a pre-specified timetable which alternated be- } \\
\text { tween hospitals." }\end{array}$ \\
\hline
\end{tabular}

Blinding of outcome as- High risk Assessors not blinded

sessment (detection bias)

All outcomes

$\begin{aligned} & \text { Incomplete outcome data } \\ & \text { (attrition bias) }\end{aligned}$
All Low risk $\quad$ Acceptable attrition. Follow-up of 96/96 people (100\%)

All outcomes

Selective reporting (re- Unclear risk

porting bias)
Based on the published report, the results for all primary and secondary outcome measures are available. The review authors did not search for the study protocol. The study pre-dates the requirement of trial registration for publication. 
Cicerone 2008

\begin{tabular}{ll}
\hline Methods & Single-blind RCT \\
\hline Participants & Mild to severe traumatic brain injury \\
& $\begin{array}{l}\text { Randomly assigned (completed) } n=68(64) \text { : intensive cognitive rehabilitation group } n=34 \text { (32); stan- } \\
\text { dard neurorehabilitation group } n=34(32)\end{array}$
\end{tabular}

Interventions Cognitive group received 'intensive neuropsychological' rehabilitation in a day hospital therapeutic environment based on the milieu model described by Ben-Yishay and Gold, with more group-based interventions

Standard rehabilitation group was given primarily individual discipline-specific out-patient intervention

\begin{tabular}{ll}
\hline Outcomes & Community Integration Questionnaire (CIQ) \\
& Perceived Quality of Life Scale (PQOL) \\
& Neuropsychological functioning \\
& Perceived self efficacy score \\
& Vocational Integration Scale \\
\hline Notes & Outcome measures administered 2 weeks post discharge and at 6 months
\end{tabular}

\section{Risk of bias}

\begin{tabular}{|c|c|c|}
\hline Bias & Authors' judgement & Support for judgement \\
\hline $\begin{array}{l}\text { Random sequence genera- } \\
\text { tion (selection bias) }\end{array}$ & Low risk & $\begin{array}{l}\text { Quote: "Randomization was conducted through the web-based interactive sta- } \\
\text { tistical calculation pages (www.statpages.org) to allocate } 48 \text { participants per } \\
\text { condition. Randomization occurred in unequal, blocked multiples of } 4 \text { to opti- } \\
\text { mize equal assignment of participants to treatment arms throughout the study } \\
\text { period and prevent anticipation of the randomization sequence. Randomiza- } \\
\text { tion was stratified by referral source (clinical or community referrals) to opti- } \\
\text { mize equal assignment between treatment arms....Participants were random- } \\
\text { ized in the order they provided written informed consent." p. } 2240\end{array}$ \\
\hline
\end{tabular}

\begin{tabular}{ll}
\hline $\begin{array}{l}\text { Allocation concealment } \\
\text { (selection bias) }\end{array}$ & Low risk \\
& $\begin{array}{l}\text { Quote: "The allocation of participants to treatment condition was concealed } \\
\text { by placing the individual randomized assignments in sequentially numbered, } \\
\text { opaque, sealed envelopes." p. } 2240\end{array}$
\end{tabular}

\begin{tabular}{|c|c|c|}
\hline $\begin{array}{l}\text { Blinding of outcome as- } \\
\text { sessment (detection bias) } \\
\text { All outcomes }\end{array}$ & Low risk & $\begin{array}{l}\text { Outcome assessors blinded. Quote: "Data entry and scoring for these mea- } \\
\text { sures were conducted by a research assistant who was blind to treatment con- } \\
\text { dition." p. } 2243\end{array}$ \\
\hline
\end{tabular}

\begin{tabular}{|c|c|c|}
\hline $\begin{array}{l}\text { Incomplete outcome data } \\
\text { (attrition bias) } \\
\text { All outcomes }\end{array}$ & Low risk & Acceptable attrition. Follow-up of $64 / 68$ people $(94 \%)$ \\
\hline $\begin{array}{l}\text { Selective reporting (re- } \\
\text { porting bias) }\end{array}$ & Unclear risk & $\begin{array}{l}\text { Based on the published report, the results for all primary and secondary out- } \\
\text { come measures are available. The review authors did not search for the study } \\
\text { protocol. The study pre-dates the requirement of trial registration for publica- } \\
\text { tion. }\end{array}$ \\
\hline
\end{tabular}


Elgmark 2007

\begin{tabular}{ll}
\hline Methods & Single-blind RCT \\
\hline Participants & $\begin{array}{l}\text { Mild traumatic brain Injury } \\
\text { Randomly assigned (completed) } n=395 \text { (355): treatment group } n=264 \text { (246); control group n=131 } \\
(109)\end{array}$ \\
\hline Interventions & Follow-up at 2 to 8 wk by telephone or letter with advice and referral as required \\
& Control = no specific treatment (routine care) \\
\hline Outcomes & Post-Concussion Symptom Questionnaire (PCSQ) \\
& Life Satisfaction Questionnaire \\
& Community Integration Questionnaire (CIQ) \\
& Short-Form Health Survey (SF-36) \\
\hline Notes & Participants sent 2 questionnaires, first between 2 and 8 wk post injury, second at $1 \mathrm{y}$
\end{tabular}

\section{Risk of bias}

\begin{tabular}{|c|c|c|}
\hline Bias & Authors' judgement & Support for judgement \\
\hline $\begin{array}{l}\text { Random sequence genera- } \\
\text { tion (selection bias) }\end{array}$ & Low risk & $\begin{array}{l}\text { Automated randomisation process. Quote: "The patient was allocated to ei- } \\
\text { ther the intervention group or controls by the automatic randomization proce- } \\
\text { dure using the method introduced by Pocock for optimized allocation. The two } \\
\text { groups were balanced according to the following ten variables..." p } 153\end{array}$ \\
\hline $\begin{array}{l}\text { Allocation concealment } \\
\text { (selection bias) }\end{array}$ & Low risk & $\begin{array}{l}\text { Authors' judgement: Based on the quote above, allocation concealment was } \\
\text { probably done. }\end{array}$ \\
\hline $\begin{array}{l}\text { Blinding of outcome as- } \\
\text { sessment (detection bias) } \\
\text { All outcomes }\end{array}$ & Low risk & $\begin{array}{l}\text { Outcome assessors were adequately blinded. Quote "Blinding of outcome as- } \\
\text { sessment was effected by using mailed questionnaires for self-rating; the data } \\
\text { thus collected were entered by a secretary having no information of the alloca- } \\
\text { tion and then send to the statisticians." p } 153\end{array}$ \\
\hline $\begin{array}{l}\text { Incomplete outcome data } \\
\text { (attrition bias) } \\
\text { All outcomes }\end{array}$ & Low risk & Acceptable attrition. Follow-up of 355/395 people (89.87\%) \\
\hline $\begin{array}{l}\text { Selective reporting (re- } \\
\text { porting bias) }\end{array}$ & Unclear risk & $\begin{array}{l}\text { Based on the published report, the results for all primary and secondary out- } \\
\text { come measures are available. The review authors did not search for the study } \\
\text { protocol. The study (1997-2001) pre-dates the requirement of trial registration } \\
\text { for publication (2005). }\end{array}$ \\
\hline
\end{tabular}

\section{Kwakkel 1999}

\begin{tabular}{ll}
\hline Methods & Single-blind RCT \\
\hline Participants & Middle cerebral artery stroke \\
& Randomly assigned (completed) $\mathrm{n}=101$ (81): leg training group $\mathrm{n}=31$ (26); arm training group $\mathrm{n}=33$ \\
& $(29) ;$ control group $\mathrm{n}=37(34)$ \\
\hline
\end{tabular}


Kwakkel 1999 (Continued)

Interventions Intensive arm or leg training by physio/occupational therapists vs immobilisation with inflatable splint

\begin{tabular}{ll}
\hline Outcomes & Primary outcomes: Barthel ADL Index \\
& Mobility: Functional Ambulation Category (FAC) \\
& Dexterity: Action Research Arm Test \\
& Secondary outcomes: Participation: Sickness Impact Profile (SIP), Nottingham Health Profile (NHP), \\
& Frenchay Activities Index \\
\hline Notes & Follow-up: 6 mo
\end{tabular}

\section{Risk of bias}

\begin{tabular}{|c|c|c|}
\hline Bias & Authors' judgement & Support for judgement \\
\hline $\begin{array}{l}\text { Random sequence genera- } \\
\text { tion (selection bias) }\end{array}$ & Low risk & Quote: "random number tables for each participating hospital". p 192 \\
\hline $\begin{array}{l}\text { Allocation concealment } \\
\text { (selection bias) }\end{array}$ & Low risk & Quote: "random number tables for each participating hospital". p 192 \\
\hline $\begin{array}{l}\text { Blinding of outcome as- } \\
\text { sessment (detection bias) } \\
\text { All outcomes }\end{array}$ & Unclear risk & $\begin{array}{l}\text { Participants unblinded after } 6 \text { mo, but primary outcomes examined at } 6,9 \text { and } \\
12 \text { mo - therefore, only partially blinded. On the other hand, no significant in- } \\
\text { tergroup differences in the unblinded period, so risk of bias graded as 'unclear' }\end{array}$ \\
\hline $\begin{array}{l}\text { Incomplete outcome data } \\
\text { (attrition bias) } \\
\text { All outcomes }\end{array}$ & Low risk & Acceptable attrition. Follow-up of $81 / 101$ people $(80 \%)$ \\
\hline $\begin{array}{l}\text { Selective reporting (re- } \\
\text { porting bias) }\end{array}$ & Unclear risk & $\begin{array}{l}\text { Based on the published report, the results for all primary and secondary out- } \\
\text { come measures are available. The review authors did not search for the study } \\
\text { protocol. The study pre-dates the requirement of trial registration for publica- } \\
\text { tion }\end{array}$ \\
\hline
\end{tabular}

Ozdemir 2001

\begin{tabular}{ll}
\hline Methods & Controlled study \\
\hline Participants & Stroke patients $n=60$ \\
& $\begin{array}{l}\text { Recuited } n=60: \text { in-patient group } n=30 ; \text { home group } n=30 \\
\text { (all completed) }\end{array}$ \\
\hline
\end{tabular}

Interventions In-patient rehabilitation vs home exercise programme

\begin{tabular}{ll}
\hline Outcomes & $\begin{array}{l}\text { Impairment: Ashworth Scale; Brunnstrom stages; Mini-Mental State Examination (MMSE) } \\
\text { Activity: Functional Independence Measure (FIM) }\end{array}$ \\
\hline Notes & Variable measurements before and after rehabilitation (mean $64 \mathrm{~d}$ ) \\
\hline
\end{tabular}

\section{Risk of bias}

\begin{tabular}{lll}
\hline Bias & Authors' judgement & Support for judgement \\
\hline $\begin{array}{l}\text { Random sequence genera- } \\
\text { tion (selection bias) }\end{array}$ & High risk & $\begin{array}{l}\text { Quote: "Sixty patients were randomized into 2 equal groups by selecting pa- } \\
\text { tients consecutively, one by one, according to when they enrolled in the study } \\
(x+1) \text {. Thirty patients in group 1 received intense multidisciplinary rehabilita- }\end{array}$
\end{tabular}


Ozdemir 2001 (Continued)

tion services as inpatients in the rehabilitation clinic. The 30 patients in group

2 were given rehabilitation services in their own homes. p. 1376

\begin{tabular}{|c|c|c|}
\hline $\begin{array}{l}\text { Allocation concealment } \\
\text { (selection bias) }\end{array}$ & High risk & Authors' judgement: no indication that the allocation method was concealed \\
\hline $\begin{array}{l}\text { Blinding of outcome as- } \\
\text { sessment (detection bias) } \\
\text { All outcomes }\end{array}$ & High risk & $\begin{array}{l}\text { Blinding of outcome assessors not specified. Authors' judgement: Probably } \\
\text { not done. Participants receiving inpatient rehabilitation were assessed at the } \\
\text { hospital, while those receiving rehabilitation at home were assessed at home. }\end{array}$ \\
\hline $\begin{array}{l}\text { Incomplete outcome data } \\
\text { (attrition bias) } \\
\text { All outcomes }\end{array}$ & Low risk & Acceptable attrition. Follow-up of $60 / 60$ people (100\%) \\
\hline $\begin{array}{l}\text { Selective reporting (re- } \\
\text { porting bias) }\end{array}$ & Unclear risk & $\begin{array}{l}\text { Based on the published report, the results for all primary and secondary out- } \\
\text { come measures are available. The review authors did not search for the study } \\
\text { protocol. The study pre-dates the requirement of trial registration for publica- } \\
\text { tion }\end{array}$ \\
\hline
\end{tabular}

Paniak 1998

\begin{tabular}{ll}
\hline Methods & Single-blind RCT \\
\hline Participants & $\begin{array}{l}\text { Moderate to severe TBI } \\
\text { Randomly assigned (completed) } \mathrm{n}=119(111) \text { : treatment group } \mathrm{n}=53 \text { (59); control group } \mathrm{n}=58 \text { (60) }\end{array}$ \\
\hline Interventions & Treatment as needed with full MD programme vs single session - educational input \\
\hline Outcomes & $\begin{array}{l}\text { Impairment: Problem checklist } \\
\text { Participation: Community Integration Questionnaire (CIQ) } \\
\text { Health status: Short-Form Health Survey (SF-36) } \\
\text { Work status }\end{array}$ \\
\hline Notes & Follow-up: 3 to 4 mo
\end{tabular}

\section{Risk of bias}

\begin{tabular}{lll}
\hline Bias & Authors' judgement & Support for judgement \\
\hline $\begin{array}{l}\text { Random sequence genera- } \\
\text { tion (selection bias) }\end{array}$ & Unclear risk & $\begin{array}{l}\text { Method of randomisation not specified. Paper previously scored as having ad- } \\
\text { equate randomisation; therefore, we have downgraded the van Tulder score } \\
\text { Quote: "Patients were randomly assigned..." p. 1013 }\end{array}$ \\
\hline $\begin{array}{ll}\text { Allocation concealment } \\
\text { (selection bias) }\end{array}$ & Unclear risk & Method of allocation concealment not specified \\
\hline $\begin{array}{l}\text { Blinding of outcome as- } \\
\text { sessment (detection bias) }\end{array}$ & Unclear risk & $\begin{array}{l}\text { Van Tulder scoring explicitly states that when patient-reported outcome mea- } \\
\text { All outcomes }\end{array}$ \\
$\begin{array}{l}\text { sures are used, the trial cannot be positively scored for blinding for outcome } \\
\text { assessment. Paper previously graded as adequate so we have downgraded the } \\
\text { van Tulder score, but risk of bias remains unclear }\end{array}$ \\
$\begin{array}{l}\text { Incomplete outcome data } \\
\begin{array}{l}\text { All outcomes } \\
\text { attion bias) }\end{array}\end{array}$ & Low risk & Acceptable attrition. Follow-up of 111/119 people (93\%) \\
\hline
\end{tabular}


Paniak 1998 (Continued)

Selective reporting (re- Unclear risk $\quad$ Based on the published report, the results for all primary and secondary outporting bias) come measures are available. The review authors did not search for the study protocol. The study pre-dates the requirement of trial registration for publication

Powell 2002

\begin{tabular}{ll}
\hline Methods & Single-blind RCT \\
\hline Participants & $\begin{array}{l}\text { Moderate to severe TBI } \\
\text { Randomly assigned (completed) } \mathrm{n}=110 \text { (94): treatment group } \mathrm{n}=54 \text { (48); control group } \mathrm{n}=56 \text { (46) }\end{array}$ \\
\hline Interventions & $\begin{array}{l}\text { Community-based outreach MD team } \\
\text { Visits } \times 2 / \text { wk. Mean } 6 \text { mo in duration } \\
\text { Control - written information only }\end{array}$ \\
\hline Outcomes & $\begin{array}{l}\text { Activity: Barthel Index; Functional Assessment Measure (FIM+FAM) } \\
\text { Participation: Brain Injury Comunity Rehabilitation Outcome Scales (BICRO-39) } \\
\text { Mood: Hospital Anxiety and Depression Scale (HADS) } \\
\text { Maximum Gain Index (MGI) }\end{array}$ \\
\hline Notes & Variable measurement (mean 2 y) \\
\hline
\end{tabular}

\section{Risk of bias}

\begin{tabular}{lll}
\hline Bias & Authors' judgement & Support for judgement \\
\hline $\begin{array}{ll}\text { Random sequence genera- } \\
\text { tion (selection bias) }\end{array}$ & Low risk & $\begin{array}{l}\text { There was no randomisation sequence. Quote: "Randomisation was conduct- } \\
\text { ed on an individual basis. Information/outreach codes (I and O) were written } \\
\text { onto squares of paper, in equal proportion, and these were placed in a sealed, } \\
\text { opaque envelope. This was prepared and held by the clinical director of the } \\
\text { team. Once a participant's eligibility and agreement to participate had been } \\
\text { established, one of the codes was drawn at random from the envelope by a } \\
\text { therapist or other staff member who had not been involved in the patient's as- } \\
\text { signment, and it was then discarded and the envelope resealed." p. 194 }\end{array}$ \\
\hline
\end{tabular}

Allocation concealment $\quad$ Unclear risk
(selection bias)

\begin{tabular}{|c|c|c|}
\hline $\begin{array}{l}\text { Blinding of outcome as- } \\
\text { sessment (detection bias) } \\
\text { All outcomes }\end{array}$ & Low risk & $\begin{array}{l}\text { Although blinding was reportedly broken in some cases, this potentially ap- } \\
\text { plies to all single-blinded studies, whether or not this is openly recognised by } \\
\text { study authors. Quote: "the independent follow up assessor was not informed } \\
\text { of participants' allocation codes at any stage throughout data collection or da- } \\
\text { ta entry; the codes were entered only when the database was complete." p. } \\
194\end{array}$ \\
\hline
\end{tabular}

\begin{tabular}{lll}
\hline $\begin{array}{l}\text { Incomplete outcome data } \\
\text { (attrition bias) } \\
\text { All outcomes }\end{array}$ & Low risk & Acceptable attrition. Follow-up of 94/110 people (85\%) \\
\hline $\begin{array}{l}\text { Selective reporting (re- } \\
\text { porting bias) }\end{array}$ & Low risk & $\begin{array}{l}\text { Based on the published report, the results for all primary and secondary out- } \\
\text { come measures are available. The review authors did not search for the study } \\
\text { protocol. The study pre-dates the requirement of trial registration for publica- } \\
\text { tion }\end{array}$ \\
\hline
\end{tabular}


Salazar 2000

\begin{tabular}{ll}
\hline Methods & Unblinded RCT \\
\hline Participants & $\begin{array}{l}\text { Defence veterans moderate to severe TBI } \\
\text { Randomly assigned (completed) } \mathrm{n}=120(107) ; \text { in-patient } \mathrm{n}=67(60) ; \text { home } \mathrm{n}=53(47)\end{array}$ \\
\hline Interventions & $\begin{array}{l}\text { In-patient: intensive 8-wk programme vs } \\
\text { Home: weekly telephone contact with counselling and advice from nurse }\end{array}$ \\
\hline Outcomes & $\begin{array}{l}\text { Work status: return to work } \\
\text { Fitness for military duty }\end{array}$ \\
\hline Notes & Follow-up: $1 \mathrm{y}$
\end{tabular}

\section{Risk of bias}

\begin{tabular}{lll}
\hline Bias & Authors' judgement & Support for judgement \\
\hline $\begin{array}{ll}\text { Random sequence genera- } \\
\text { tion (selection bias) }\end{array}$ & Low risk & $\begin{array}{l}\text { Quote: "Randomization for the first } 40 \text { participants was weighted at a 2:1 ra- } \\
\text { tio in favor of the in-hospital group to help build that program. The last } 79 \text { pa- } \\
\text { tients enrolled were randomized at a 1:1 ratio. Analysis of outcomes stratified } \\
\text { for these } 2 \text { cohorts did not change results." p. } 3076\end{array}$
\end{tabular}

\begin{tabular}{lll}
\hline $\begin{array}{l}\text { Allocation concealment } \\
\text { (selection bias) }\end{array}$ & Low risk & $\begin{array}{l}\text { Quote: "Blocked randomization was done by an independent study statistician } \\
\text { (K.S.) using variable-sized blocks to prevent investigators from guessing the } \\
\text { code." p. } 3076\end{array}$ \\
\hline $\begin{array}{l}\text { Blinding of outcome as- } \\
\text { sessment (detection bias) } \\
\text { All outcomes }\end{array}$ & High risk & Not blinded \\
\hline $\begin{array}{l}\text { Incomplete outcome data } \\
\text { (attrition bias) } \\
\text { All outcomes }\end{array}$ & Low risk & Acceptable attrition. Follow-up of 107/120 people (89\%) \\
\hline $\begin{array}{l}\text { Selective reporting (re- } \\
\text { porting bias) }\end{array}$ & Low risk & $\begin{array}{l}\text { Based on the published report, the results for all primary and secondary out- } \\
\text { come measures are available. The review authors did not search for the study } \\
\text { protocol. The study pre-dates the requirement of trial registration for publica- } \\
\text { tion }\end{array}$ \\
\hline
\end{tabular}

\section{Semlyen 1998}

\begin{tabular}{ll}
\hline Methods & Unblinded controlled study \\
\hline Participants & $\begin{array}{l}\text { Patients with moderate to severe } \mathrm{n}=51 \\
\text { Total } \mathrm{n}=51 \text { : treatment group } \mathrm{n}=33, \text { control group } \mathrm{n}=18 \\
\text { (all completed) }\end{array}$ \\
\hline Interventions & $\begin{array}{l}\text { Co-ordinated MD rehabilitation on a specialist brain injury rehabilitation unit (HM) vs other rehabilita- } \\
\text { tion (OR) in local district services }\end{array}$ \\
\hline Outcomes & $\begin{array}{l}\text { Activity and independence: Barthel Index } \\
\text { Functional Assessment Measure (FIM+FAM) } \\
\text { Newcastle Independence Assesment Form (NIAF) }\end{array}$
\end{tabular}


Semlyen 1998 (Continued)

Care-giver's health: General Health Questionnaire (GHQ-28)

Notes Follow-up: to $2 \mathrm{y}$

\section{Risk of bias}

\section{Bias \\ Authors' judgement Support for judgement}

Random sequence genera- High risk tion (selection bias)

There was no randomisation sequence. Quote: "Two groups of patients were selected using the same set of inclusion criteria. All individuals received initial management in the Regional Neurosciences Centre at Newcastle General Hospital. When the neurosurgical team considered the individual ready for transfer, the patient was either set to Hunters Moor Regional Rehabilitation Centre or to a local hospital. This selection process was based partly on geography (the further the patient lived away from Newcastle the more likely they were to be sent back to a local hospital near home) and partly on bed availability at Hunters Moor. (If a bed was not available within a few days the patient was more likely to be sent to the local hospital.) One group received a coordinated, multidisciplinary rehabilitation service at Hunters Moor." p. 679

\begin{tabular}{lll}
\hline $\begin{array}{l}\text { Allocation concealment } \\
\text { (selection bias) }\end{array}$ & High risk & Not done \\
\hline $\begin{array}{l}\text { Blinding of outcome as- } \\
\text { sessment (detection bias) } \\
\text { All outcomes }\end{array}$ & High risk & Unblinded \\
\hline $\begin{array}{l}\text { Incomplete outcome data } \\
\text { (attrition bias) } \\
\text { All outcomes }\end{array}$ & Low risk & Attrition acceptable. Follow up of 51/51 people (100\%) \\
\hline $\begin{array}{l}\text { Selective reporting (re- } \\
\text { porting bias) }\end{array}$ & Low risk & $\begin{array}{l}\text { Based on the published report, the results for all primary and secondary out- } \\
\text { come measures are available. The review authors did not search for the study } \\
\text { protocol. The study pre-dates the requirement of trial registration for publica- } \\
\text { tion }\end{array}$ \\
\end{tabular}

Shiel 2001

\begin{tabular}{ll}
\hline Methods & Unblinded RCT \\
\hline Participants & $\begin{array}{l}\text { Patients with moderate to severe TBI } \mathrm{n}=51 \\
\text { Randomly assigned } \mathrm{n}=51 \text { : intensive rehabilitation group } \mathrm{n}=24 \text {; routine group } \mathrm{n}=27 \\
\text { (all completed) }\end{array}$ \\
\hline Interventions & $\begin{array}{l}\text { Intensive rehabilitation (with additional healthcare professional experienced in BI) vs standard treat- } \\
\text { ment }\end{array}$ \\
\hline Outcomes & $\begin{array}{l}\text { Disability: Functional Assessment Measure (FIM+FAM) } \\
\text { Healthcare: length of stay }\end{array}$ \\
\hline Notes & Admission to discharge \\
\hline
\end{tabular}

\section{Risk of bias}


Shiel 2001 (Continued)

Random sequence genera- Low risk tion (selection bias)
Quote: "The research unit experimental officer (MEB), who was otherwise uninvolved in the research, implemented the randomization using a computer package. Age, centre and severity of injury, judged on the basis of the GCS, were used to stratify the allocation. In order to match groups as equally as possible, random permuted bocks within strata were used. ... Subjects were recruited by the researchers based at each centre who telephoned details of the injury severity, centre and age to the experimental officer who then gave the treatment allocation." p. 503

Allocation concealment Low risk

(selection bias) ticipant characteristics for allocation concealment to be scored positively.
Van Tulder guidance requires that those allocating have no knowledge of parComplex reallocation process performed to equalise groups in this study relied on some knowledge of participant characteristics. Therefore, it was scored negatively on van Tulder - this nevertheless poses low risk of bias, as the adjustment was made to correct failure of randomisation in relation to severity

\begin{tabular}{lll}
\hline $\begin{array}{l}\text { Blinding of outcome as- } \\
\text { sessment (detection bias) } \\
\text { All outcomes }\end{array}$ & Low risk & $\begin{array}{l}\text { Quote: "Outcome measurement at discharge and one year after injury was } \\
\text { done by a masked assessor and the codes were only broken when all one year } \\
\text { assessments were complete." p. } 503\end{array}$ \\
\hline $\begin{array}{l}\text { Incomplete outcome data } \\
\text { (attrition bias) } \\
\text { All outcomes }\end{array}$ & Low risk & Acceptable attrition. Follow-up of $51 / 51$ people $(100 \%)$ \\
\hline $\begin{array}{l}\text { Selective reporting (re- } \\
\text { porting bias) }\end{array}$ & Unclear risk & $\begin{array}{l}\text { Based on the published report, the results for all primary and secondary out- } \\
\text { come measures are available. The review authors did not search for the study } \\
\text { protocol. The study pre-dates the requirement of trial registration for publica- } \\
\text { tion }\end{array}$
\end{tabular}

Slade 2002

\begin{tabular}{ll}
\hline Methods & Single-blind RCT \\
\hline Participants & Mixed brain injury (moderate to severe) and stroke \\
& $\begin{array}{l}\text { Randomly assigned (completed) } \mathrm{n}=161(131) \text { : intensive group } \mathrm{n}=80 \text { (75); standard treatment group } \mathrm{n} \\
=81(76)\end{array}$ \\
\hline Interventions & Intensive MD rehabilitation: intensive group received 67\% more therapy \\
\hline Outcomes & Healthcare: length of stay: controlled for ADL ability; Barthel Index \\
\hline Notes & Admission to discharge
\end{tabular}

\section{Risk of bias}

Bias Authors' judgement Support for judgement

Random sequence genera- Low risk tion (selection bias)
Quote: "Randomisation occurred when the admission date of the patient was known, in order to allow for the timetabling of therapy, usually undertaken a week in advance. Patients were randomised to experimental and control groups by the university epidemiological unit. Randomisations used successive blocks of 8 or 12. This prevented unequal group sizes, so that in a block of 8 forinstance there would be 4 randomisations in the experimental group and 4 in the control group in any combination e.g. eeccecec or ccceecee. The blocks were of different sizes to prevent anticipation by staff on group ran- 
Slade 2002 (Continued)

domisation. Runs of control or experimental randomisations were limited to

four, to ensure intensive therapy could be delivered." p 34

\begin{tabular}{lll}
\hline $\begin{array}{l}\text { Allocation concealment } \\
\text { (selection bias) }\end{array}$ & High risk & Allocation concealment inadequate; van Tulder re-scored to reflect this \\
\hline $\begin{array}{l}\text { Blinding of outcome as- } \\
\text { sessment (detection bias) } \\
\text { All outcomes }\end{array}$ & Unclear risk & $\begin{array}{l}\text { Participants and team members blinded to participant grouping. Unclear how } \\
\text { successful this blinding was - some team members did know. Van Tulder rat- } \\
\text { ing also re-scored to reflect this }\end{array}$ \\
\hline $\begin{array}{l}\text { Incomplete outcome data } \\
\text { (attrition bias) }\end{array}$ & Low risk & Acceptable attrition. Follow-up of 131/161 people (81\%) \\
$\begin{array}{l}\text { All outcomes } \\
\begin{array}{l}\text { Selective reporting (re- } \\
\text { porting bias) }\end{array}\end{array}$ & Unclear risk & $\begin{array}{l}\text { Based on the published report, the results for all primary and secondary out- } \\
\text { come measures are available. The review authors did not search for the study } \\
\text { protocol. The study pre-dates the requirement of trial registration for publica- } \\
\text { tion }\end{array}$ \\
\hline
\end{tabular}

Smith 1981

\begin{tabular}{|c|c|}
\hline Methods & Unblinded RCT \\
\hline Participants & $\begin{array}{l}\text { Stroke patients discharged from hospital } \\
\text { Total randomly assigned } n=133 \text { : intensive treatment group } n=46 \text {; conventional treatment group } n= \\
43 ; \text { control group } n=44 \\
\text { (all completed) }\end{array}$ \\
\hline Interventions & $\begin{array}{l}\text { Out-patient physiotherapy/occupational therapy for up to } 6 \text { mo } \\
\text { Intensive }=4 \mathrm{~d} / \mathrm{wk} \\
\text { Conventional = } 3 \text { half-days } / \mathrm{wk} \\
\text { Control = health visitor encourages self exercise }\end{array}$ \\
\hline Outcomes & ADL dependency: Northwick Park ADL Index \\
\hline Notes & Follow-up: at 3 and 12 months \\
\hline
\end{tabular}

\section{Risk of bias}

\begin{tabular}{lll}
\hline Bias & Authors' judgement & Support for judgement \\
\hline $\begin{array}{l}\text { Random sequence genera- } \\
\text { tion (selection bias) }\end{array}$ & Low risk & Adequate randomisation; author communication \\
\hline $\begin{array}{l}\text { Allocation concealment } \\
\text { (selection bias) }\end{array}$ & Low risk & Adequate allocation concealment; author communication \\
\hline $\begin{array}{l}\text { Blinding of outcome as- } \\
\text { sessment (detection bias) } \\
\text { All outcomes }\end{array}$ & Low risk & Blinded \\
\hline $\begin{array}{l}\text { Incomplete outcome data } \\
\text { (attrition bias) } \\
\text { All outcomes }\end{array}$ & Low risk & Attrition rate acceptable \\
\hline
\end{tabular}


Smith 1981 (Continued)

Selective reporting (re- Low risk Results for all primary and secondary outcome measures reported porting bias)

Wade 1997

\begin{tabular}{ll}
\hline Methods & Single-blind RCT \\
\hline Participants & TBI - all severities (presenting via A\&E) \\
& $\begin{array}{l}\text { Randomly assigned (completed) } n=1156 \text { (478): treatment group } n=579 \text { (252); control group } n=577 \\
(226)\end{array}$
\end{tabular}

Interventions Oxford Head Injury Service (OxHIS)

Advice and referral as required

Control: standard services only

\begin{tabular}{ll}
\hline Outcomes & $\begin{array}{l}\text { Symptoms: Post concussion: Rivermead Post-concussion symptoms Questionnaire (RPQ) } \\
\text { Social disability: Rivermead Follow-Up Questionnaire (RHFUQ); post-traumatic amnesia }\end{array}$ \\
\hline Notes & 6 months
\end{tabular}

\section{Risk of bias}

\begin{tabular}{|c|c|c|}
\hline Bias & Authors' judgement & Support for judgement \\
\hline $\begin{array}{l}\text { Random sequence genera- } \\
\text { tion (selection bias) }\end{array}$ & Low risk & $\begin{array}{l}\text { Quote: "...of whom } 1156 \text { were randomised into two equal groups, using a list of } \\
\text { computer generated random numbers..." p. } 479\end{array}$ \\
\hline $\begin{array}{l}\text { Allocation concealment } \\
\text { (selection bias) }\end{array}$ & Low risk & Allocation concealment acceptable - study author communication \\
\hline $\begin{array}{l}\text { Blinding of outcome as- } \\
\text { sessment (detection bias) } \\
\text { All outcomes }\end{array}$ & Low risk & $\begin{array}{l}\text { Quote: "At six months after injury, all randomised patients were approached } \\
\text { by one of two clinicians who had not been involved in the early follow up ser- } \\
\text { vice, and who remained unaware to which group patients had been assigned." } \\
\text { p. } 479\end{array}$ \\
\hline $\begin{array}{l}\text { Incomplete outcome data } \\
\text { (attrition bias) } \\
\text { All outcomes }\end{array}$ & Low risk & Attrition acceptable given study design. Follow-up of $478 / 1156$ people (41\%) \\
\hline $\begin{array}{l}\text { Selective reporting (re- } \\
\text { porting bias) }\end{array}$ & Unclear risk & $\begin{array}{l}\text { Based on the published report, the results for all primary and secondary out- } \\
\text { come measures are available. The review authors did not search for the study } \\
\text { protocol. The study pre-dates the requirement of trial registration for publica- } \\
\text { tion }\end{array}$ \\
\hline
\end{tabular}

Wade 1998

\begin{tabular}{ll}
\hline Methods & Single-blind RCT \\
\hline Participants & TBI - all severities (but only if admitted to hospital) \\
& $\begin{array}{l}\text { Randomly assigned (completed) } \mathrm{n}=321(218) \\
\text { Treatment } \mathrm{n}=184(132) ; \text { control } \mathrm{n}=130(86)\end{array}$ \\
\hline Interventions & Oxford Head Injury Service (OxHIS) \\
\hline
\end{tabular}


Wade 1998 (Continued)

Advice and referral as required

Control: standard services only

\begin{tabular}{ll}
\hline Outcomes & $\begin{array}{l}\text { Symptoms: Post concussion: Rivermead Post-concussion symptoms Questionnaire (RPQ) } \\
\text { Social disability: Rivermead Follow-Up Questionnaire (RHFUQ); post-traumatic amnesia }\end{array}$ \\
\hline Notes & $6 \mathrm{mo}$
\end{tabular}

\section{Risk of bias}

\begin{tabular}{|c|c|c|}
\hline Bias & Authors' judgement & Support for judgement \\
\hline $\begin{array}{l}\text { Random sequence genera- } \\
\text { tion (selection bias) }\end{array}$ & Low risk & Computer-generated random numbers \\
\hline $\begin{array}{l}\text { Allocation concealment } \\
\text { (selection bias) }\end{array}$ & Low risk & Allocation concealment adequate - study author communication \\
\hline $\begin{array}{l}\text { Blinding of outcome as- } \\
\text { sessment (detection bias) } \\
\text { All outcomes }\end{array}$ & Low risk & Outcome assessors adequately blinded \\
\hline $\begin{array}{l}\text { Incomplete outcome data } \\
\text { (attrition bias) } \\
\text { All outcomes }\end{array}$ & Low risk & Attrition acceptable given design - study author communication \\
\hline $\begin{array}{l}\text { Selective reporting (re- } \\
\text { porting bias) }\end{array}$ & Low risk & Results for all primary and secondary outcome measures reported \\
\hline
\end{tabular}

\section{Werner 1996}

\begin{tabular}{ll}
\hline Methods & Single-blind RCT \\
\hline Participants & $\begin{array}{l}\text { Stroke patients }-\geq 1 \text { y since stroke (mean 2.9 y) } \\
\text { Randomly assigned (completed) } \mathrm{n}=49(35) \text { : treatment group } \mathrm{n}=33 \text { (28); control group } \mathrm{n}=16 \text { (7) } \\
(5 \text { additional non-randomised controls recruited) }\end{array}$ \\
\hline Interventions & $\begin{array}{l}\text { Late treatment: } \\
\text { Out-patient physio/OT for } 3 \text { mo vs no treatment }\end{array}$ \\
\hline Outcomes & $\begin{array}{l}\text { Activity: Functional Independence Measure - Motor subscale (FIM-Motor) } \\
\text { Restriction of participation: Sickness Impact Profile (SIP) } \\
\text { Mood: Beck Depression Inventory (BDI) }\end{array}$ \\
\hline Notes & Follow-up: at 3 and 9 mo
\end{tabular}

\section{Risk of bias}

\begin{tabular}{lll}
\hline Bias & Authors' judgement & Support for judgement \\
\hline $\begin{array}{l}\text { Random sequence genera- } \\
\text { tion (selection bias) }\end{array}$ & Low risk & Random numbers table used \\
\hline $\begin{array}{l}\text { Allocation concealment } \\
\text { (selection bias) }\end{array}$ & High risk & Inadequate concealment \\
\hline
\end{tabular}


Werner 1996 (Continued)
Blinding of outcome as-
Low risk
Outcome assessors adequately blinded sessment (detection bias)

All outcomes

\begin{tabular}{lll}
$\begin{array}{l}\text { Incomplete outcome data } \\
\text { (attrition bias) } \\
\text { All outcomes }\end{array}$ & High risk & Attrition rate unacceptably high \\
\hline $\begin{array}{l}\text { Selective reporting (re- } \\
\text { porting bias) }\end{array}$ & Low risk & Results for all primary and secondary outcome measures reported \\
\hline
\end{tabular}

Zhu 2007

\begin{tabular}{ll}
\hline Methods & Single-blind RCT \\
\hline Participants & Moderate to severe TBI \\
& Randomly assigned $\mathrm{n}=68$ : intensive group $\mathrm{n}=36 ;$ conventional treatment $\mathrm{n}=32$ \\
& (all completed) \\
\hline
\end{tabular}

\begin{tabular}{ll} 
Interventions & Multi-disciplinary rehabilitation at 2 intensities: \\
& Intensive: $4 \mathrm{~h} / \mathrm{d}, 5 \mathrm{~d} / \mathrm{wk}$ \\
& Conventional: $2 \mathrm{~h} / \mathrm{d}, 5 \mathrm{~d} / \mathrm{wk}$ \\
\hline Outcomes & Global outcome: Glasgow Outcome Scale (GOS) \\
& Activity (disability): Functional Independence Measure (FIM) \\
& Neurobehavioural Cognitive Status Examination (NCSE) \\
\hline Notes & Assessment points: $0,1,2,3,4,5,8,10$, and 12 mo
\end{tabular}

Risk of bias

\begin{tabular}{lll}
\hline Bias & Authors' judgement & Support for judgement \\
\hline $\begin{array}{l}\text { Random sequence genera- } \\
\text { tion (selection bias) }\end{array}$ & Low risk & $\begin{array}{l}\text { Quote: "The patients were then randomly assigned to intensive or control } \\
\text { groups using stratified blocked randomization. The patients were first strati- } \\
\text { fied according to the severity of the brain injury (moderate or severe) and then } \\
\text { pooled into groups of } 10 . \text { Randomization was conducted separately for each of } \\
\text { the moderate-to-severe sub-groups by drawing one of several double-sealed } \\
\text { envelopes. The number of envelopes assigned to the intensive or conventional } \\
\text { groups in each randomization was kept as equal as possible. The randomiza- } \\
\text { tions were conducted by a research assistant who was not involved in the clin- } \\
\text { ical management. The patients, along with the sealed envelopes, were then } \\
\text { transferred to the rehabilitation hospital where the rehabilitation programme } \\
\text { was carried out. All patients were assessed by the same multi-disciplinary re- } \\
\text { habilitation team before the treatment protocol assignment, as indicated in } \\
\text { the sealed envelope, was revealed." p. } 683\end{array}$ \\
\hline
\end{tabular}

Allocation concealment Low risk

Quote: "Double-sealed envelopes". Authors' judgement: Probably done.

(selection bias) 
Zhu 2007 (Continued)

Blinding of outcome as- Low risk Quote: "All assessments were conducted in the acute hospital by personnel sessment (detection bias)

All outcomes who were not involved in the randomization and who did not provide the rehabilitation training." p. 684

\begin{tabular}{|c|c|c|}
\hline $\begin{array}{l}\text { Incomplete outcome data } \\
\text { (attrition bias) } \\
\text { All outcomes }\end{array}$ & Low risk & Acceptable attrition. Follow-up of $35 / 49$ people $(71 \%)$ \\
\hline $\begin{array}{l}\text { Selective reporting (re- } \\
\text { porting bias) }\end{array}$ & Unclear risk & $\begin{array}{l}\text { Based on the published report, the results for all primary and secondary out- } \\
\text { come measures are available. The review authors did not search for the study } \\
\text { protocol. The study pre-dates the requirement of trial registration for publica- } \\
\text { tion }\end{array}$ \\
\hline
\end{tabular}

\section{Abbreviations:}

ADLs = activities of daily living.

AMPS = Assessment of Motor and Process Skills.

$\mathrm{BI}=$ Brain Injury.

DRS = Disability Rating Score.

FIM = Functional Independence Measure.

FMA $=$ Fugl-Meyer Assessment.

GHQ-28 = General Health Questionnaire 28.

GOSE = Glasgow Outcome Scale Extended.

HINT = Head Injury Neurorehabilitation Team.

$\mathrm{ICU}=$ Intensive Care Unit.

$\mathrm{MBI}=$ Modified Barthel Index.

$M D=$ multi-disciplinary.

NCSE = Neurobehavioural Cognitive Status Examination.

NIAF = Newcastle Independent Assessment Form.

NIHSS = National Institutes of Health Stroke Scale.

OT = occupational therapy.

PT = physiotherapy.

$\mathrm{RCT}=$ randomised controlled trial.

Characteristics of excluded studies [ordered by study ID]

\begin{tabular}{ll}
\hline Study & Reason for exclusion \\
\hline Bjorkdahl 2007 & $\begin{array}{l}\text { Fatally flawed: small numbers with high chance of type Il error and poorly matched groups at base- } \\
\text { line }\end{array}$ \\
\hline Browne 2013 & $\begin{array}{l}\text { Fatally flawed: poor matching of groups at baseline (lack of functional outcome measures), signifi- } \\
\text { cantly large attrition rate of } 30 \% \text { and very low quality as per van Tulder criteria }\end{array}$ \\
\hline Ownsworth 2008 & $\begin{array}{l}\text { Fatally flawed: very small numbers with high chance of type Il error, and, importantly, no evidence } \\
\text { of outcome comparisons between intervention and control groups, which in this case included } \\
\text { those on a waitlist }\end{array}$ \\
\hline Relander 1972 & $\begin{array}{l}\text { Fatally flawed: }>\text { 40\% attrition at 1-y follow-up. Outcome measured by questionnaire only, with no } \\
\text { validating evidence presented }\end{array}$ \\
\hline Sonoda 2004 & $\begin{array}{l}\text { Low methodological quality as per van Tulder criteria } \\
\text { Criteria }\end{array}$ \\
\hline
\end{tabular}


Characteristics of ongoing studies [ordered by study ID]

\section{NCT00869154}

\begin{tabular}{ll}
\hline Trial name or title & Multidisciplinary Treatment in Patients With Mild Traumatic Brain \\
\hline Methods & Randomised controlled trial \\
\hline Participants & People with a traumatic brain injury with brief loss of consciousness, \\
\hline Interventions & Intervention: Multidisciplinary care follow-up \\
& Control: Primary care follow-up \\
\hline Outcomes & Primary outcome: Return to work. \\
& Secondary outcomes: \\
& $\begin{array}{l}\text { 1. Glasgow Outcome Scale Extended score } \\
\text { 2. The Rivermead Post concussion symptoms questionnaire score } \\
\text { 3. Patient's Global Impression of Change }\end{array}$
\end{tabular}

\begin{tabular}{ll}
\hline Starting date & March 2009 \\
\hline Contact information & $\begin{array}{l}\text { Haukeland University Hospital, Bergen, Norway } \\
\text { Jan Sture Skouen, MD, PhD }\end{array}$ \\
\hline
\end{tabular}

Notes

\section{ADDITIONAL TABLES}

\section{Table 1. Scoring criteria based on the method of van Tulder (1997)}

\begin{tabular}{ll}
\hline Criterion & Score positive if: \\
\hline Eligibility criteria specified & A list of inclusion/exclusion criteria was explicitly stated. \\
\hline Method of randomisation & A random (unpredictable) assignment sequence was used. \\
\hline $\begin{array}{l}\text { Treatment allocation conceal- } \\
\text { ment }\end{array}$ & $\begin{array}{l}\text { Assignment was concealed from investigators. Assignment was generated by an independent } \\
\text { person not responsible for determining the eligibility of patients. This person has no information } \\
\text { about individuals included in the trial and has no influence on the assignment sequence nor on the } \\
\text { decision about eligibility of patients. }\end{array}$ \\
\hline $\begin{array}{l}\text { Similarity of baseline charac- } \\
\text { teristics }\end{array}$ & $\begin{array}{l}\text { Study groups were comparable at baseline for important prognostic parameters. To receive a 'yes', } \\
\text { groups had to be similar at baseline regarding demographic factors, duration and severity of com- } \\
\text { plaints, percentage of patients with neurological symptoms and value of main outcome mea- } \\
\text { sure(s). }\end{array}$
\end{tabular}

Treatment and control inter-

Details are given of the programme, including disciplines involved and treatment duration. ventions specifically described

Care provider blinded to the Treating team is blinded regarding the intervention (NB: rarely possible in this context).
intervention

Co-interventions avoided or Co-interventions should be avoided in the trial design or similar between index and control. equal 
Table 1. Scoring criteria based on the method of van Tulder (1997) (Continued)

Compliance

Compliance was measured and satisfactory in all study groups.

Participant blinded to the intervention

Participant was blinded regarding the intervention (NB: rarely possible in this context if consent procedures are properly applied).

Outcome assessor blinded to the intervention

Outcome assessor was blinded regarding treatment allocation, and standardised assessment measures were used to structure the interviews. Scored negative if only self reported (questionnaire) outcomes were used and no observer outcomes were provided.

Outcome measures relevant Outcome measures reflected disability (activity) or participation as relevant to the intervention.

Adverse effects described Any adverse effects of the intervention are described.

Withdrawal rate described and acceptable

Number of participants included in the study who did not complete the observation period or were not included in the analysis must be described and reasons given. If percentage of withdrawals and dropouts does not exceed $20 \%$ for immediate- and short-term follow-up or $30 \%$ for intermediateand long-term follow-up, and does not lead to substantial bias, 'yes' is scored.

Short-term outcome measurement

Outcomes were measured at the end of treatment (e.g. admission to discharge) or within 6 months of the end of treatment.

Long-term outcome measure- $\quad$ Outcomes were measured at 1 year or longer.

ment

Timing of outcome assessTiming of outcome assessment should be identical for all intervention groups and for all important ment in both groups comparaoutcome assessments.

ble

Sample size described for each Number of participants was stated for each group. group

Intention-to-treat analysis

All randomly assigned participants were included in the analysis (minus missing values), irrespective of non-compliance and co-interventions. If loss to follow-up was substantial ( $\geq 20 \%)$, an intention-to-treat analysis as well as an alternative analysis that accounts for missing values (e.g. a worst-case analysis) should have been performed.

Point estimates and measures of variability

A mean or median figure was given for each important outcome parameter, together with a measure of variability such as standard deviation, standard error of the mean or $95 \%$ confidence intervals.

Table 2. Methodological quality as assessed by the van Tulder method

\begin{tabular}{ll}
\hline Category of evidence & Criteria \\
\hline Strong evidence & Consistent statistically significant findings in outcome measures in $\geq 2$ high-quality RCTs. \\
\hline Moderate evidence & $\begin{array}{l}\text { Consistent statistically significant findings in outcome measures in } \geq 1 \text { high-quality RCT and } \geq 1 \\
\text { controlled study. }\end{array}$ \\
\hline Limited evidence & $\begin{array}{l}\text { Consistent statistically significant findings in outcome measures in } \geq 1 \text { high-quality RCT, or } \\
\text { Consistent statistically significant findings in outcome measures in } \geq 2 \text { controlled studies. }\end{array}$ \\
\hline Indicative findings & $\begin{array}{l}\text { Consistent statistically significant findings in process or outcome measures in } \geq 1 \text { controlled stud- } \\
\text { ies. }\end{array}$
\end{tabular}


Table 2. Methodological quality as assessed by the van Tulder method (Continued)

Table 3. Methodological quality as assessed by the van Tulder method

\begin{tabular}{|c|c|c|c|c|c|}
\hline Study ID & $\begin{array}{l}\text { Internal } \\
\text { validity }\end{array}$ & $\begin{array}{l}\text { Descrip- } \\
\text { tive crite- } \\
\text { ria }\end{array}$ & $\begin{array}{l}\text { Statisti- } \\
\text { cal crite- } \\
\text { ria }\end{array}$ & $\begin{array}{l}\text { Total } \\
\text { score }\end{array}$ & Positive criteria \\
\hline Kwakkel 1999 & 8 & 5 & 2 & 15 & a,bi,bii,c,d,f,g,j,l,mi,mii,n,o,p,q. \\
\hline Wade 1997 & 8 & 4 & 2 & 14 & a,bi,bii,c,d,f,g,i,j,l,mi,n,o,q. \\
\hline Wade 1998 & 8 & 4 & 2 & 14 & a,bi,bii,c,d,f,g,i,j,l,mi,n,o,q. \\
\hline Powell 2002 & 8 & 4 & 2 & 14 & a,bi,bii,c,d,f,g,i,j,l,mii,n,o,q. \\
\hline Cicerone 2008 & 8 & 4 & 2 & 14 & a,bi,bii,c,d,g,i,j,l,mi,n,o,p,q \\
\hline Smith 1982 & 7 & 5 & 2 & 14 & a,bi,c,d,f,g,i,j,l,mi,mii,n,o. \\
\hline Salazar 2000 & 7 & 5 & 2 & 14 & a,bi,c,d,f,g,j,l,mi,mii,n,o,p,q. \\
\hline Paniak 1998 & 6 & 5 & 2 & 13 & a,c,d,f,g,j,l,mi,mii,n,o,p,q. \\
\hline Slade 2002 & 7 & 3 & 2 & 12 & a,bi,bii,c,d,f,g,j,l,mi,o,p,q \\
\hline Shiel 2001 & 7 & 3 & 2 & 12 & a,bi,d,g,h,i,j,l,mi,o,q. \\
\hline Zhu 2007 & 6 & 4 & 2 & 12 & a.bi,bii,c,d,i,j,l,mi,mii,n,o,p,q \\
\hline Elgmark 2007 & 6 & 4 & 2 & 12 & a,bi,bii,c,d,i,j,l,mii,n,o,p,q \\
\hline Bowen 2001 & 4 & 4 & 2 & 10 & $a, c, d, f, j, l, m i, n, o, p, q$. \\
\hline Bjorkdahl 2006 & 5 & 3 & 2 & 10 & d,i,j,l,mi,mii,n,o,p,q \\
\hline Bai 2012 & 5 & 3 & 1 & 9 & $a, c, g, i, j, l, m i, n, o$ \\
\hline Werner 1996 & 4 & 4 & 1 & 9 & a,bi,d,i,j,mi,mii,n,o. \\
\hline Semlyen 1998 & 4 & 4 & 1 & 9 & a,d,f,g,j,l,mi,mii,n,o. \\
\hline Andelic 2012 & 4 & 4 & 1 & 9 & a,c,d,g,j,l,mii,n,o \\
\hline Ozdemir 2001 & 3 & 4 & 2 & 9 & a,c,d,f,g,j,mi,o,q. \\
\hline
\end{tabular}

Table 4. Results from the four studies predominantly addressing the milder ambulatory group

\begin{tabular}{|c|c|c|}
\hline $\begin{array}{l}\text { Paniak } \\
1998 \text { and } \\
2000\end{array}$ & $\begin{array}{l}\text { Participant } \\
\text { and group } \\
\text { compar- }\end{array}$ & $\begin{array}{l}\text { Patients with TBI admitted to hospital (all severities); mean age } 33 \text { y } \\
\text { Intervention: 'treatment as needed' (TAN) }(n=58)\end{array}$ \\
\hline
\end{tabular}


Table 4. Results from the four studies predominantly addressing the milder ambulatory group (Continued)

Control: single session (SS) of education and advice $(n=53)$

\begin{tabular}{|c|c|c|c|c|}
\hline $\begin{array}{l}\text { Primary } \\
\text { outcomes }\end{array}$ & \multicolumn{4}{|c|}{$\begin{array}{l}\text { Impairment: Problem Checklist (PCL) } \\
\text { Participation: Community Integration Questionnaire (CIQ) } \\
\text { Health status: Short-Form } 36 \text { (SF-36) } \\
\text { Work status: socio-economic status (SES) }\end{array}$} \\
\hline $\begin{array}{l}\text { Assessment } \\
\text { points }\end{array}$ & \multicolumn{4}{|c|}{3 to 4 months $(n=111)$ and 1 year $(n=105)$} \\
\hline $\begin{array}{l}\text { Summary of } \\
\text { results }\end{array}$ & \multicolumn{4}{|c|}{$\begin{array}{l}\text { Participation (CIQ) did not change significantly for either group } \\
\text { Impairment (PCL) and health status (SF-36): Repeated measures MANOVA showed significant effects for } \\
\text { time in both groups, which were maintained at } 1 \text { year } \\
\text { Results showed no significant group interaction or time by group for any of the primary outcomes at ei- } \\
\text { ther time point }\end{array}$} \\
\hline $\begin{array}{l}\text { Vocational } \\
\text { status } \\
\text { (SES) }\end{array}$ & $\begin{array}{l}\text { Intervention } \\
\text { Mean (SD) }\end{array}$ & $\begin{array}{l}\text { Control } \\
\text { Mean (SD) }\end{array}$ & Difference in mean & $\begin{array}{l}\text { P value } \\
\text { (MANOVA) }\end{array}$ \\
\hline Pre-injury & $37.2(18.7)$ & $34.3(18.5)$ & 2.9 & $\mathrm{~N} / \mathrm{S}$ \\
\hline Baseline & $26.9(20.7)$ & $23.2(19.9)$ & 0.8 & $\mathrm{~N} / \mathrm{S}$ \\
\hline 3 to $4 \mathrm{mo}$ & $32.5(20.2)$ & $32.8(19.7)$ & 0.3 & $\mathrm{~N} / \mathrm{S}$ \\
\hline $1 \mathrm{y}$ & $34.8(19.7)$ & $36.7(21.0)$ & 1.9 & $\mathrm{~N} / \mathrm{S}$ \\
\hline
\end{tabular}

Authors'

conclusions

Interventions appear to be equally effective

\begin{tabular}{lll}
$\begin{array}{l}\text { Salazar } \\
2000\end{array}$ & $\begin{array}{l}\text { Participant } \\
\text { and group } \\
\text { compar- } \\
\text { isons }\end{array}$ & $\begin{array}{l}\text { Active duty military personnel with moderate to severe TBI; mean age 25y } \\
\text { Intervention: 8-week intensive in-patient cognitive-behavioural programme }(\mathrm{n}=67) \\
\text { Control: limited home programme of weekly telephone support from psychiatric nurse (educational } \\
\text { material, counselling and suggested home exercises) }(\mathrm{n}=53)\end{array}$ \\
\cline { 2 - 3 } & $\begin{array}{l}\text { Primary } \\
\text { outcomes }\end{array}$ & Work status: return to work \\
& $\begin{array}{l}\text { Assessment } \\
\text { points }\end{array}$ & 1 year to fitness for military duty \\
\hline $\begin{array}{l}\text { Summary of } \\
\text { results }\end{array}$ & $\begin{array}{l}\text { No overall differences in outcomes between groups } \\
\text { Post hoc analysis demonstrated significant group interaction (in favour of the intervention group) for } \\
\text { 'fitness for military duty' at } 1 \text { year for the more severe subgroup, who were unconscious for }>1 \mathrm{~h}\end{array}$ \\
\hline
\end{tabular}


Table 4. Results from the four studies predominantly addressing the milder ambulatory group (Continued)

\begin{tabular}{lllll}
$\begin{array}{l}\text { Vocational } \\
\text { status at }\end{array}$ & $\begin{array}{l}\text { Intervention } \\
\text { \% achieved }\end{array}$ & $\begin{array}{l}\text { Control } \\
\text { \% achieved }\end{array}$ & Difference & P value \\
(Fisher's exact) \\
\hline $\begin{array}{l}\text { Return to } \\
\text { work }\end{array}$ & $90 \%$ & $94 \%$ & $4 \%(-5.14)$ & $\mathrm{N} / \mathrm{S}$ \\
\hline $\begin{array}{l}\text { Fit for mili- } \\
\text { tary duty }\end{array}$ & $73 \%$ & $66 \%$ & $7 \%(-10.24)$ & $\mathrm{N} / \mathrm{S}$ \\
\hline
\end{tabular}

Post hoc analysis of subgroup unconscious for $>1 \mathrm{~h}(\mathrm{n}=75)$

\begin{tabular}{lllll} 
& $(\mathbf{n = 3 5 )}$ & $(\mathbf{n = 4 0 )}$ & Difference & P value \\
\hline $\begin{array}{l}\text { Fit for mili- } \\
\text { tary duty }\end{array}$ & $80 \%$ & $58 \%$ & $22 \%$ & 0.05 \\
\hline $\begin{array}{l}\text { Authors' } \\
\text { conclusions }\end{array}$ & $\begin{array}{l}\text { Overall benefit of in-patient cognitive rehabilitation programme similar to that of limited home rehabil- } \\
\text { itation, although institutional therapy may be beneficial for selected patients with severe TBI }\end{array}$ \\
\hline
\end{tabular}

\begin{tabular}{lll}
\hline Wade & $\begin{array}{l}\text { Participant } \\
\text { and group } \\
\text { compar- } \\
\text { isons }\end{array}$ & All patients presenting to Accident and Emergency following TBI; age 16 to 65 y \\
1997 & Contervention: telephone follow-up at 7 to 10 days with advice and referral as required $(n=252)$ \\
& & Controspecific intervention (standard services only) $(n=226)$
\end{tabular}

(NB: Despite major efforts to trace and contact patients, follow-up interview at 6 months could be achieved in only 478 of 1156 (41\%) participants randomly assigned)

\begin{tabular}{|c|c|c|c|}
\hline $\begin{array}{l}\text { Primary } \\
\text { outcomes }\end{array}$ & \multicolumn{3}{|c|}{$\begin{array}{l}\text { Social disability: Rivermead Head Injury Follow-Up Questionnaire (RFUQ) } \\
\text { Symptoms: Rivermead Post-concussion Symptoms Questionnaire (RPQ) }\end{array}$} \\
\hline $\begin{array}{l}\text { Assessment } \\
\text { points }\end{array}$ & \multicolumn{3}{|l|}{6 months } \\
\hline $\begin{array}{l}\text { Summary of } \\
\text { results }\end{array}$ & \multicolumn{3}{|c|}{$\begin{array}{l}\text { No overall differences between intervention and control groups } \\
\text { Post hoc analysis revealed significant group interaction (in favour of the active intervention group) with } \\
\text { respect to social disability in a subgroup of individuals with more severe injury ( }>1 \mathrm{~h} \text { PTA) }\end{array}$} \\
\hline $\begin{array}{l}\text { Health sta- } \\
\text { tus } \\
\text { at } 6 \mathrm{mo}\end{array}$ & $\begin{array}{l}\text { Intervention } \\
\text { Mean (SD) }\end{array}$ & $\begin{array}{l}\text { Control } \\
\text { Mean (SD) }\end{array}$ & $\begin{array}{l}\text { P value } \\
\text { (Mann-Whitney) }\end{array}$ \\
\hline RFUQ & $3.6(6.0)$ & $3.3(6.3)$ & $\mathrm{N} / \mathrm{S}$ \\
\hline RPQ & 7.7 (10.9) & $6.8(10.0)$ & $\mathrm{N} / \mathrm{S}$ \\
\hline \multicolumn{4}{|c|}{ Post hoc analysis of subgroup with PTA $>1 h(n=121)$} \\
\hline & $(n=71)$ & $(n=53)$ & \\
\hline RFUQ & $0.85(0.89)$ & $1.17(1.07)$ & 0.003 \\
\hline
\end{tabular}


Table 4. Results from the four studies predominantly addressing the milder ambulatory group (Continued)
$\mathrm{RPQ}$
$2.03(0.85)$
$2.21(0.89)$
$\mathrm{N} / \mathrm{S}$

Authors' Routine follow-up does not appear to be necessary for all patients presenting with head injury, but a conclusions subgroup of patients with more severe TBI may benefit from such intervention

\begin{tabular}{|c|c|c|c|c|}
\hline \multirow[t]{8}{*}{1998} & $\begin{array}{l}\text { Participant } \\
\text { and group } \\
\text { compar- } \\
\text { isons }\end{array}$ & \multicolumn{3}{|c|}{$\begin{array}{l}\text { All patients admitted to hospital following TBI (i.e. a more severe group than the total group reported } \\
\text { in Wade 1997); age } 16 \text { to } 65 \mathrm{y} \\
\text { Intervention: telephone follow-up at } 7 \text { to } 10 \text { days with advice and referral as required }(n=132) \\
\text { Control: no specific intervention (standard services only) }(n=86) \\
\text { (NB: follow-up data obtained in } 218(69 \%) \text { of } 314 \text { participants randomly assigned) }\end{array}$} \\
\hline & $\begin{array}{l}\text { Primary } \\
\text { outcomes }\end{array}$ & \multicolumn{3}{|c|}{$\begin{array}{l}\text { Social disability: Rivermead Head Injury Follow-Up Questionnaire (RFUQ) } \\
\text { Symptoms: Rivermead Post-concussion Symptoms Questionnaire (RPQ) }\end{array}$} \\
\hline & $\begin{array}{l}\text { Assessment } \\
\text { points }\end{array}$ & \multicolumn{3}{|l|}{6 months } \\
\hline & $\begin{array}{l}\text { Summary of } \\
\text { results }\end{array}$ & \multicolumn{3}{|c|}{$\begin{array}{l}\text { Significant group interaction (in favour of the active intervention group) with respect to social disabili- } \\
\text { ty and post-concussion symptoms. Subgroup analysis demonstrated that the main benefit appeared in } \\
\text { the group with PTA }<7 \text { days }\end{array}$} \\
\hline & $\begin{array}{l}\text { Health sta- } \\
\text { tus } \\
\text { at } 6 \text { mo }\end{array}$ & $\begin{array}{l}\text { Intervention } \\
\text { Mean (SD) }\end{array}$ & $\begin{array}{l}\text { Control } \\
\text { Mean (SD) }\end{array}$ & $\begin{array}{l}\text { P value } \\
\text { (Mann-Whitney U test) }\end{array}$ \\
\hline & RFUQ & $5.36(7.81)$ & $8.23(8.75)$ & 0.01 \\
\hline & RPQ & $9.8(11.7)$ & $13.9(13.6)$ & 0.02 \\
\hline & $\begin{array}{l}\text { Authors' } \\
\text { conclusions }\end{array}$ & \multicolumn{3}{|c|}{$\begin{array}{l}\text { Early intervention by a specialist service significantly reduced social morbidity and severity of post- } \\
\text { concussion symptoms } 6 \text { months after head injury, in the group of patients who required admission to } \\
\text { hospital. Possibly most beneficial for the moderate to severe group, some of whom may not present } \\
\text { without pro-active intervention }\end{array}$} \\
\hline
\end{tabular}

\section{Elgmark Participant All patients aged 16 to 60 with mild traumatic brain injury according to American Congress of Rehabili- 2007 and group tation medicine criteria \\ compar- \\ isons Intervention: follow-up at 2 to 8 weeks by telephone or letter with advice and referral as required $(\mathrm{n}=$ 264 - 96 received intervention; 150 declined); 18 lost to follow-up}

Control: no specific intervention (regular care) ( $n=131) ; 22$ lost to follow-up

246 treatment and 109 control included in intention-to-treat analysis
Primary Symptoms: change in post-concussion symptoms - Swedish Post-concussion Symptoms Question- outcomes naire (PCSQ)

Social disability: Community Integration Questionnaire (CIQ), Life Satisfaction Questionnaire, ShortForm Health Survey (SF-36) 
Table 4. Results from the four studies predominantly addressing the milder ambulatory group (Continued)

\begin{tabular}{|c|c|c|c|}
\hline $\begin{array}{l}\text { Assessment } \\
\text { points }\end{array}$ & \multicolumn{3}{|l|}{1 y post injury } \\
\hline $\begin{array}{l}\text { Summary of } \\
\text { results }\end{array}$ & \multicolumn{3}{|c|}{$\begin{array}{l}\text { No statistically significant differences were found between intervention and control groups. Partici- } \\
\text { pants who experienced few PCS } 2 \text { to } 8 \text { weeks post injury declined rehabilitation and returned to work. } \\
\text { Those who suffered several PCS and accepted rehabilitation did not recover after } 1 \mathrm{y}\end{array}$} \\
\hline $\begin{array}{l}\text { Health sta- } \\
\text { tus } \\
\text { at } 6 \text { mo }\end{array}$ & $\begin{array}{l}\text { Intervention } \\
\text { Mean (SD) }\end{array}$ & $\begin{array}{l}\text { Control } \\
\text { Mean (SD) }\end{array}$ & Significance \\
\hline Total PCSQ & $5.2(5.3)$ & $4.4(5.3)$ & $\mathrm{N} / \mathrm{S}$ \\
\hline CIQ & $20.3(4.0)$ & $19.8(4.0)$ & 0.02 \\
\hline $\begin{array}{l}\text { Authors' } \\
\text { conclusions }\end{array}$ & \multicolumn{3}{|c|}{$\begin{array}{l}\text { In this particular study of MTBI, active rehabilitation did not change outcomes to a significant degree. } \\
\text { Additional studies should focus on patients who remain symptomatic during the first } 1 \text { to } 3 \text { months and } \\
\text { should test various types of interventions }\end{array}$} \\
\hline
\end{tabular}

PTA = post-traumatic amnesia; TBI = traumatic brain injury.

Table 5. Results from the two studies addressing out-patient rehabilitation (Continued)

\begin{tabular}{|c|c|c|c|c|c|}
\hline \multirow[t]{6}{*}{$\begin{array}{l}\text { Smith } \\
1981\end{array}$} & $\begin{array}{l}\text { Participant } \\
\text { and } \\
\text { group compar- } \\
\text { isons }\end{array}$ & \multicolumn{4}{|c|}{$\begin{array}{l}\text { Patients suitable for out-patient rehabilitation following discharge from hospital after acute stroke } \\
(n=133) \text {; mean age } 63 y \\
\text { Intervention: out-patient physiotherapy and occupational therapy for } 6 \text { months at } 2 \text { levels of inten- } \\
\text { sity: } \\
\text { - Intensive ( } 4 \text { whole days per week) }(n=46) \text { or } \\
\text { - Conventional ( } 3 \text { half-days per week) }(n=43) \text { vs } \\
\text { Control: no routine rehabilitation, health visitor encourages home exercises as learned in hospital } \\
(n=44)\end{array}$} \\
\hline & $\begin{array}{l}\text { Primary out- } \\
\text { comes }\end{array}$ & Dependency for ADL: Nor & wick Park ADL score & & \\
\hline & $\begin{array}{l}\text { Assessment } \\
\text { points }\end{array}$ & 3 and 12 months & & & \\
\hline & $\begin{array}{l}\text { Summary of } \\
\text { results }\end{array}$ & $\begin{array}{l}\text { Significantly greater decre } \\
\text { months. Difference is sust } \\
\text { (NB: trend towards better } \\
\text { tested statistically) }\end{array}$ & $\begin{array}{l}\text { se in } A D L \text { scores in intNerv } \\
\text { ned at } 1 \text { y follow-up with } \\
\text { sults from intensive rehat }\end{array}$ & $\begin{array}{l}\text { tion groups cc } \\
\text { ater number } 0 \\
\text { ation than frc }\end{array}$ & $\begin{array}{l}\text { ontrols at } 3 \\
\text { participants }\end{array}$ \\
\hline & $\begin{array}{l}\text { Decrease in } \\
\text { ADL score }\end{array}$ & Intensive rehabilitation & $\begin{array}{l}\text { Conventional rehabili- } \\
\text { tation }\end{array}$ & Control & P value \\
\hline & $\begin{array}{l}\text { Mean change } 0 \\
\text { to } 3 \mathrm{~m}\end{array}$ & $3.54(n=41)$ & $2.87(n=40)$ & $1.50(n=42)$ & $\begin{array}{l}1 \text { vs 3: } P \text { value } \\
<0.01 \\
1 / 2 \text { vs 3: } P \text { val- } \\
\text { ue }<0.01\end{array}$ \\
\hline
\end{tabular}


Table 5. Results from the two studies addressing out-patient rehabilitation (Continued)
Mean change $0 \quad 3.50(n=36)$
$2.89(n=36)$
$0.60(n=35)$
1 vs 3: $P$ value
to $12 \mathrm{~m}$
(1)
$<0.05$
Authors' con- Out-patient rehabilitation following stroke appears to be effective. Decreasing intensity of rehabilita- clusions tion was associated with an increase in both the proportion of participants who deteriorated and the extent to which they deteriorated

$\begin{array}{lll}\begin{array}{l}\text { Werner } \\ 1996\end{array} & \begin{array}{l}\text { Participant } \\ \text { and }\end{array} & \begin{array}{l}\text { Patients discharged from in-patient rehabilitation and } \geq 1 \text { y (mean 2.9 y) after stroke ( } \mathrm{n}=49) ; \text { mean } \\ \text { age } 63 \mathrm{y}\end{array} \\ & \begin{array}{l}\text { group compar- } \\ \text { isons }\end{array} & \begin{array}{l}\text { Intervention: out-patient physiotherapy and occupational therapy (2 hours, } 4 \text { times per week, for } 3 \\ \text { months) }(\mathrm{n}=33)\end{array}\end{array}$

Control: no specific intervention $(n=16)$

(NB: 28\% (5/33 intervention group and 9/16 control group) did not complete follow-up: 5 non-randomised controls were subsequently recruited to make control numbers up to 12 )

\begin{tabular}{|c|c|c|c|c|}
\hline $\begin{array}{l}\text { Primary out- } \\
\text { comes }\end{array}$ & \multicolumn{4}{|c|}{$\begin{array}{l}\text { Activity: Functional Independence Measure - Motor (FIM-MM) } \\
\text { Limitation of participation: Sickness Impact Profile (SIP) } \\
\text { Depression: Beck Depression Inventory (BDI) }\end{array}$} \\
\hline $\begin{array}{l}\text { Assessment } \\
\text { points }\end{array}$ & \multicolumn{4}{|c|}{3 and 9 months } \\
\hline $\begin{array}{l}\text { Summary of } \\
\text { results }\end{array}$ & \multicolumn{4}{|c|}{$\begin{array}{l}\text { Significant changes in FIM and SIP at } 3 \text { months maintained at } 9 \text { months. Trend towards improved } \\
\text { mood did not reach significance }\end{array}$} \\
\hline $\begin{array}{l}\text { Mean change } \\
\text { in score }\end{array}$ & $\begin{array}{l}\text { Intervention } \\
(n=28)\end{array}$ & $\begin{array}{l}\text { Control } \\
(n=12)\end{array}$ & Difference in mean & $\begin{array}{l}\text { P value } \\
\text { (t-tests) }\end{array}$ \\
\hline $\begin{array}{l}\text { FIM-MM (0 to } 3 \\
\text { mo) }\end{array}$ & 6.6 & 1.5 & 5.1 & 0.03 \\
\hline $\begin{array}{l}\text { FIM-MM (3 to } 9 \\
\text { mo) }\end{array}$ & 0.7 & -1.0 & 1.7 & $\mathrm{~N} / \mathrm{S}$ \\
\hline SIP (0 to $3 \mathrm{mo})$ & -5.2 & 2.6 & 7.8 & 0.04 \\
\hline $\mathrm{BDI}$ (0 to $3 \mathrm{mo}$ ) & -2.6 & 0.2 & 2.8 & $\mathrm{~N} / \mathrm{S}$ \\
\hline BDI (3 to $9 \mathrm{mo})$ & 0.7 & 0.5 & 0.2 & $\mathrm{~N} / \mathrm{S}$ \\
\hline $\begin{array}{l}\text { Authors' con- } \\
\text { clusions }\end{array}$ & $\begin{array}{l}\text { Significant gai } \\
\text { bilitation serv }\end{array}$ & attained $\mathrm{i}$ & roke survivor, despite & n-patient reha- \\
\hline
\end{tabular}

ADLs = activities of daily living.

Table 6. Results from the three studies addressing community team-based rehabilitation

$\begin{array}{lll}\text { Powell } & \text { Participant } & \text { Patients (16 to } 65 \text { y) with severe traumatic brain injury } 3 \text { mo to } 20 \text { y previously ( } n=110 \text { allocated: } 94 \\ 2002 & \text { and } & \text { (85\%) completed follow-up) }\end{array}$


Table 6. Results from the three studies addressing community team-based rehabilitation (Continued) group com- Intervention: inter-disciplinary team interventions: 2 sessions per week for mean 27.3 (SD 19.1) parisons weeks in community settings (home, work or day centres) $(n=48)$

Control: written information only $(n=46)$

\section{Primary out- Activity: Barthel Index (BI)}

comes

Participation: Brain Injury Community Rehabilitation Outcome (BICRO-39)

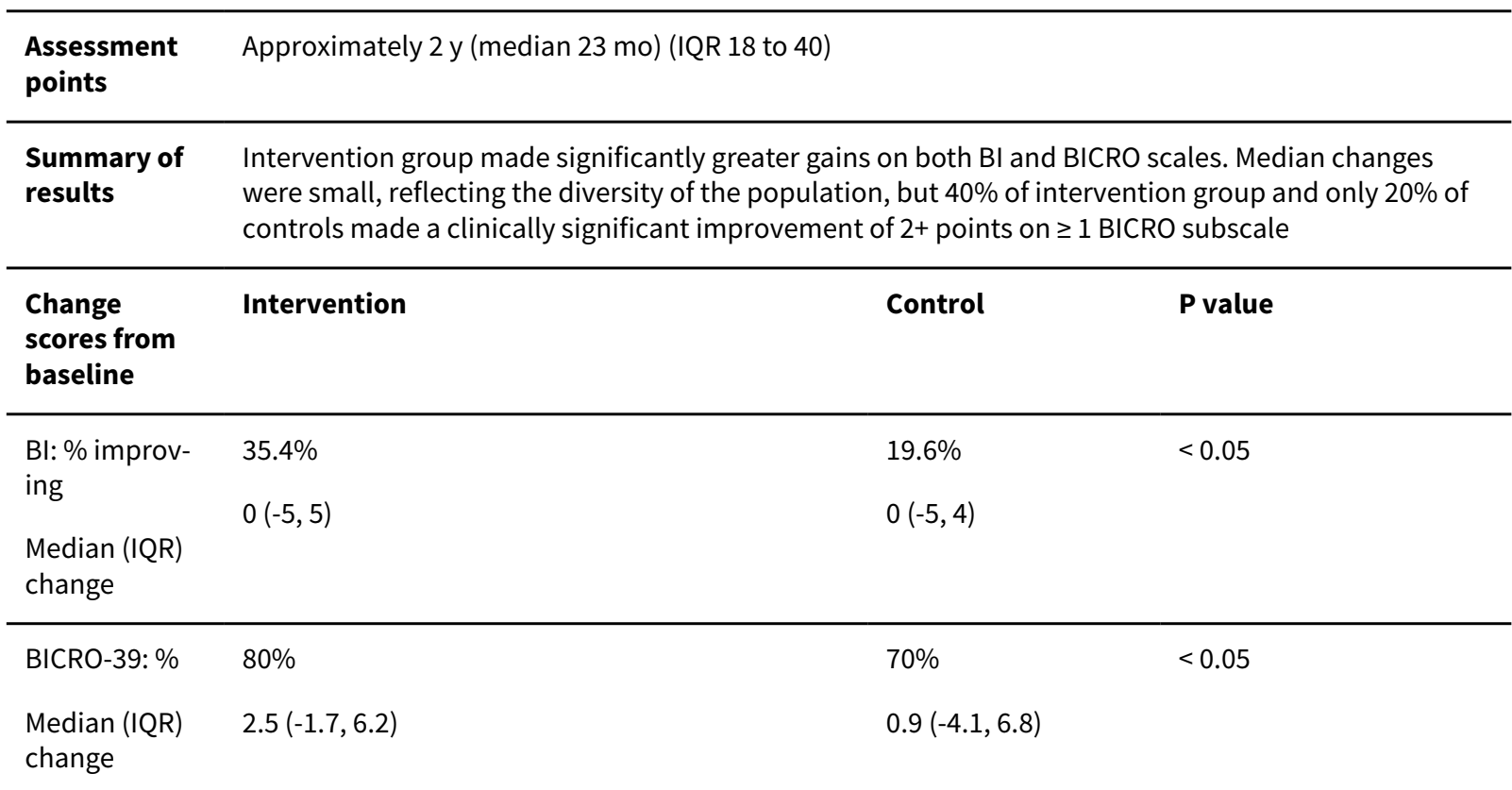

Authors' con- Multi-disciplinary community rehabilitation, even years after injury, can make clinically significant clusions gains which outlive the active treatment period.

\begin{tabular}{|c|c|c|}
\hline \multirow[t]{5}{*}{$\begin{array}{l}\text { Bowen } \\
2001\end{array}$} & $\begin{array}{l}\text { Participant } \\
\text { and } \\
\text { group com- } \\
\text { parisons }\end{array}$ & $\begin{array}{l}\text { Carers of young adult ( } 16 \text { to } 65 \mathrm{y} \text { ) TBI survivors with hospital stay } \geq 3 \text { days ( } n=96) \\
\text { Intervention: active intervention from Head Injury Neurorehabilitation Team (HINT) } \\
\text { - Early intervention - whilst still in hospital }(n=41) \\
\text { - Late intervention - after discharge from hospital }(n=28) \\
\text { Control: no specific intervention - existing services only }(n=27) \\
\text { (NB: } 20 / 96(21 \%) \text { received service other than that allocated - only } 56 \% \text { allocated to early intervention } \\
\text { actually received it) }\end{array}$ \\
\hline & $\begin{array}{l}\text { Primary out- } \\
\text { comes }\end{array}$ & $\begin{array}{l}\text { Information received: carer perceptions of how well informed they are - } 7 \text { questions } \\
\text { Emotional state: Wimbledon Self-report Scale (WSS) }\end{array}$ \\
\hline & $\begin{array}{l}\text { Assessment } \\
\text { points }\end{array}$ & 6 mo post injury \\
\hline & $\begin{array}{l}\text { Summary of } \\
\text { results }\end{array}$ & $\begin{array}{l}\text { Analyses adjusted for potential confounding factors confirmed a clinically plausible superior outcome } \\
\text { for both treatment groups compared with controls, but none of the results reached significance (set } \\
\text { at } P \text { value }<0.01 \text { ) }\end{array}$ \\
\hline & $\begin{array}{l}\text { Mean change } \\
\text { from baseline }\end{array}$ & Control \\
\hline
\end{tabular}


Table 6. Results from the three studies addressing community team-based rehabilitation (Continued)

\begin{tabular}{lllll} 
& $(\mathbf{n = 4 1 )}$ & $(\mathbf{n = 2 8 )}$ & $(\mathbf{n = 2 7 )}$ & (t-tests) \\
\hline $\begin{array}{l}\text { \% poorly in- } \\
\text { formed }\end{array}$ & $46 \%-64 \%$ & $46 \%-81 \%$ & $63 \%-89 \%$ & $\mathrm{~N} / \mathrm{S}$ \\
\hline $\begin{array}{l}\text { WSS, median } \\
\text { (IQR) }\end{array}$ & $3(0-9)$ & $2(0-6)$ & $8(1-15)$ & $\mathrm{N} / \mathrm{S}$ \\
\hline
\end{tabular}

Authors' con- Hypothesis not confirmed, but absence of effect cannot be proven with these data, which may reflect clusions type Il error in view of mixing of groups. Longer-term follow-up data also required

\begin{tabular}{|c|c|c|c|c|c|}
\hline \multirow[t]{10}{*}{$\begin{array}{l}\text { Bjorkdahl } \\
2006\end{array}$} & \multirow{2}{*}{$\begin{array}{l}\begin{array}{l}\text { Participant } \\
\text { and }\end{array} \\
\text { group com- } \\
\text { parisons }\end{array}$} & \multicolumn{4}{|c|}{$\begin{array}{l}\text { Stroke patients (mean age } 53 \text { y) discharged from an in-patient rehabilitation programme } \\
\text { - Intervention 1: short programme ( } 3 \mathrm{wk} \text { ) of home-based rehabilitation programme, individually tai- } \\
\text { lored, focussed on activities within their natural context }(n=30) \\
\text { - Control: programme of similar length in 'ordinary' day clinic rehabilitation }(n=29)\end{array}$} \\
\hline & & \multicolumn{4}{|c|}{$\begin{array}{l}\text { Functional assessment: Motor and Process Skills (AMPS); secondary measures: mobility ( } 30 \mathrm{~m} \text { walk- } \\
\text { ing test); FIM, instrumental activity measure }\end{array}$} \\
\hline & $\begin{array}{l}\text { Assessment } \\
\text { points }\end{array}$ & \multicolumn{4}{|c|}{ End of intervention ( 3 wk post discharge), 3 and 12 mo } \\
\hline & $\begin{array}{l}\text { Summary of } \\
\text { results }\end{array}$ & \multicolumn{4}{|c|}{$\begin{array}{l}\text { Both groups improved significantly from discharge to 1-y follow-up. No significant differences be- } \\
\text { tween groups for any of the } 4 \text { assessments, at any time point, although trends show earlier gains in } \\
\text { the home-rehabilitation group. Only the day clinic group changed 'significantly' on the FIM, but de- } \\
\text { gree of change was small ( } 5 \text { FIM points over } 1 \text { y). Costs of home rehabilitation programme were less } \\
\text { than half those of the day clinic }\end{array}$} \\
\hline & $\begin{array}{l}\text { Rasch trans- } \\
\text { formed AMPS } \\
\text { data (logits) }\end{array}$ & \multicolumn{2}{|l|}{$\begin{array}{l}\text { Home }(n=30) \\
\text { Mean (SD) }\end{array}$} & \multicolumn{2}{|c|}{$\begin{array}{l}\text { Day clinic }(n=39) \\
\text { Mean (SD) }\end{array}$} \\
\hline & & Motor & Process & Motor & Process \\
\hline & Discharge & 1.45 & 1.00 & 1.42 & 1.18 \\
\hline & $3 w k$ & 1.71 & 1.26 & 1.52 & 1.37 \\
\hline & $3 \mathrm{mo}$ & 2.02 & 1.23 & 1.88 & 1.54 \\
\hline & $1 \mathrm{y}$ & 2.18 & 1.55 & 2.28 & 1.59 \\
\hline
\end{tabular}

Authors' con- Both rehabilitation programmes could be recommended, but additional studies are required to declusions fine patients who may benefit specifically from home rehabilitation. Costs should be taken into consideration

\section{Table 7. Results from the two studies addressing in-patient rehabilitation}

\section{Semlyen Partici- Consecutive patients in-hospital with severe TBI and referred for in-patient rehabilitation within 4 weeks 1998 pant and of injury; age 16 to $62 \mathrm{y}$}

Intervention: multi-disciplinary specialist rehabilitation service - Hunter's Moor (HM) $(n=33)$ 
Table 7. Results from the two studies addressing in-patient rehabilitation (Continued)

group Control: 'Other rehabilitation' (OR) in local non-specialist services in district hospitals $(n=18)$

compar-

isons

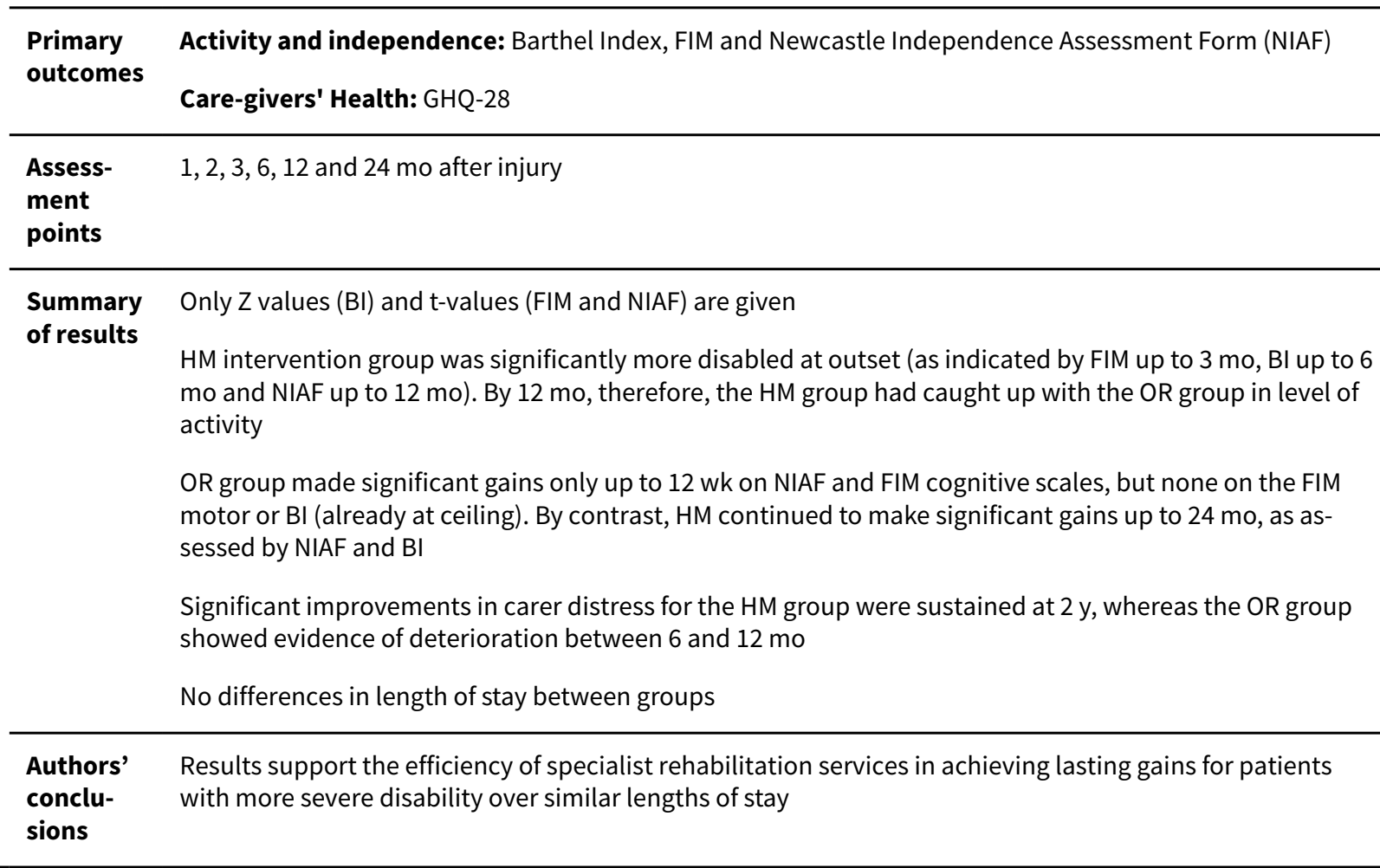

Ozedemir Partici- Stroke patients referred for rehabilitation after medical stabilisation $(\mathrm{n}=60)$; mean age 59.1 y (SD 5.9)

$2001 \quad$ pant and

Group 1: in-patient rehabilitation $(n=30)-\geq 2 h / d$ of formal therapy, $5 \mathrm{~d} / \mathrm{wk}$

group

compar- Group 2: home-based rehabilitation $(n=30)$ - team visited home for $2 \mathrm{~h} / \mathrm{wk}$ and instructed family in home

isons exercises - family provided therapy $\geq 2 \mathrm{~h} / \mathrm{d}, 7 \mathrm{~d} / \mathrm{wk}$

Mean duration of rehabilitation $64 \mathrm{~d}$ in both groups

\begin{tabular}{llll}
\hline $\begin{array}{l}\text { Primary } \\
\text { outcomes }\end{array}$ & $\begin{array}{l}\text { Impairment: Brunnstrom score, Ashworth (spasticity) } \\
\text { Activity: FIM, Mini-Mental State Examination (MMSE) }\end{array}$ \\
\hline $\begin{array}{l}\text { Assess- } \\
\text { ment } \\
\text { points }\end{array}$ & Before and after rehabilitation & \\
\hline $\begin{array}{l}\text { Summary } \\
\text { of results }\end{array}$ & $\begin{array}{l}\text { Significant group differences in favour of in-patient group for change in Brunnstrom, FIM and MMSE } \\
\text { scores, but no differences in spasticity }\end{array}$ & Proup 2 \\
\hline $\begin{array}{l}\text { Change } \\
\text { scores }\end{array}$ & Group 1 & Mean (SD) & (t-tests) \\
\hline $\begin{array}{l}\text { Ashworth } \\
\text { UE }\end{array}$ & 0.5 (1.2) & 0.2 (0.5) & N/S \\
\hline
\end{tabular}


Table 7. Results from the two studies addressing in-patient rehabilitation (Continued)

\begin{tabular}{llll}
$\begin{array}{l}\text { Ashworth } \\
\text { LE }\end{array}$ & $0.2(1.2)$ & $0.1(0.3)$ & $\mathrm{N} / \mathrm{S}$ \\
\hline $\begin{array}{l}\text { Brunnstrom } \\
(\mathrm{UE})\end{array}$ & $2.0(1.2)$ & $0.3(0.6)$ & $<0.001$ \\
\hline $\begin{array}{l}\text { Brunnstrom } \\
(\mathrm{LE})\end{array}$ & $2.4(1.2)$ & $0.8(0.6)$ & $<0.001$ \\
\hline FIM & $59.6(14.2)$ & $12.3(13.4)$ & $<0.001$ \\
\hline $\begin{array}{l}\text { MMSE } \\
4.8(5.0)\end{array}$ & $2.0(2.1)$ & $<0.001$ \\
\hline $\begin{array}{l}\text { Authors' } \\
\text { conclu- } \\
\text { sions }\end{array}$ & $\begin{array}{l}\text { Intensive in-patient rehabilitation provided significantly more favourable functional and cognitive out- } \\
\text { comes than home-based rehabilitation programme }\end{array}$
\end{tabular}

Table 8. Results from the four studies addressing enhanced intensity of rehabilitation (Continued)

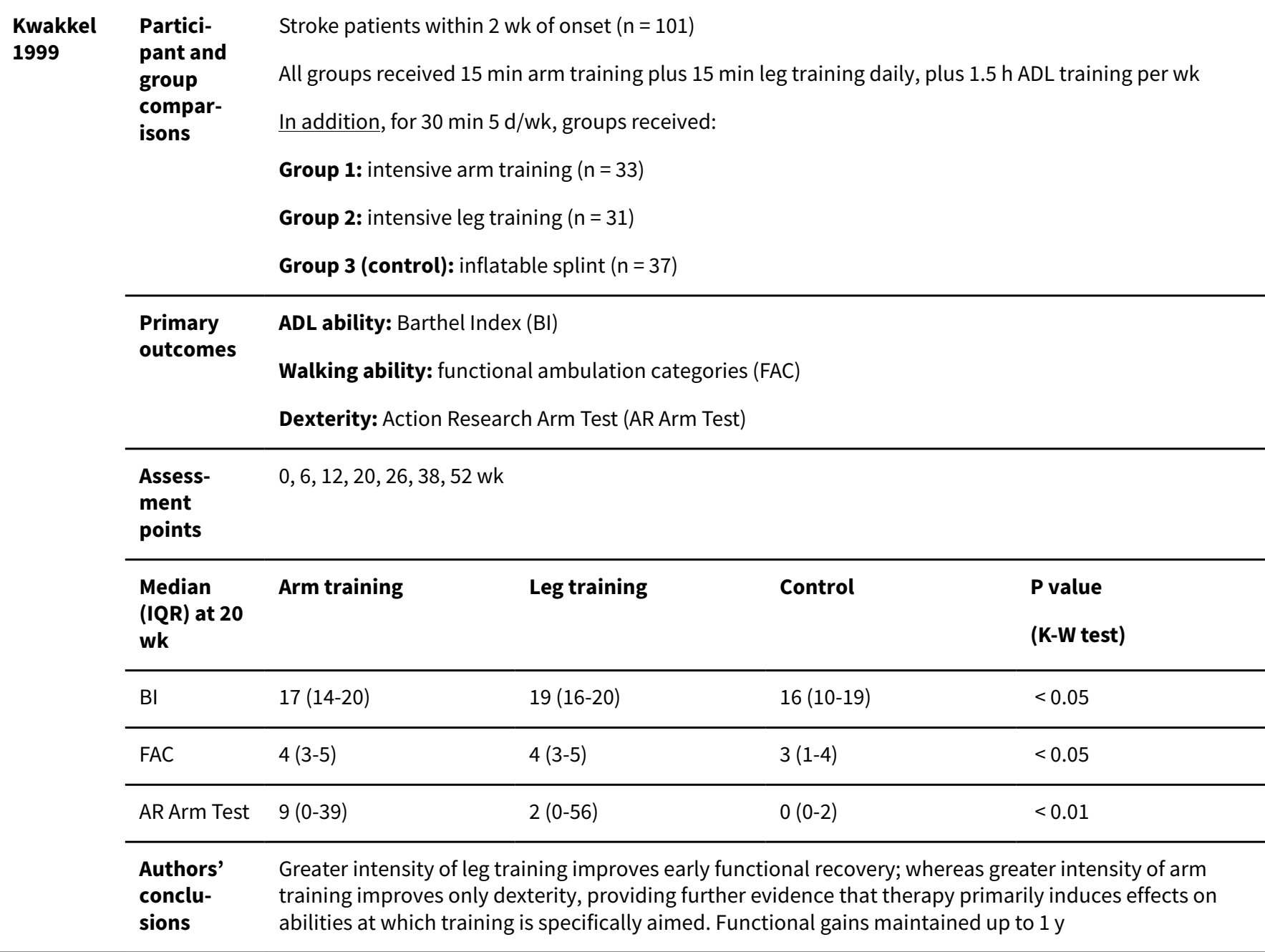


Table 8. Results from the four studies addressing enhanced intensity of rehabilitation (Continued)

\begin{tabular}{|c|c|c|c|c|}
\hline \multirow[t]{7}{*}{ Zhu 2001} & \multirow{2}{*}{$\begin{array}{l}\text { Partici- } \\
\text { pant and } \\
\text { group } \\
\text { compar- } \\
\text { isons } \\
\begin{array}{l}\text { Primary } \\
\text { outcomes }\end{array}\end{array}$} & \multicolumn{3}{|c|}{$\begin{array}{l}\text { Patients aged } 12 \text { to } 65 \text { y with moderate to severe TBI up to } 6 \text { mo post injury }(n=68) \\
\text { Interventions: multi-disciplinary rehabilitation at } 2 \text { intensities: } \\
\text { - Intensive: } 4 \mathrm{~h} / \mathrm{d}, 5 \mathrm{~d} / \mathrm{wk}(\mathrm{n}=36) \\
\text { - Conventional: } 2 \mathrm{~h} / \mathrm{d}, 5 \mathrm{~d} / \mathrm{wk}(\mathrm{n}=32)\end{array}$} \\
\hline & & \multicolumn{3}{|c|}{$\begin{array}{l}\text { Global outcome: Glasgow Outcome Scale (GOS) } \\
\text { Activity (disability): FIM, Neurobehavioural Cognitive Status Examination (NCSE) }\end{array}$} \\
\hline & $\begin{array}{l}\text { Assess- } \\
\text { ment } \\
\text { points }\end{array}$ & \multicolumn{3}{|c|}{$0,1,2,3,4,5,8,10$ and $12 \mathrm{mo}$} \\
\hline & $\begin{array}{l}\text { Summary } \\
\text { of results }\end{array}$ & \multicolumn{3}{|c|}{$\begin{array}{l}\text { No statistically significant differences in FIM or NSCE between groups. However, significantly greater } \\
\text { number of participants achieved maximal FIM and GOS scores within } 3 \text { mo, although no differences were } \\
\text { noted at later time points and up to } 1 \text { year }\end{array}$} \\
\hline & $\begin{array}{l}\text { Outcome } \\
\text { at } 6 \mathrm{mo}\end{array}$ & Intensive $(n=36)$ & Conventional $(n=32)$ & $\begin{array}{l}\text { P value } \\
\left(\text { Chi }^{2}\right)\end{array}$ \\
\hline & $\begin{array}{l}\% \text { good } \\
\text { GOS } \\
3 \mathrm{mo} \\
12 \mathrm{mo}\end{array}$ & 38 & 14 & $\begin{array}{l}\mathrm{Chi}^{2} 3.9, \mathrm{df} 1, \mathrm{P} \text { value }=0.044 \\
P \text { value }=0.483\end{array}$ \\
\hline & $\begin{array}{l}\% \text { full FIM } \\
3 \text { mo } \\
12 \text { mo }\end{array}$ & 47 & 19 & $\begin{array}{l}\mathrm{Chi}^{2} \text { 5.8, } \mathrm{df} 1, \mathrm{P} \text { value }=0.015 \\
\mathrm{P} \text { value }=0.242\end{array}$ \\
\hline
\end{tabular}

Authors' Early intensive rehabilitation can improve functional outcomes of patients with TBI in the early months conclu- post injury, and hence may increase the chance of their early return to work Intensive rehabilitation in sions this study speeded up recovery rather than changing final outcomes

\begin{tabular}{|c|c|c|}
\hline \multirow[t]{3}{*}{$\begin{array}{l}\text { Shiel } \\
2001\end{array}$} & $\begin{array}{l}\text { Partici- } \\
\text { pant and } \\
\text { group } \\
\text { compar- } \\
\text { isons }\end{array}$ & $\begin{array}{l}\text { Patients with moderate to severe TBI (age } 16 \text { to } 70 \text { y) admitted for rehabilitation ( } \mathrm{n}=51 \text { ); stratified and } \\
\text { randomly assigned on age and GCS } \\
\text { Intervention groups } \\
\text { - Enhanced intensity: intervention by an experienced rehabilitation professional (nurse at one centre, } \\
\text { occupational therapist at the other) }(\mathrm{N}=24) \\
\text { - Routine: multi-disciplinary rehab }(\mathrm{n}=27) \\
\text { (NB: study conducted across } 2 \text { centres, which had very different structures and processes, } 1 \text { offering sig- } \\
\text { nificantly more routine therapy than the other. Participants at each centre were randomly assigned to } \\
\text { received standard and enhanced therapy according to their practice }\end{array}$ \\
\hline & $\begin{array}{l}\text { Primary } \\
\text { outcomes }\end{array}$ & Activity (disability): FIM+FAM \\
\hline & $\begin{array}{l}\text { Assess- } \\
\text { ment } \\
\text { points }\end{array}$ & Admission and discharge \\
\hline
\end{tabular}


Table 8. Results from the four studies addressing enhanced intensity of rehabilitation (Continued)

Summary Despite procedural differences between centres, no significant differences in FIM+FAM change scores of results were reported between centres. Significant differences were observed between intensive and routine intervention groups and were greatest in the domains of self care, continence, locomotion and psychosocial function. No significant difference in length of stay overall, but possibly skewed by very prolonged LOS for intervention group at 1 centre

\begin{tabular}{|c|c|c|c|}
\hline $\begin{array}{l}\text { Change } \\
\text { scores dur- } \\
\text { ing admis- } \\
\text { sion }\end{array}$ & $\begin{array}{l}\text { Enhanced intensity } \\
\text { Median (IQR) }\end{array}$ & $\begin{array}{l}\text { Routine } \\
\text { Median (IQR) }\end{array}$ & $\begin{array}{l}\text { P } \\
\text { (Mann-Whitney) }\end{array}$ \\
\hline $\begin{array}{l}\text { FIM+FAM } \\
\text { Motor }\end{array}$ & $74(47-95)$ & $21(2-48)$ & $<0.01$ \\
\hline $\begin{array}{l}\text { FIM+FAM } \\
\text { Cognitive }\end{array}$ & $40(14-45)$ & $12(5-22)$ & $<0.01$ \\
\hline $\begin{array}{l}\text { Authors' } \\
\text { conclu- } \\
\text { sions }\end{array}$ & \multicolumn{3}{|c|}{ Increased intensity of rehabilitation is associated with enhanced function recovery } \\
\hline
\end{tabular}

$\begin{array}{lll}\text { Slade } & \begin{array}{l}\text { Partici- } \\ \text { pant and } \\ \text { group } \\ \text { compar- } \\ \text { isons }\end{array} & \begin{array}{l}\text { Patients with acquired brain injury (stroke, TBI or MS) aged } 16 \text { to } 65 \text { y admitted for rehabilitation ( } \mathrm{n}= \\ \text { Interventions: multi-disciplinary rehabilitation at } 2 \text { intensities: }\end{array} \\ & \begin{array}{l}\text { - Intensive: allocated } 62.5 \% \text { of total available therapy time }(\mathrm{n}=75) \\ \text { - Control: allocated } 37.5 \% \text { of total available therapy time }(\mathrm{n}=66)\end{array}\end{array}$

(NB: Although in theory the intensive group should have received $67 \%$ more therapy than controls, in reality, they received only $30 \%$ more)

\begin{tabular}{ll}
$\begin{array}{l}\text { Primary } \\
\text { outcomes }\end{array}$ & $\begin{array}{l}\text { Length of stay (LOS) } \\
\text { ADL ability: Modified Barthel Index }\end{array}$ \\
\hline $\begin{array}{l}\text { Assess- } \\
\text { ment } \\
\text { points }\end{array}$ & Admission and discharge \\
\hline $\begin{array}{l}\text { Summary } \\
\text { of results }\end{array}$ & $\begin{array}{l}\text { No significant differences in discharge Barthel scores were reported (data not given), but this is expect- } \\
\text { ed, as patients are discharged at the point at which they are sufficiently independent to manage in the } \\
\text { community. This question is then whether more intensive therapy reaches that point earlier }\end{array}$ \\
$\begin{array}{l}\text { Mean LOS for all participants was } 84.6 \text { d. Straightforward comparison showed no significant group inter- } \\
\text { actions }\end{array}$ \\
$\begin{array}{l}\text { However, a multiple regression model was applied to take account of confounders of experimental de- } \\
\text { sign that could not be controlled for (impairment mix, community delays, missed treatment, etc.); this } \\
\text { demonstrated a 14-d reduction for the intensive group }\end{array}$ \\
\hline $\begin{array}{l}\text { Authors' } \\
\text { conclu- } \\
\text { sions }\end{array}$ & $\begin{array}{l}\text { Intensive rehabilitation has the potential to reduce length of stay, but concurrently, LOS in both groups } \\
\text { was increased by 16 d as the result of external delays in discharge }\end{array}$ \\
\hline
\end{tabular}


Table 9. Results from the two studies addressing early vs delayed rehabilitation (Continued)

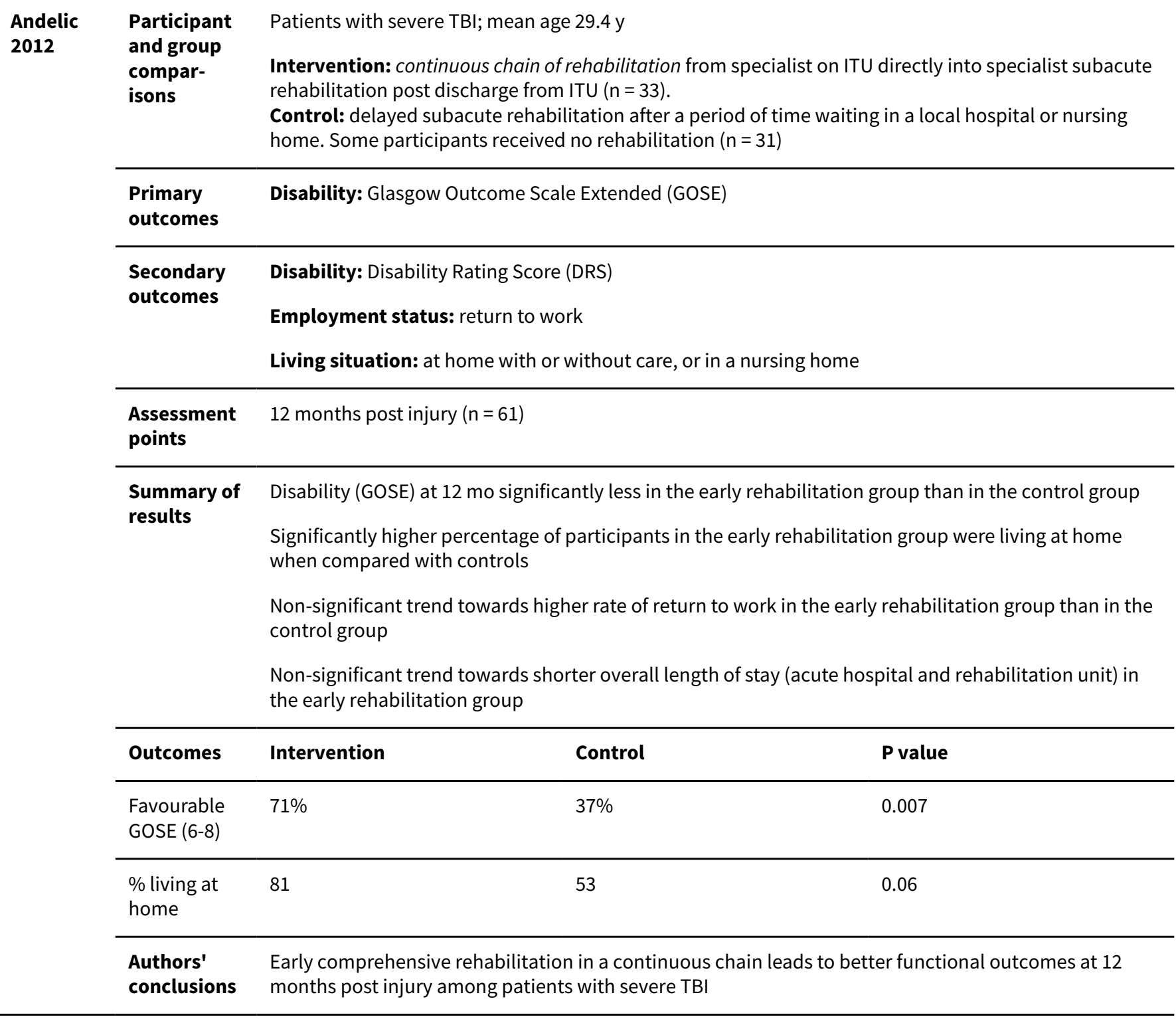

\begin{tabular}{lll} 
Bai 2012 & $\begin{array}{l}\text { Participant } \\
\text { and group } \\
\begin{array}{l}\text { compar- } \\
\text { isons }\end{array}\end{array}$ & $\begin{array}{l}\text { Patients with moderate to severe intracerebral haemorrhage; mean age 61 y } \\
\text { Intervention: early rehabilitation commencing in the Emergency Department and continuing for 6 mo } \\
\text { Controls: standard medical care }(\mathrm{n}=183)\end{array}$ \\
\hline $\begin{array}{ll}\text { Primary } \\
\text { outcomes }\end{array}$ & $\begin{array}{l}\text { Impairment: Fugl-Meyer Assessment (FMA) } \\
\text { Disability: Modified Barthel Index (MBI) }\end{array}$ \\
\hline $\begin{array}{l}\text { Assessment } \\
\text { points }\end{array}$ & Outcome measures administered at 1, 3 and 6 mo \\
\hline
\end{tabular}


Table 9. Results from the two studies addressing early vs delayed rehabilitation (Continued)

Summary of At baseline, post hoc testing showed no significant differences between FMA and MBI scores in the 2 results groups

At 1, 3 and 6 mo, intervention group had significantly higher FMA and MBI scores

Authors' Early rehabilitation can significantly improve ADLs and motor recovery in patients with intracranial conclusions haemorrhage

Table 10. Results from the two studies addressing the therapeutic environment as a model of rehabilitation (Continued)

\begin{tabular}{|c|c|c|}
\hline \multirow[t]{6}{*}{$\begin{array}{l}\text { Cicerone } \\
2008\end{array}$} & $\begin{array}{l}\text { Participant } \\
\text { and group } \\
\text { comparisons }\end{array}$ & $\begin{array}{l}\text { Mixed severity traumatic brain injury; mean age } 36.6 \text { y } \\
\text { Intervention: intensive cognitive rehabilitation provided in a therapeutic environment }(n=34) \text { with a } \\
\text { focus on group work } \\
\text { Control: standard neurorehabilitation; mostly individual, discipline-specific therapy }(n=34)\end{array}$ \\
\hline & $\begin{array}{l}\text { Primary } \\
\text { outcomes }\end{array}$ & $\begin{array}{l}\text { Community integration: Community Integration Questionnaire (CIQ) } \\
\text { Life satisfaction: Perceived Quality of Life Scale (PQOL) }\end{array}$ \\
\hline & $\begin{array}{l}\text { Secondary } \\
\text { outcomes }\end{array}$ & $\begin{array}{l}\text { Neuropsychological functioning } \\
\text { Perceived self-efficacy } \\
\text { Vocational outcome: Vocational Integration Scale (VIS) }\end{array}$ \\
\hline & $\begin{array}{l}\text { Assessment } \\
\text { points }\end{array}$ & 2 wk before treatment, 2 wk post treatment and 6 mo follow-up \\
\hline & $\begin{array}{l}\text { Summary of } \\
\text { results }\end{array}$ & $\begin{array}{l}\text { Treatment arm showed significantly improved community integration and quality of life scores - not } \\
\text { seen in control arm } \\
\text { Self efficacy was significantly improved in the treatment arm - another improvement not seen in the } \\
\text { control arm }\end{array}$ \\
\hline & & $\begin{array}{l}\text { Additionally, treatment group had a significantly higher rate of employment compared with control } \\
\text { group }\end{array}$ \\
\hline
\end{tabular}

\begin{tabular}{|c|c|c|c|c|}
\hline \multirow[b]{2}{*}{$\begin{array}{l}\text { Outcome } \\
\text { measures }\end{array}$} & \multicolumn{4}{|c|}{ Standard neurorehabilitation } \\
\hline & Pre-Tx & Post-Tx & Follow-up & P value \\
\hline CIQ & 12.1 & 11.7 & 12.9 & $>0.05$ \\
\hline PQOL & 61.2 & 62.2 & 59.6 & $>0.05$ \\
\hline $\begin{array}{l}\text { Authors' } \\
\text { conclusions }\end{array}$ & \multicolumn{4}{|c|}{$\begin{array}{l}\text { This trial demonstrates that an intensive cognitive rehabilitation programme can produce significant- } \\
\text { ly better outcomes when compared with standard neurorehabilitation }\end{array}$} \\
\hline
\end{tabular}

\footnotetext{
Salazar Participant Active duty military personnel with moderate to severe TBI; mean age $25 \mathrm{y}$ and
} 
Table 10. Results from the two studies addressing the therapeutic environment as a model of rehabilitation (Continued) 2000 group com- Intervention: 8-week intensive in-patient cognitive-behavioural programme $(n=67)$ parisons

Control: limited home programme of weekly telephone support from psychiatric nurse (educational material, counselling and suggested home exercises) $(n=53)$

\begin{tabular}{|c|c|c|c|c|}
\hline $\begin{array}{l}\text { Primary } \\
\text { outcomes }\end{array}$ & \multicolumn{4}{|c|}{$\begin{array}{l}\text { Work status: return to work } \\
\text { return to fitness for military duty }\end{array}$} \\
\hline $\begin{array}{l}\text { Assessment } \\
\text { points }\end{array}$ & \multicolumn{4}{|l|}{$1 \mathrm{y}$} \\
\hline $\begin{array}{l}\text { Summary } \\
\text { of results }\end{array}$ & \multicolumn{4}{|c|}{$\begin{array}{l}\text { No overall differences in outcomes between groups } \\
\text { Post hoc analysis demonstrated significant group interaction (in favour of the intervention group) for } \\
\text { 'fitness for military duty' at } 1 \mathrm{y} \text { for members of the more severe subgroup, who were unconscious for } \\
>1 \mathrm{~h}\end{array}$} \\
\hline $\begin{array}{l}\text { Vocational } \\
\text { status } \\
\text { at } 1 \text { y }\end{array}$ & $\begin{array}{l}\text { Intervention } \\
\% \text { achieved }\end{array}$ & $\begin{array}{l}\text { Control } \\
\text { \% achie }\end{array}$ & Difference & $\begin{array}{l}\text { P value } \\
\text { (Fisher's exact) }\end{array}$ \\
\hline $\begin{array}{l}\text { Return to } \\
\text { work }\end{array}$ & $90 \%$ & $94 \%$ & $4 \%(-5,14)$ & $\mathrm{N} / \mathrm{S}$ \\
\hline $\begin{array}{l}\text { Fit for military } \\
\text { duty }\end{array}$ & $73 \%$ & $66 \%$ & $7 \%(-10.24)$ & $\mathrm{N} / \mathrm{S}$ \\
\hline \multicolumn{5}{|c|}{ Post hoc analysis of subgroup unconscious for $>1 h(n=75)$} \\
\hline & $(n=35)$ & $(n=40)$ & Difference & P value \\
\hline $\begin{array}{l}\text { Fit for military } \\
\text { duty }\end{array}$ & $80 \%$ & $58 \%$ & $22 \%$ & 0.05 \\
\hline $\begin{array}{l}\text { Authors' con- } \\
\text { clusions }\end{array}$ & \multicolumn{4}{|c|}{$\begin{array}{l}\text { Overall benefit of in-patient cognitive rehabilitation programme similar to that of limited home reha- } \\
\text { bilitation, although institutional therapy may be beneficial for selected patients with more severe TB }\end{array}$} \\
\hline
\end{tabular}

\section{APPENDICES}

\section{Appendix 1. Search strategies}

The keywords and medical subject headings have not been changed for this update. The Cochrane Library search strategy has been modified because of changes in the search interface since the last update.

\section{Cochrane Injuries Group Specialised Register}

$\# 1$ (rehabilitat*) AND ( INREGISTER)

\#2 \#1 AND \#2

\#3 ((multi-disciplinary or inter-disciplinary or integrated or multi-modal or multi-professional) AND (therap* or restor $^{\star}$ or care $^{\star}$ or team $\left.{ }^{\star}\right)$ ) AND ( INREGISTER)

\#4 \#3 AND \#4

\section{CENTRAL}

\#1MeSH descriptor: [Craniocerebral Trauma] explode all trees 
\#2MeSH descriptor: [Stroke] explode all trees \#3MeSH descriptor: [Anoxia] explode all trees \#4MeSH descriptor: [Anoxia] explode all trees \#5(brain or head or intracran* or cerebr* or cerebellar or brainstem or vertebrobasilar) near/3 (injur ${ }^{\star}$ or infarc $^{\star}{\text { or ischem* }{ }^{\star} \text { or ischaem }}^{\star}$ or thrombo* or apoplexy or emboli* or hemorrhag* or haemorrhage* or hematoma* or haematoma* or aneurysm* or anoxi* or hypoxi $\left.{ }^{\star}\right): t i, a b, k w$ (Word variations have been searched)

\#6encephaliti* or mening*:ti,ab,kw (Word variations have been searched)

$\# 7 \# 1$ or \#2 or \#3 or \#4 or \#5 or \#6

\#8MeSH descriptor: [Rehabilitation Centers] explode all trees

\#9MeSH descriptor: [Rehabilitation] explode all trees

\#10rehabilitat*:ti,ab,kw (Word variations have been searched)

$\# 11 \# 8$ or \#9 or \#10

$\# 12 \mathrm{MeSH}$ descriptor: [Comprehensive Health Care] explode all trees

\#13MeSH descriptor: [Critical Pathways] explode all trees

\#14MeSH descriptor: [Delivery of Health Care] explode all trees

\#15MeSH descriptor: [Patient Care Team] explode all trees

$\# 16$ (multi-disciplinary or inter-disciplinary or integrated or multi-modal or multi-professional) near/3 (therap* or restor ${ }^{\star}$ or care* or team $\left.{ }^{\star}\right)$ :ti,ab,kw (Word variations have been searched)

\#17(activit* near/3 daily living) or ADL or EADL:ti,ab,kw (Word variations have been searched)

\#18(self or personal or alone or own) near/3 (care or manag*):ti,ab,kw (Word variations have been searched)

\#19(self or personal or alone or own) near/3 (dress ${ }^{\star}$ or feed $^{*}$ or eat ${ }^{*}$ or toilet ${ }^{\star}$ or bath* or mobil* or driving or drive or (public next transport $\left.{ }^{\star}\right)$ ):ti,ab,kw (Word variations have been searched)

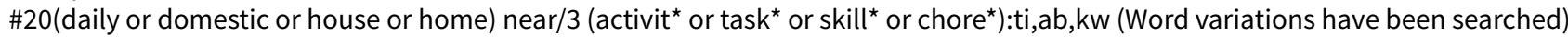

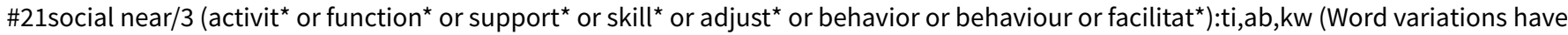
been searched)

\#22community near/5 (re-integrat* or rehabilit* $^{\star}$ )

$\# 23 \# 12$ or \#13 or \#14 or \#15 or \#16 or \#17 or \#18 or \#19 or \#20 or \#21 or \#22

$\# 24 \# 7$ and \#11 and \#23

Ovid MEDLINE(R), Ovid MEDLINE(R) In-Process \& Other Non-Indexed Citations, Ovid MEDLINE(R) Daily and Ovid OLDMEDLINE(R)

1. exp Craniocerebral Trauma/

2. exp Stroke/

3. $\exp$ Anoxia/

4. exp Hypoxia, Brain/

5. ((brain or head or intracran* or cerebr ${ }^{\star}$ or cerebellar or brainstem or vertebrobasilar) adj3 (injur* or infarc* or isch?em or thrombo* or apoplexy or emboli* or h?emorrhag* or h?ematoma* or aneurysm or anoxi* or hypoxi)).ab,ti.

6. (encephaliti or mening $\left.{ }^{\star}\right) \cdot$ ab,ti.

7. 1 or 2 or 3 or 4 or 5 or 6

8. rehabilitation.fs.

9. exp Rehabilitation/

10. exp Rehabilitation Centers/

11. "rehabilitat".ab,ti.

12. 8 or 9 or 10 or 11

13. 7 and 12

14. exp Comprehensive Health Care/

15. exp Critical Pathways/

16. exp "Delivery of Health Care"/

17. exp Patient Care Team/

18. ((multi?disciplinary or inter?disciplinary or integrated or multi?modal or multi?professional) adj3 (therap* or restor ${ }^{\star}$ or care* or team $\left.\left.{ }^{\star}\right)\right) \cdot$ ab,ti.

19. ((activit* adj3 daily living) or ADL or EADL).ab,ti.

20. ((self or personal or alone or own) adj3 (care or manag*)).ab,ti.

21. ((self or personal or alone or own) adj3 (dress or feed $^{\star}$ or eat* or toilet* or bath ${ }^{\star}$ or mobil* or driving or drive or (public adj1 transport $\left.\left.\left.{ }^{\star}\right)\right)\right) \cdot a b$, ti.

22. ((daily or domestic or house or home) adj3 (activit* or task $^{\star}$ or skill ${ }^{\star}$ or chore ch $\left.^{\star}\right)$.ab,ti.

23. (social adj3 (activit ${ }^{\star}$ or function ${ }^{\star}$ or support ${ }^{\star}$ or skill* or $^{\text {adjust }}{ }^{\star}$ or behavio?r or facilitat $\left.\left.{ }^{\star}\right)\right)$.ab,ti.

24. (community adj5 (re?integrat ${ }^{\star}$ or rehabilit $\left.^{\star}\right)$ ).ab,ti.

25. or/14-24

26. 13 and 25

27. randomi?ed.ab,ti.

28. randomized controlled trial.pt.

29. controlled clinical trial.pt. 
30. placebo.ab.

31. clinical trials as topic.sh.

32. randomly.ab.

33. trial.ti.

34. Comparative Study/

35.27 or 28 or 29 or 30 or 31 or 32 or 33 or 34

36. (animals not (humans and animals)).sh.

37.35 not 36

38. 26 and 37

\section{Embase Classic + Embase (OvidSP)}

1. exp Head Injury/

2. $\exp$ CEREBROVASCULAR ACCIDENT/

3. $\exp$ ANOXIA/

4. $\exp$ STROKE/

5. ((brain or head or intracran* or cerebr ${ }^{\star}$ or cerebellar or brainstem or vertebrobasilar) adj3 (injur ${ }^{\star}$ or infarc ${ }^{\star}$ or isch?em or thrombo* or apoplexy or emboli* or h?emorrhag* or h?ematoma* or aneurysm or anoxi* or hypoxi*)).ab,ti.

6. (encephaliti* or mening $\left.{ }^{\star}\right)$.ab,ti.

7. or/1-6

8. exp Rehabilitation/

9. "Rehabilitation and Physical Medicine".ec.

10. exp Rehabilitation Care/

11. exp REHABILITATION CENTER/

12. rehabilitat*.ab,ti.

13. rh.fs.

14. or/8-13

15. 7 and 14

16. exp Clinical Pathway/

17. exp Treatment Planning/

18. exp Health Care Delivery/

19. exp Daily Life Activity/

20. ((multi?disciplinary or inter?disciplinary or integrated or multi?modal or multi?professional) adj3 (therap* or restor $^{\star}$ or care $^{\star}$ or team $\left.\left.{ }^{\star}\right)\right) \cdot$ ab,ti.

21. ((activit* adj3 daily living) or ADL or EADL).ab,ti.

22. ((self or personal or alone or own) adj3 (care or manag*)).ab,ti.

23. ((self or personal or alone or own) adj3 (dress ${ }^{\star}$ or feed ${ }^{\star}$ or eat ${ }^{\star}$ or toilet ${ }^{\star}$ or bath ${ }^{\star}$ or mobil ${ }^{\star}$ or driving or drive or (public adj1 transport $\left.\left.\left.{ }^{\star}\right)\right)\right) . a b, t i$.

24. ((daily or domestic or house or home) adj3 (activit ${ }^{\star}$ or task $^{\star}$ or skill* or chore $\left.{ }^{\star}\right)$ ).ab,ti.

25. (social adj3 (activit ${ }^{\star}$ or function ${ }^{\star}$ or support ${ }^{\star}$ or skill ${ }^{\star}$ or adjust ${ }^{\star}$ or behavio?r or facilitat $\left.{ }^{\star}\right)$ ).ab,ti.

26. (community adj5 (re?integrat* ${ }^{\star}$ or rehabilit $\left.\left.{ }^{\star}\right)\right) \cdot$ ab,ti.

27. or $/ 16-26$

28. 15 and 27

29. exp Randomized Controlled Trial/

30. exp controlled clinical trial/

31. exp controlled study/

32. comparative study/

33. randomi?ed.ab,ti.

34. placebo.ab.

35. ${ }^{\star}$ Clinical Trial/

36. exp major clinical study/

37. randomly.ab.

38. (trial or study).ti.

39. 29 or 30 or 31 or 33 or 34 or 35 or 36 or 37 or 38

40. exp animal/ not (exp human/ and exp animal/)

41.39 not 40

42. 28 and 41

ISI Web of Science: Science Citation Index-Expanded (SCI-EXPANDED) \& Conference Proceedings Citation Index-Science (CPCI-S) $\mathrm{TS}=\left(\left(\right.\right.$ brain or head or intracran ${ }^{\star}$ or cerebr ${ }^{\star}$ or cerebellar or brainstem or vertebrobasilar) and (injur ${ }^{\star}$ or infarc ${ }^{\star}$ or ischem $^{\star}$ or ischaem ${ }^{\star}$ or thrombo* or apoplexy or emboli* or hemorrhag* or haemorrhage* or hematoma* or haematoma* or aneurysm or anoxi ${ }^{\star}$ or hypoxi $\left.^{\star}\right)$ ) AND TS $=\left(\right.$ rehabilitat $\left.^{\star}\right)$ AND TS $=(($ multi-disciplinary or inter-disciplinary or integrated or multi-modal or multi-professional) and (therap* or restor $^{\star}$ or care $^{\star}$ or team $\left.{ }^{\star}\right)$ ) 


\section{Clinicaltrials.gov}

multi-disciplinary AND INFLECT EXACT "Interventional" [STUDY-TYPES] AND ( brain OR head OR injury OR injuries) [DISEASE] AND ( therapy OR therapies OR rehabilitation ) [TREATMENT]

\section{WHO International Clinical Trials Portal}

Condition: brain OR head OR injury OR injuires

Intervention: therapy OR therapies OR rehabilitation

Recruiting: ALL

\section{WHAT'S NEW}

\begin{tabular}{lll}
\hline Date & Event & Description \\
\hline 14 September 2015 & $\begin{array}{l}\text { New citation required and conclusions } \\
\text { have changed }\end{array}$ & $\begin{array}{l}\text { This review has been updated, with } 3 \text { new studies included. } \\
\text { The conclusions have changed. The authors of the review have } \\
\text { changed; Anton Pick contributed to this version of the review }\end{array}$ \\
\hline 14 September 2015 & New search has been performed & $\begin{array}{l}\text { Updated the search and included } 3 \text { additional trials. Revised } \\
\text { tables and text accordingly, with } 2 \text { new additional tables sum- } \\
\text { marising the evidence for early compared with delayed rehabili- } \\
\text { tation and cognitive-behavioural rehabilitation in a therapeutic } \\
\text { milieu-based environment }\end{array}$ \\
& $\begin{array}{l}\text { Expanded the 'Risk of bias' table and reviewed van Tulder scores, } \\
\text { providing reasons for changes in ratings }\end{array}$ \\
\hline
\end{tabular}

\section{H IST ORY}

Protocol first published: Issue 2, 2003

Review first published: Issue 3, 2005

\begin{tabular}{lll}
\hline Date & Event & Description \\
\hline 23 November 2010 & Amended & $\begin{array}{l}\text { Reformatted tables. Content of the manuscript remains un- } \\
\text { changed }\end{array}$ \\
\hline 23 March 2009 & New search has been performed & $\begin{array}{l}\text { Included 2 new trials in this update } \\
\text { Amended Results and Conclusions of the review accordingly }\end{array}$ \\
\hline 11 July 2008 & Amended & Converted to new review format \\
\hline
\end{tabular}

\section{CONTRIBUTIONS OFAUTHORS}

LTS: planned the review protocol and methods, with input from DTW and PD; also co-ordinated the search with support from the Cochrane Injuries Group and led selection and evaluation of trials.

AN, AP and LTS: independently handsearched article abstracts and agreed on the short list of trials for inclusion; when opinions differed, DTW arbitrated.

AN, LTS, AP and DTW: performed independent quality assessments and then agreed on final quality scores for articles included in the analysis. 
PBD: in addition to his role the original conceptual design, has read and commented on drafts of this update and approved the final submission.

LTS: played the role of lead author; however, all review authors contributed to the final write-up and discussion.

\section{DECLARATIONS OF INTEREST}

All review authors are clinicians engaged in the field of brain injury rehabilitation who naturally wish to provide an effective and efficient service for their patients. No review authors have personal or financial interests in the findings of this review.

DW: As a part of my work I see people with spasticity to advise on management. My employer is paid for each patient I see. I also teach, but neither I nor my employer get paid for this. I give evidence, legally and in advising NHS bodies etc about rehabilitation and the need for multidisciplinary teams, and I write about such teams but rarely get paid for this.

LTS: None known.

AP: None known.

AN: None known.

PBD: None known.

\section{SOURCES OF SUPPORT}

\section{Internal sources}

- King's College London, UK.

- London North West Hospitals Trust, UK.

\section{External sources}

- Luff Foundation, UK.

- Department of Health Research and Development Programme, UK.

- Dunhill Medical Trust, UK.

\section{N DEX TERMS}

\section{Medical Subject Headings (MeSH)}

Age Factors; Brain Injuries [etiology] [ ${ }^{*}$ rehabilitation]; Cognitive Behavioral Therapy; Counseling; Critical Care [ ${ }^{*}$ methods] [standards]; Patient Care Team; Randomized Controlled Trials as Topic; Rehabilitation, Vocational; Stroke [complications]

\section{MeSH check words}

Adolescent; Adult; Aged; Humans; Middle Aged 